ANÁLISIS DE LA NORMA INTERNACIONAL DE INFORMACIÓN FINANCIERA (NIIF 15), EN LAS EMPRESAS COLOMBIANAS DE CONSTRUCCIÓN QUE CONTRATAN CON ENTIDADES PÚBLICAS.

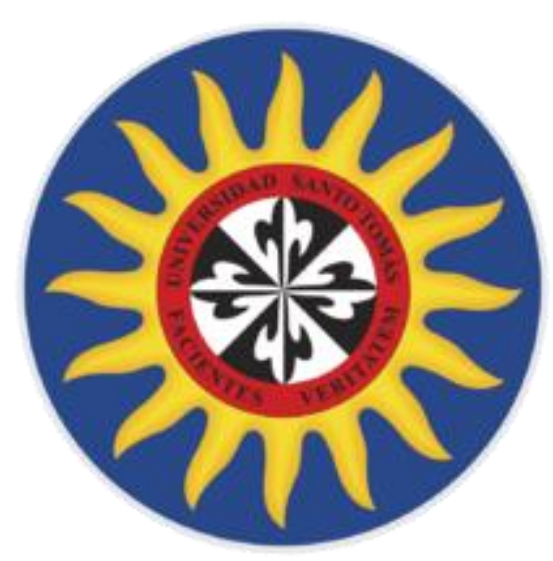

LUIS SEBASTIAN AVELLA MARTÍNEZ

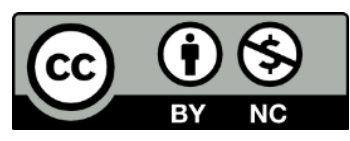

UNIVERSIDAD SANTO TOMÁS

CONTADURÍA PÚBLICA

VILLAVICENCIO

2019 


\title{
ANÁLISIS DE LA NORMA INTERNACIONAL DE INFORMACIÓN FINANCIERA (NIIF 15), EN LAS EMPRESAS COLOMBIANAS DE CONSTRUCCIÓN QUE CONTRATAN CON ENTIDADES PÚBLICAS.
}

\section{LUIS SEBASTIAN AVELLA MARTÍNEZ}

Trabajo de grado presentado como requisito para optar al título de:

Contador Público

\author{
Asesor técnico y metodológico: \\ C.P. SANDY TATIANA MENDOZA GÓMEZ \\ Contador Público
}

\author{
UNIVERSIDAD SANTO TOMÁS \\ CONTADURÍA PÚBLICA \\ VILLAVICENCIO
}

2019 
Autoridades Académicas

P. JUAN UBALDO LÓPEZ SALAMANCA, O.P.

Rector General

\title{
P. MAURICIO ANTONIO CORTÉS GALLEGO, O. P. \\ Vicerrector Académico General
}

\section{P. JOSÉ ARTURO RESTREPO RESTREPO, O.P. Rector Sede Villavicencio}

\section{P. FERNANDO CAJICA GAMBOA, O.P.}

Vicerrector Académico Sede Villavicencio

\section{Adm. JULIETH ANDREA SIERRA TOBÓN}

Secretaria de División Sede Villavicencio

\author{
Dr. Javier Mauricio Álzate Tabares \\ Decano Facultad de Contaduría Pública
}




\section{Agradecimientos}

A la universidad Santo Tomás que brindó la oportunidad de cursar el pregrado como estudiante de contaduría pública, una profesión tan vital para el desarrollo de la sociedad en un mundo que sufre constantes cambios en materia económica y política en donde se requieren profesionales éticos con alto grado de integridad para el desarrollo de nuestro país.

Al Ingeniero Oscar Wilson Chávez Riveros, asesor científico quien oriento con sabiduría y profesionalismo; atreves del suministro información técnica y legal sobre el proceso de contratación de contratos de construcción con entidades públicas y su tratamiento administrativo. A la Dra. Lorena Emily Bernal Barreto, asesora científica quien oriento con sabiduría y profesionalismo; a través de ella se adquirió conocimiento a partir de pautas contables y el tratamiento bajo estándares internacionales NIIF como normas locales en los contratos de construcción.

La Dra. Sandy Tatiana Mendoza Gómez, asesora de metodología y técnica, que con sus enseñanzas y valiosas orientaciones contribuyo el desarrollo de esta investigación.

A todos los docentes que dictaron las diferentes cátedras y permitieron lograr la feliz culminación del pregrado con el debido éxito. 


\section{Tabla de contenido}

Pág.

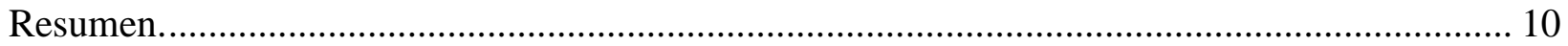

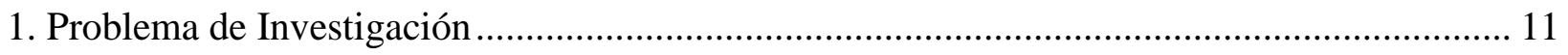

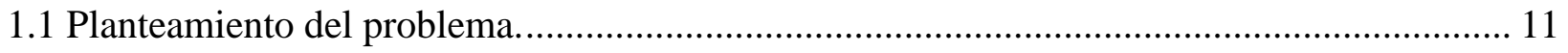

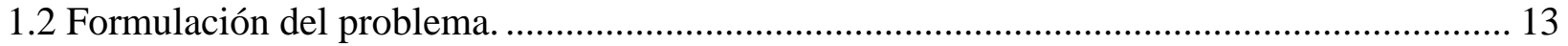

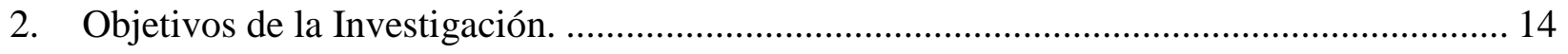

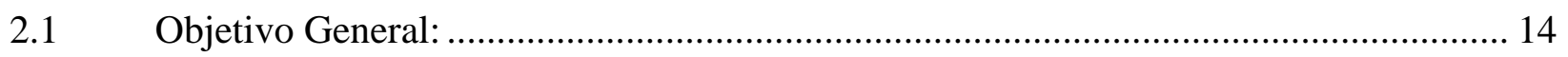

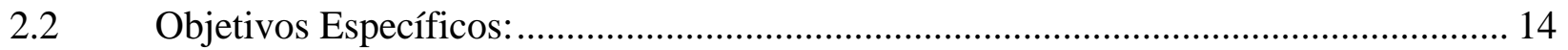

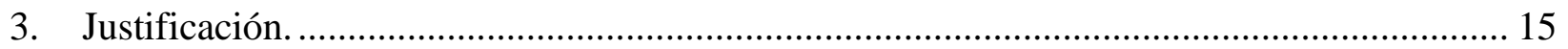

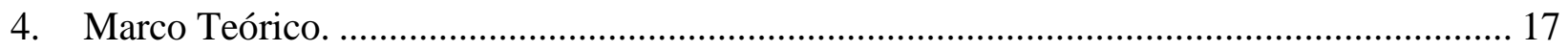

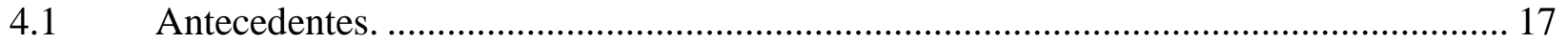

4.2 Estándares Internacionales de contabilidad relacionados con los contratos de

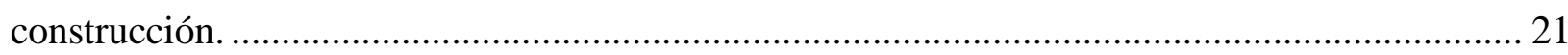

4.2.1 Norma Internacional de Contabilidad NIC 11 ............................................. 22

4.2.2 Norma Internacional de Información Financiera (NIIF) 15 ..................................... 23

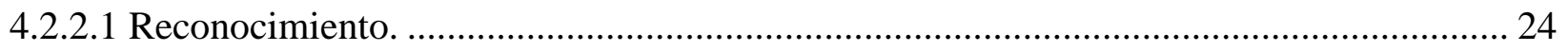

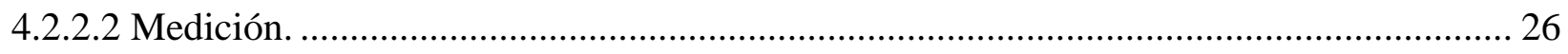

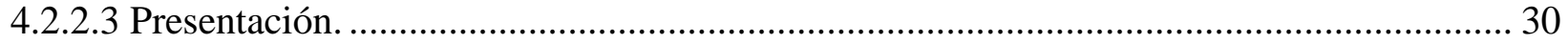

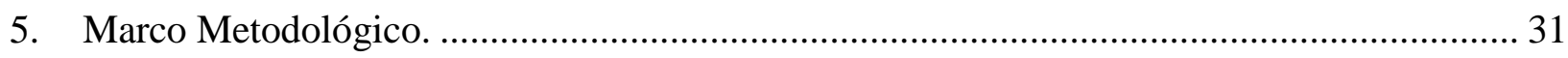

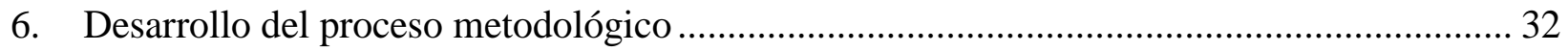

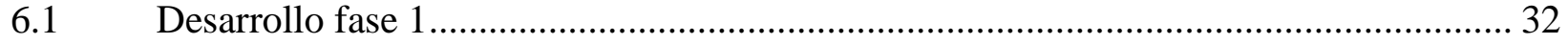

6.1.1 Estado Actual de las empresas de la construcción en Colombia. .......................... 32

6.1.2 El sector de la construcción en cifras años 2015 - 2017. ............................................ 43

6.1.3 Normatividad Colombiana para el sector de la construcción. ........................................... 66

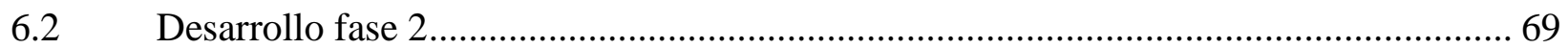

6.2.1 Análisis Actual de la Administración Contable del Sector de la Construcción que

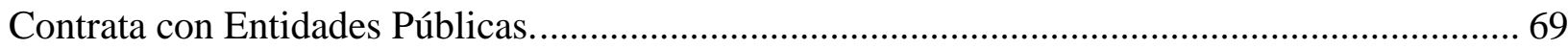

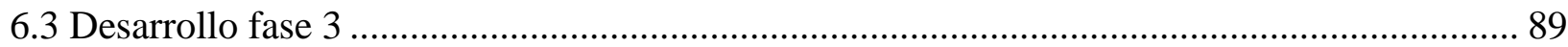


6.3.1 Análisis las implicaciones de la NIIF 15 para las empresas de la construcción..... 90

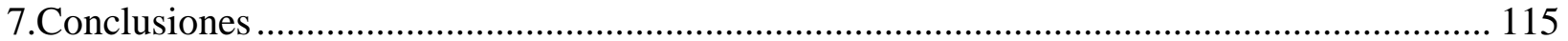

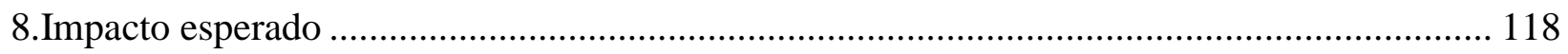

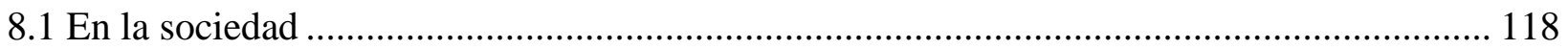

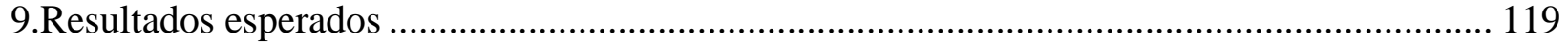

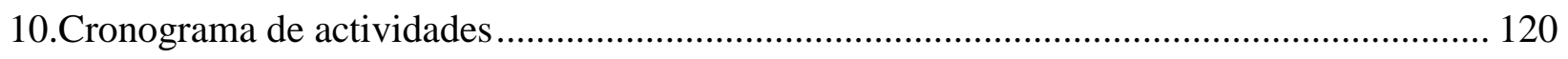

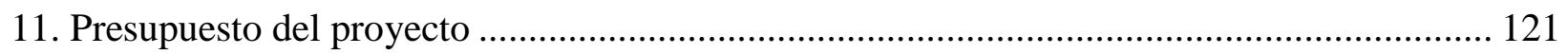

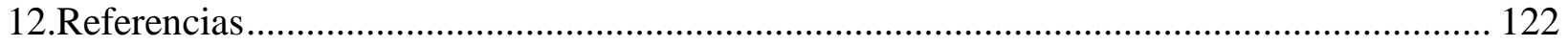




\section{Índice de tablas}

Pág.

Tabla 1. Valor agregado sector construcción a precios constantes, series Desestacionalizadas Tercer trimestre de 2017.

Tabla 2. Variación y contribución trimestral, por estado de obra, según áreas de cobertura Año 2015. 49

Tabla 3. Variación y contribución trimestral, por estado de obra, según áreas de cobertura Año 2016. 51

Tabla 4. Variación y contribución trimestral, por estado de obra, según áreas de cobertura Año 2017.

Tabla 5. Variación y contribución trimestral, por estado de obra, según áreas de cobertura Año 2015 por destino. 54

Tabla 6. Variación y contribución trimestral, por estado de obra, según áreas de cobertura Año 2016 por destino. 56

Tabla 7.Variación y contribución trimestral, por estado de obra, según áreas de cobertura Año 2017 por destino. 58

Tabla 8.Variación y contribución a la variación del área aprobada, según destinos 302 municipios doce meses a diciembre (2015- 2016).

Tabla 9. Número de ocupados totales, No ocupados en el sector de la construcción, tasa de ocupación y tasa de desempleo. 65

Tabla 10. Acta de Conformación Unión Temporal Mejores Vías 2015 ................................... 70

Tabla 11. Registro Contable No 1, Unión Temporal Mejores Vías 2015 ................................. 71

Tabla 12.Gastos Administrativos, Unión Temporal Mejores Vías 2015 ................................. 72

Tabla 13.Registro Contable No 2, Orden de Operación 001 Unión Temporal Mejores Vías 2015. 73

Tabla 14.Compras de Materiales Primer Corte Unión Temporal Mejores Vías 2015............... 74

Tabla 15. Registro contable No 3, Compras de materiales primer corte unión temporal mejores vías 2015. 75 
Tabla 16.Registro Contable No 4, Salida De Materia Prima Del Inventario Unión Temporal

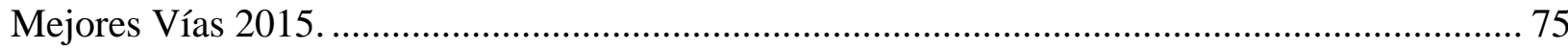

Tabla 17. Gastos Administrativos Unión Temporal Mejores Vías 2015 a diciembre................ 76

Tabla 18.Comprobante De Pago Nomina General Unión Temporal Mejores Vías 2015 Periodo Diciembre. 77

Tabla 19. Comprobante De Pago Nomina Empleado Agapito Torres, Unión Temporal Mejores Vías 2015 Periodo Diciembre. 78

Tabla 20. Registro Contable No 5, Nomina Periodo Diciembre Empleado Agapito Torres Unión

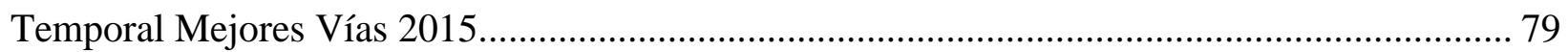

Tabla 21.Registro Contable No 6, CIF 1, Unión Temporal Mejores Vías 2015...................... 80

Tabla 22.Registro Contable No 7, CIF 2, Unión Temporal Mejores Vías 2015. ..................... 81

Tabla 23.Registro Contable No 8, CIF 3, Unión Temporal Mejores Vías 2015...................... 81

Tabla 24.Registro Contable No 9, CIF 4, Unión Temporal Mejores Vías 2015...................... 82

Tabla 25.Registro Contable No 10, Factura 001 Parcia 1, Unión Temporal Mejores Vías 2015.84

Tabla 26. Registro Contable No 11, Comprobante de Egreso 407, Unión Temporal Mejores Vías

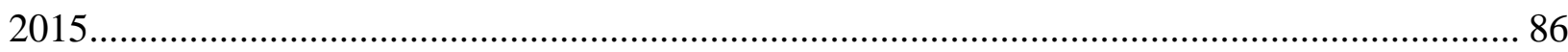

Tabla 27.Comparación normativa, reconocimiento, medición y revelación. .......................... 102

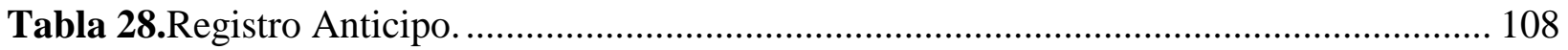

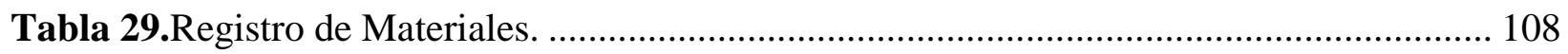

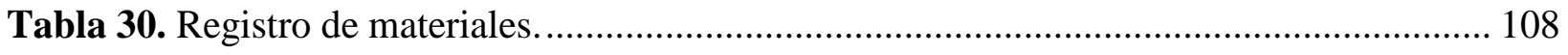

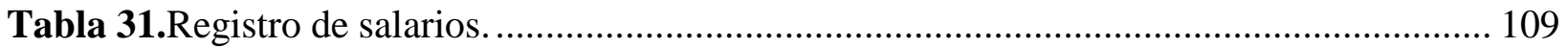

Tabla 32. Registro Transporte de materiales. ................................................................ 109

Tabla 33.Registro de diseños técnicos, paisajismo y eléctricos......................................... 110

Tabla 34. Registro de costos de licitación y estudios previos y adjudicación. ........................ 110

Tabla 35. Registro Primer Corte de Avance de Obra. ........................................................ 110

Tabla 36.Resultado Grado de Terminación Contrato de Obra............................................... 114

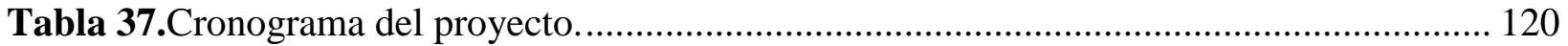

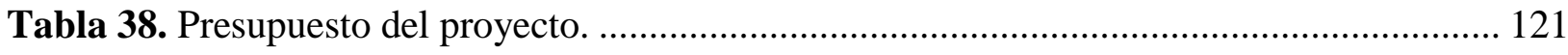




\section{Índice de Figuras}

Pág.

Figura 1. Variación anual del valor agregado Construcción Tercer Trimestre 2017.................. 43

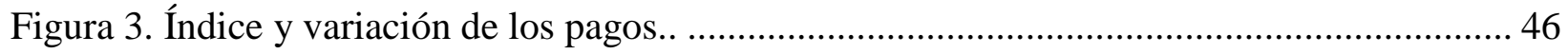

Figura 4. Índice y variación año corrido de las obligaciones en obras civiles, ......................... 47

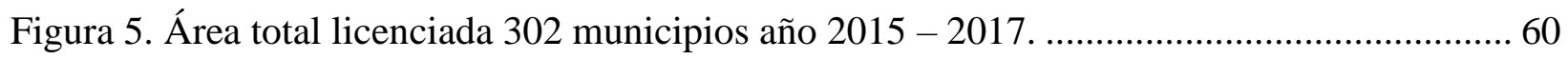

Figura 6. Participación aprobada según Departamentos y Bogotá D.C 88 municipios, doce meses

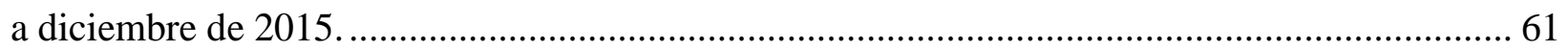

Figura 7. Variación, contribución a la variación y distribución del área total aprobada 302

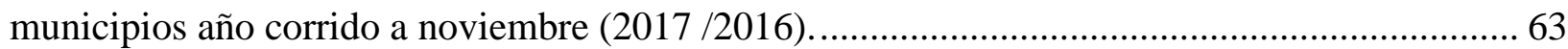

Figura 8. Factura De Venta 001 Parcial No 1 Unión Temporal Mejores Vías 2015 ................... 83

Figura 9. Comprobante De Egreso 407 Parcial No 1 a Favor de La Unión Temporal Mejores

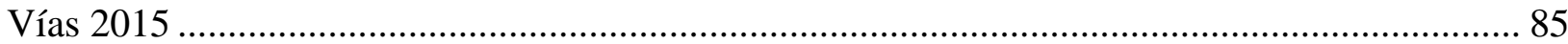

Figura 10. Certificado De Ingresos Y Retenciones Unión Temporal Mejores Vías 2015 Periodo

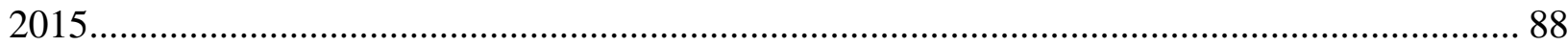

Figura 11. Impacto en el reconocimiento de ingresos NIIF 15....................................... 101

Figura 12. Desafíos para la gerencia en el reconocimiento de ingresos NIIF 1 .................... 101

Figura 13. Formula determinación grado de terminación Contrato de Construcción................. 114 


\section{Resumen}

La presente investigación tiene como objetivo abordar un análisis del estándar internacional de contabilidad NIIF $15^{1}$ en las empresas Colombianas de construcción que contratan con entidades públicas, y sus afectos en el tratamiento contable bajo criterios de reconocimiento, medición, presentación y revelación. Lo anterior se aborda mediante una revisión teórica sobre el estado actual de las empresas de la construcción, se analizan las condiciones actuales de administración contable y sus implicaciones de la NIIF 15 para estas entidades.

Mediante este proyecto se logra identificar las principales diferencias del estándar internacional de contabilidad NIIF 15 frente a las normas tradicionales de contabilidad aplicadas en Colombia en el sector de la construcción que contratan con entidades públicas.

Esta investigación es de tipo cualitativa y cuantitativa combinando modalidades exploratorias y descriptivas con el fin de alcanzar cada uno de los objetivos. El proceso investigativo estará enmarcado en utilizar instrumentos como encuestas y métodos vivenciales.

Palabras claves: NIIF 15, sector construcción, estándares internacionales de contabilidad, entidades públicas, contratos.

\footnotetext{
${ }^{1}$ Norma Internacional de Información Financiera relacionada a los Ingresos de Actividades Ordinarias Procedentes de Contratos con Clientes.
} 


\section{Problema de Investigación}

\subsection{Planteamiento del problema.}

Teniendo en cuenta el documento denominado el sector de la construcción: un sector líder lo largo de la historia de Colombia se indica que el rubro de la construcción y la infraestructura se ha considerado como uno de los sectores que ha generado muchos beneficios entre los cuales no solo encontramos el incremento del PIB en la economía colombiana sino beneficios sociales y culturales; para poder analizar como este rubro se convirtió en un motor elemental para el país es pertinente recordar los principales hechos que lo conllevaron (Hernandez, 2003, pág. 1). Así mismo (Hernández, 2003) menciona que a mediados del siglo XIX una de las preocupaciones de la Colombia colonial fue la exterminación de la esclavitud, erradicación de los feudos españoles y una constante búsqueda de la independencia y de los derechos humanos, escrutando un desesperado crecimiento urbanístico, industrial y económico, conllevando a un cambio en el estilo de vida de muchos colombianos de la época, desplazándose de la zona rural a la urbana, reduciendo la producción en actividades agropecuarias, generando un incremento en el sector industrializado provocando un acelerado crecimiento de las ubres de aquella época (pág. 1).

A partir de estos eventos el gobierno de Colombia como república libre y soberana con el trascurso de los años ha velado para lograr el bienestar social atendiendo prioridades que ha generado la urbanización con su contante evolución como: son la edificación de áreas de recreación, salud, educación, cultura y vivienda con el objetivo de satisfacer las necesidades básicas de los Colombianos (Umaña, 2003, pág. 3).

Ahora bien, el rubro de la construcción se ha convertido con el paso de los años en un factor elemental para la economía colombiana no solo abriendo nuevos campos para la generación de empleo; además incentivando la importancia de la inversión, el ahorro en el sector financiero. Es importante resaltar que, dentro de los sectores económicos, la construcción y la infraestructura afecta la economía según (Hernandez, 2003) existen tres niveles los cuales contribuyen a la creación de empresas, familia y el desarrollo económico del estado de manera que al momento de realizar una obra civil y arquitectónica patrocina el surgimiento de salarios, ingresos, utilidades e 
impuestos (pag 1).

Ahora bien un incremento acelerado en el sector de la construcción y la ingeniería apoyan un constante crecimiento sobre los demás sectores de la economía por eso la construcción de obras públicas, privadas se embarca dentro de los sectores líderes en Colombia; mas sin embargo en este mundo globalizado de constante cambio, el mercado internacional ha propiciado nuevas exigencias entre la cuales es elemental hablar un solo idioma en la práctica contable; para poder solucionar este acontecimiento en Colombia se adoptan los Estándares Internacionales de Contabilidad emitidos por el IASB $^{2}$ y IASC ${ }^{3}$, estas normas intervienen no solo contablemente en una organización , sino también socialmente, sistemáticamente y financieramente entre otras áreas elementales de la organización.

La adopción de las Normas Internacionales de Información Financiera conocidas como NIIF en Colombia trae grandes ventajas y cambios en las diferentes técnicas contables implementadas en el rubro de la construcción, siendo un factor elemental en la economía colombiana como se mencionó anteriormente. Es imperativo que los contratistas colombianos empiecen a analizar e implementar estas normas a la hora de ejecutar y gestionar los proyectos de construcción tanto para el sector público como el privado.

En el sector de la construcción en Colombia es un proceso bastante arduo implementar las normas internacionales debido a diferentes factores, entre los cuales es preciso señalar la falta de conocimiento y análisis a la hora de planificar, gestionar y proponer los proyectos de construcción aplicando la NIIF 15.

Debido a la naturaleza administrativa y de desarrollo de este tipo contratos no se pueden visualizar fácilmente los principios legales-contables, sin embargo con la implementación de la NIC11 en las organizaciones se soluciona esta gran problemática respecto a la clasificación y tratamiento de los ingresos, costos y gastos de los proyectos de construcción e ingeniería, que con el tratamiento tradicional bajo los Principio de Contabilidad Generalmente Aceptados en Colombia existen vacíos con respecto al tratamiento contable.

Con la implementación de la las NIIF 15 en las empresas contratistas le es posible realizar una mejor gestión de los proyectos y realizar la correspondiente clasificación de ingresos, costos,

\footnotetext{
${ }^{2}$ International Acounting Standars Board (IASB) - Junta de Normas Internacionales de Contabilidad.

${ }^{3}$ International Acounting Standars Comitte (IASC) - Comité de Normas Internacionales de Contabilidad.
} 
gastos al momento de la culminación del contrato de construcción, es posible medir estos elementos mediante el porcentaje de ejecución de la obra facilitando la correspondiente realización de los estados financieros enfocados con mayor precisión a la realidad del proyecto y facilitando la futura toma de decisiones a las organizaciones.

Es imperativo que las organizaciones tengan en cuenta estos cambios contables para la gestión y ejecución de los contratos de construcción, garantizando una mayor calidad de la información financiera.

\subsection{Formulación del problema}

¿Cuáles son las implicaciones de la Norma Internacional de Información Financiera (NIIF 15), en las empresas Colombianas de Construcción que contratan con entidades públicas? 


\section{Objetivos de la Investigación}

\section{$2.1 \quad$ Objetivo General}

Analizar la Norma Internacional de Información Financiera (NIIF 15), en las empresas Colombianas de Construcción que contratan con entidades públicas.

\subsection{Objetivos Específicos}

- Revisar la teoría sobre el estado actual de las empresas de la construcción.

- Analizar las condiciones actuales de administración contable en el rubro de la construcción

- Analizar las implicaciones de la NIIF 15 para las empresas de la construcción. 


\section{Justificación}

Con la ley 1314 del 2009 Colombia decide adoptar las Normas Internacionales de Información Financiera (NIIF), con el objetivo de hablar un solo idioma ya las empresas corren una constante carrera capitalista.

Es importante resaltar que con la implementación de las NIIF Y NIC en Colombia, se buscan aportar nuevas y prácticas en las compañías para el avance de las organizaciones y el crecimiento en el mercado facilitando la toma de decisiones.

En Colombia las empresas que se dedican al rubro de la construcción generan un factor primordial en la economía nacional sin embargo ya transcurridos unos años después de la adopción se siguen presentando dificultades e intransigencia en la aplicación de las normas internacionales NIC Y NIIF, debido a la falta de conocimiento de estos estándares.

Se considera de suma importancia indagar sobre los contratistas que licitan con entidades gubernamentales y ejecutan contratos construcción en Colombia, ya que además aportar en la economía de un país trae consigo grandes impactos sociales, económicos y culturales.

También es preciso resaltar que las organizaciones que se dedican a este campo, no poseen una efectiva administración a la hora de ejecutar un contrato de construcción dificultando el tratamiento contable fiable a la hora de analizar y realizar estados financieros en las organizaciones.

La investigación trata de analizar las empresas de construcción desde tratamiento administrativo y contable en los diferentes contratos de construcción; su respectiva discriminación de los ingresos, gastos y costos ordinarios a la hora de ejecución y liquidación.

Ahora bien, es preciso señalar la importancia de analizar el grado de implementación de la normatividad NIIF 15 en las empresas de la construcción, la cual poseen directrices que van enfocadas en los diferentes sujetos de los contratos de construcción; en primera instancia los contratistas como los contratantes. 
Siguiendo lo anterior y de acuerdo a la Ley 80 de $1993{ }^{4}$ se indica que la contratación que haya sido resultado de un proceso de licitación o concurso público, la interventoría es la entidad encargada de responder por los hechos y omisiones que causen daño o perjuicio a los contratantes (Ley 80, 1993). De acuerdo a lo anterior es importante resaltar que el sector de la construcción ha venido presentando acontecimientos significativos de corrupción y desfalcos en empresas contratistas en Colombia como el caso OBREDECH, que presento problemas a la hora de ejecutar los contratos.

Se considera de suma importancia este trabajo para dar ejemplo a otras empresas dedicadas al sector de la construcción haciendo a la ves aportes en la sociedad resaltando la importancia de estar ante la vanguardia de la normatividad internacional contable.

La investigación es consciente de la necesidad que existe en realizar el respectivo análisis general de la situación financiera implementando la NIIF 15 en las empresas de la construcción que contratan con entidades públicas para así poder orientar y determinar las posibles falencias que poseen las organizaciones en todas sus operaciones administrativas y contables.

La propuesta es factible porque cuenta con total disponibilidad de la organización y su colaboración en todos los temas de índole administrativo y contable, cabe mencionar que el tema a tratar; ha despertado interés y generado inquietudes en el cuerpo administrativo de la organización dada la problemática presentada relacionada con los contratos de construcción ejecutados.

El presente trabajo se dirige hacia el análisis del grado de implementación de la NIIF 15 en las organizaciones del rubro de la construcción que contratan con entidades públicas, en sus diferentes actividades que al implementar esta norma se verán beneficiadas en la presentación de la información financiera.

\footnotetext{
${ }^{4}$ Ley que expide el Estatuto General de Contratación de la Administración Pública.
} 


\section{Marco Teórico}

\subsection{Antecedentes}

Comencemos mencionando que a finales del siglo XIX la gran preocupación de los colombianos de fue lograr alcanzar la independencia aboliendo todas las formas de esclavitud, gracias a los padres libertadores de Colombia que lograron iniciar una nueva era crecimiento en infraestructura, comercio e industrialización como república independiente.

Ahora bien, con el paso de los años el gobierno ha velado para lograr satisfacer las necesidades básicas del pueblo colombiano por medio de la generación de viviendas, construcción de áreas verdes, salud, educación y cultura generando oportunidades de laborales y de crecimiento empresarial (Umaña, 2003, pág. 1).

Según (Hernandez) un estudio de la superintendencia bancaria, en el siglo XX el sector de la construcción ha causado una aceleración en los demás sectores económicos de aquella época generando desarrollo y crecimiento, en particular el sector de la construcción de vivienda, convirtiéndose en uno de los sectores líderes, en donde el gobierno implemento una estrategia macroeconómica que incentivó al pueblo colombiano al ahorro e inversión de vivienda. (pág. 3). Cabe señalar que en esta época de los 70 la economía colombiana presentaba ciertas fluctuaciones en las tasa de interés y los precios de vivienda eran bastante riesgosos al realizar conjeturas sobre el desarrollo de crédito a largo plazo; es preciso mencionar que en esta época las entidades encargadas en la financiación de vivienda era el Banco Central Hipotecario (BCH) el cual se vio forzado a implementar una nueva unidad monetaria debido a la crisis inmobiliaria que atravesaba a causa de la inflación, denominada Unidad De Poder Adquisitivo Constante (UPAC) la cual según (Hernández,) se expresa que:

Reajustaría de acuerdo con la variación del IPC certificado por el DANE. Por su parte, el Decreto No. 678 del mismo año creó las Corporaciones de Ahorro y Vivienda, encargadas de captar recursos en unidades de poder adquisitivo constante con destino a la financiación de vivienda (pág. 2). 
A partir de la creación de la UPAC es justo mencionar que el gremio de la construcción presento gran dinamismo para esta época más sin embargo; el gobierno fue reestructurando la políticas económicas cambiando el sistema como el cálculo de la tasa de crecimiento de la UPAC atándose a la tasa de intereses a término fijo (CDT); estas estrategias deterioro el sistema ya que las garantías hipotecarias de vivienda y los salarios conllevaban a un comportamiento inflacionario y la unidad de poder adquisitivo iba creciendo desmesuradamente.

Como resultado de varios acontecimientos macroeconómicos en época de los 90 el país ingreso en una crisis financiera, provocando que el sistema entrara en dificultades debido a que las corporaciones de vivienda y ahorro se fueron deteriorando, y los salarios disminuyeron su crecimiento, dificultado el pago de las cuotas crediticias a los colombianos. "En 1998 la crisis de la banca se profundizó y llevándose por delante a varios bancos comerciales y corporaciones de ahorro y vivienda CAV. En octubre de ese año fue intervenida Gran ahorrar, una de las $\mathrm{CAV}^{5}$ más importantes del país y la primera entidad que había nacido bajo el sistema UPAC en 1972" (Diario El Tiempo, 2002).

Debido a esto las entidades optaron por ofrecer sistemas de amortización de deudas a los colombianos que poseían créditos de vivienda con estas entidades con cuotas más bajas y plazos de pago más amplios, más sin embargo esta esta estrategia damnifico a los deudores en vez de beneficiarlos ya que estos sistemas de amortización en muchos casos no alcanzaba a cubrir los intereses de plazo generando incremento de las deudas haciendo que los colombianos en muchas ocasiones pagaran más de una vez su vivienda. Para poder solucionar esta nueva problemática el gobierno a finales del siglo XIX promulgo la Ley de vivienda 546 la cual su objetivo principal es "Establecer las normas generales y señala los criterios a los cuales debe sujetarse el Gobierno Nacional para regular un sistema especializado de financiación de vivienda individual a largo plazo, ligado al índice de precios al consumidor y para determinar condiciones especiales para la vivienda" (Ley de Vivienda, 1999).

Volviendo a reestructurar el concepto inicial de la UPAC convirtiéndose en la Unidad De Valor

5 Corporaciones de ahorro y vivienda: en Colombia estas entidades podrían prestar todos los servicios que ofrecen los bancos, tienen como finalidad promover el ahorro privado y canalizarlo hacia la industria de la construcción. 
real (UVR) cuyo cálculo se enfocó en el efecto inflacionario así tanto las entidades crediticias como los deudores hipotecarios se enfrenaban a menores riesgos, adicionalmente la Superintendencia Bancaria vela rigurosamente para que no haya capitalización de los intereses ni incremento de los saldos hipotecarios.

Con base a los anterior es preciso señalar que los últimos años el sector de la construcción ha jugado un papel primordial en la economía del país sobre todo en el sector de la vivienda, la Superintendencia de Sociedades ha analizado el sector de la infraestructura y de la construcción llegando a la conclusión que "En la última década el sector Infraestructura, ha representado en promedio el 8,3\% del Producto Interno Bruto (PIB) del sector Construcción y en el último año (2012), ese porcentaje cayó al 1,5” (Superintendencia de sociedades, 2013, pág. 4). De igual forma según informe de la Superintendencia de sociedades, la mayoria de las empresas que se dedican al rubro de la construccion estan catalogadas como empresas PYMES (Superintendencia de sociedades, 2013, pág. 4).

La Superintendecia de Sociedades en su informe de estudio realizado en el periodo 2008 2012 analizado la empresas dedicadas al rubro de la construccion e ingenieria pudo indagar el comportamiento financiero de estas organizaciones con los siguientes resultados:

El comportamiento frente a los ingresos operacionales es inverso ya que las Grandes empresas generan $\$ 15,2$ billones de pesos, un 71,53\% del total de los ingresos operacionales generados por las 1.471 empresas del sector para el año 2012, seguido de las PYMES con \$6 billones de pesos, un 28,39\% de los ingresos operacionales reportados (Superintendencia de sociedades, 2013, pág. 5).

Referente al tema de investigación es necesario tener ciertos conceptos de la estructura del sector y cada uno de los individuos que participan; unos de los individuos según la Superintendencia de sociedades más importantes de este rubro es el papel que juegan las consultorías:

Las cuales son fundamentales en la realización de las obras de ingeniería, ya que son los que ofrecen el conocimiento profesional especializado y técnico, de la mano del juicio independiente y de experiencia que permite garantizar objetividad en el análisis y la toma de decisiones, dichos participantes en este rol son catalogados como la industria del conocimiento dentro del sector (Superintendencia de sociedades, 2013, pág. 5). 
Muchos contratistas acuden a estas consultorias a la hora de realizar licitaciones con entidades estatales con el objetivo de todos los proyectos de construcción e ingeniería se ejecuten con eficacia en todas las fases y son los responsables en apoyar en la toma de desiciones para realizar una correcta ejecución del proyecto de infraestructura.

Otro individuo elemental de este rubro es el constructor o mejor denominado como contratista los cuales definen la camara de comercio aquellos que:

Ejecutan sus proyectos basados en un contrato de obra pública o bajo el modelo de participación público privada $\mathrm{APP}^{6}$ en el cual se acuerda y se define la construcción de infraestructura civil de gran envergadura; estos contratos normalmente se adjudican a través el mecanismo de licitación pública, permitiendo que existan varias ofertas y así, escoger la mejor propuesta en cuanto a calidad y precio (Superintendencia De sociedades, 2013,p6).

No se puede pasar por alto unos de los individuos mas importantes en el rubro de la construcción a la hora de ejecutar un contrato, la interventoria la cual entre sus labores es la encargada de supervisar el avance finaciero y de ejecución de los proyectos de construción y sin el ningún contratista puede intervenir en ningua obra de construcción e ingeniería, sin las actividades supervisión realizadas por la interventoria la cual se expresa claramente en el articulo 84 del estatuto anticorrupción como aquella que realiza: "Supervisión e interventoría contractual implica el seguimiento al ejercicio del cumplimiento obligacional por la entidad contratante sobre las obligaciones a cargo del contratista" (Ley 1474, 2011).

De igual forma en el estatuto anticorrupción se señala que:

Los interventores y supervisores están facultados para solicitar informes, aclaraciones y explicaciones sobre el desarrollo de la ejecución contractual, y serán responsables por mantener informada a la entidad contratante de los hechos o circunstancias que puedan constituir actos de corrupción tipificados como conductas punibles, o que puedan poner o pongan en riesgo el cumplimiento del contrato, o cuando tal incumplimiento se presente.” (Ley 1474, 2011).

\footnotetext{
${ }^{6}$ Asociaciones Público Privadas: Es un esquema de ejecución de cualquier tipo de inversión en donde el sector público y el sector privado y el sector privado trabajan conjuntamente y alinean sus objetivos. son contratos a largo plazo entre un socio privado y una agencia del gobierno para promover la infraestructura.
} 
Como se puede evidenciar el papel de la interventoría es primordial ya que además de supervisar la ejecución en todo proceso de la obra da fe al contratante ya sea una entidad estatal como privada. Cabe mencionar que un claro ejemplo de deficiencias e intransigencias por parte de las interventorías como es el famoso caso de la empresa brasileña constructora ODEBRECHT, el cual no solo fue un polémico acontecimiento de corrupción política, económica y social en los proyectos de construcción e ingeniería que según el artículo de la Revista Dinero se indica que "Este escándalo afectó directamente a 2 de los 50 proyectos de infraestructura que están en marcha en la actualidad. Las obras afectadas por el escándalo de Odebrecht son la Ruta del Sol II, las obras para garantizar la navegabilidad del Río Magdalena, así como la adición del tramo OcañaGamarra" (Revista Dinero, 2017). Entre otras violaciones legales realizadas por esta organización por medio de sus proyectos de construcción e infraestructura.

\subsection{Estándares Internacionales de contabilidad relacionados con los contratos de construcción}

En pleno siglo XXI vivimos en un mundo globalizado en donde todas las organizaciones compiten una sobre carrera capitalista y es imperativo que estas se afiancen al mercado internacional desde toda perspectiva, administrativa, financiera y contable.

Los estándares internacionales de contabilidad hacen parte del desarrollo de las organizaciones, permitiendo que estas se enmarquen en el mundo globalizado de los negocios; es ahí donde gracias a la adopción de estas nuevas tendencias normativas las entidades colombianas mejoran la calidad de la información financiera y la toma de decisiones.

$\mathrm{Al}$ abordar el tema de contratos de construcción es importante señalar las normativas que enmarcan este tema tales como la NIC 11, NICSP 11, sección 23 del Estándar Internacional para Pymes y las NIIF 15 sobre Ingresos de Actividades Ordinarias Procedentes de Contratos con Clientes y otras normativas que enlazan los estándares antes mencionados.

Es importe señalar que la NIIF 15 sustituye la NIC 11 teniendo en cuenta el Decreto 2420 del 2015 artículo 2.1.2. numeral 3 a partir del 01 de enero del 2018. 


\subsubsection{Norma Internacional de Contabilidad NIC 11 .}

La NIC 11 es un estándar internacional emitido por el IASC, se denomina Contratos de Construcción cuya vigencia aplica desde el año 1995 para la preparación de estados financieros y se derogará el 1 de enero del 2018 por la NIIF 15 sobre Ingresos de Actividades Ordinarias Procedentes de Contratos con Clientes razón por la cual en el presente estudio no se profundizará sobre la NIC 11.

Según la NIC 11 El objetivo de esta Norma es:

Prescribir el tratamiento contable de los ingresos de actividades ordinarias y los costos relacionados con los contratos de construcción. Debido a la naturaleza propia de la actividad llevada a cabo en los contratos de construcción, la fecha en que la actividad del contrato comienza y la fecha en la que termina el mismo caen, normalmente, en diferentes periodos contables. Por tanto, la cuestión fundamental al contabilizar los contratos de construcción es la distribución de los ingresos de actividades ordinarias y los costos que cada uno de ellos genere, entre los periodos contables a lo largo de los cuales se ejecuta. Esta Norma utiliza los criterios de reconocimiento establecidos en el Marco Conceptual para la Preparación y Presentación de los Estados Financieros, con el fin de determinar cuándo se reconocen, los ingresos de actividades ordinarias y costos de los contratos como ingresos de actividades ordinarias y gastos en el estado del resultado integral. (International Accounting Standards Boards (IASB), 1993, pág. 4).

De igual forma dentro de la NIC 11 se señala el alcance del estándar que "debe ser aplicada para la contabilización de los contratos de construcción, en los estados financieros de los contratistas" (International Accounting Standards Boards (IASB), 1993, pág. 4).

Así mismo se define que un contrato de construcción es "Un contrato, específicamente negociado, para la fabricación de un activo o un conjunto de activos, que están íntimamente relacionados entre sí o son interdependientes en términos de su diseño, tecnología y función, o bien en relación con su último destino o utilización” (International Accounting Standards Boards (IASB), 1993, pág. 4). 
Del mismo modo en la NIC 11 los contratos de construcción se pueden clasificar, segmentar y agrupar a la hora de ejecución siempre y cuando cumpla los requisitos que se indican en la norma internacional (International Accounting Standards Boards (IASB), 1993, pág. 4).

La NIC 11 señala que:

Los requisitos contables de esta Norma se aplican, generalmente, por separado para cada contrato de construcción. No obstante, en ciertas circunstancias y a fin de reflejar mejor la esencia económica de la operación, es necesario aplicar la Norma independientemente a los componentes identificables de un contrato único, o juntar un grupo de contratos a efectos de su tratamiento contable (International Accounting Standards Boards (IASB), 1993, pág. 5).

Ahora bien, es preciso mencionar el tratamiento con el que la norma internacional estipula el correcto reconocimiento de los ingresos y gastos de actividades ordinarias correspondientes a los contratos de construcción la sé cuál menciona de la siguiente forma:

Cuando el resultado de un contrato de construcción puede ser estimado con suficiente fiabilidad, los ingresos de actividades ordinarias y los costos asociados con el mismo deben ser reconocidos como ingreso de actividades ordinarias y gastos respectivamente, con referencia al estado de realización de la actividad producida por el contrato al final del periodo sobre el que se informa. Cualquier pérdida esperada por causa del contrato de construcción debe ser reconocida inmediatamente como un gasto (International Accounting Standards Boards (IASB), 1993, pág. 9).

\subsubsection{Norma Internacional de Información Financiera (NIIF) 15 .}

El objetivo principal de la NIIF 15 es:

El objetivo de esta Norma es establecer los principios que aplicará una entidad para presentar información útil a los usuarios de los estados financieros sobre la naturaleza, importe, calendario e incertidumbre de los ingresos de actividades ordinarias y flujos de efectivo que surgen de un contrato con un cliente (International Accounting Standards Boards, 2014).

Así mismo el alcance de la NIIF 15 consiste en:

Una entidad aplicará esta Norma a un contrato (distinto de un contrato enumerado en el párrafo 5) solo si la contraparte del contrato es un cliente. Un cliente es una parte que ha contratado con una 
entidad para obtener bienes o servicios que son resultado de las actividades ordinarias de la referida entidad a cambio de una contraprestación (International Accounting Standards Boards, 2014).

Dentro de la NIIF 15 se define que un contrato es

Un acuerdo entre dos o más partes que crea derechos y obligaciones exigibles. La exigibilidad de los derechos y obligaciones de un contrato es una cuestión del sistema legal. Los contratos pueden ser escritos, orales o estar implícitos en las prácticas tradicionales del negocio de una entidad (International Accounting Standards Boards, 2014).

Ahora bien, es importante tener en cuenta el reconocimiento, medición y presentación de los contratos de acuerdo a lo señalado por la NIIF 15.

\subsubsection{Reconocimiento.}

La norma estipula los criterios de se debe tener en cuenta la hora de realizar la medición de un contrato de construcción, lo primero que se debe tener en cuenta es Una entidad contabilizará un contrato con un cliente que queda dentro del alcance de esta Norma solo cuando se cumplan todos los criterios (International Accounting Standards Boards, 2014).

Así mismo la norma estipula que requisitos se deben tener en cuenta a la hora de que un contrato realizar una combinación de contratos: "Una entidad combinará dos o más contratos realizados aproximadamente al mismo tiempo, con el mismo cliente (o con partes relacionadas del cliente) y contabilizará los contratos como uno único” (International Accounting Standards Boards, 2014).

En cuanto a las modificaciones del contrato en el rubro de la construcción es un concepto que se debe tener presente ya que es elemental a la hora de ejecutar un contrato ahora bien la norma internacional concierta este concepto como:

un cambio en el alcance o en el precio (o en ambos) de un contrato que se aprueba por las partes. En algunos sectores industriales y jurisdicciones, la modificación de un contrato puede describirse como una orden de cambio, una variación o una modificación. Existe la modificación de un contrato cuando las partes aprueban un cambio que les crea nuevos derechos y obligaciones exigibles en el contrato, o bien cambios en los existentes. La modificación de un contrato podría aprobarse por 
escrito, por acuerdo oral o de forma implícita por las prácticas tradicionales del negocio. Si las partes del contrato no han aprobado la modificación, una entidad continuará aplicando esta Norma al contrato existente hasta que la modificación sea aprobada (International Accounting Standards Boards, 2014).

Así mismo para la empresa contratistas le es imperativo saber identificar con facilidad las obligaciones de desempeño en las cuales son los compromisos que recaen a la hora de firmar un contrato de este tipo para así mismo se ejecute eficientemente; mas sin embargo la norma internacional nos define como obligaciones de desempeño cuando:

Al comienzo del contrato, una entidad evaluará los bienes o servicios comprometidos en un contrato con un cliente e identificará como una obligación de desempeño cada compromiso de transferir al cliente (International Accounting Standards Boards, 2014).

A) un bien o servicio (o un grupo de bienes o servicios) que es distinto; o

B) una serie de bienes o servicios distintos que son sustancialmente iguales y que tienen el mismo patrón de transferencia al cliente (International Accounting Standards Boards, 2014).

De igual forma la norma internacional direcciona como se debe reconocer la satisfacción de un objetivo de desempeñado estipulado en el contrato de obra acordado entre las partes "mediante la transferencia de los bienes o servicios comprometidos (es decir, uno o varios activos) al cliente. Un activo se transfiere cuando (o a medida que) el cliente obtiene el control de ese activo" (International Accounting Standards Boards, 2014).

De igual modo en el sector de la construcción los contratistas poseen la caracteriza de desarrollar las obligaciones de desempeño a lo largo del tiempo debido al tiempo de ejecución de este tipo de contratos, los resultados de estas obligaciones son reconocidas mediante las parciales también llamadas cortes de obra en donde el contratista mediante evidencias muestra al contratante los compromisos ejecutados. En la norma internacional define como obligaciones que se satisfacen a lo largo del tiempo como el control de un bien o servicio a lo largo del tiempo y, por ello, satisface una obligación de desempeño y reconoce los ingresos de actividades ordinarias a lo largo del tiempo teniendo en cuenta los requisitos contenidos en el estándar (International Accounting Standards Boards, 2014). 
De igual forma si una obligación estipulada en el contrato no se desarrolla a lo largo del tiempo de ejecución de la obra, la norma internacional define a aquella obligaciones que se satisfacen en determinado momento "Para determinar el momento concreto en que un cliente obtiene el control de un activo comprometido y la entidad satisface una obligación de desempeño, la entidad considerará los requerimientos de control de los párrafos 31 a 34 .Además, una entidad considerará indicadores estipulados en la norma" (International Accounting Standards Boards, 2014).

A si mismo se reconocerá la medición del progreso hacia una obligación de desempeño logrando con completa satisfacción cuando:

una entidad reconocerá los ingresos de actividades ordinarias a lo largo del tiempo midiendo el progreso hacia el cumplimiento completo de esa obligación de desempeño. El objetivo al medir el progreso es representar el desempeño de una entidad al transferir el control de los bienes o servicios comprometidos con el cliente (es decir, la satisfacción de una obligación de desempeño de una entidad) (International Accounting Standards Boards, 2014).

Una entidad aplicará un método único de medir el progreso de cada obligación de desempeño satisfecha a lo largo del tiempo y lo aplicará de forma congruente a obligaciones de desempeño similares y en circunstancias parecidas. Al final de cada periodo de presentación, una entidad medirá nuevamente su progreso hacia el cumplimiento completo de una obligación de desempeño satisfecha a lo largo del tiempo (International Accounting Standards Boards, 2014).

\subsubsection{Medición.}

La norma internacional estipula como medición:

Cuando (o a medida que) una obligación de desempeño se satisface, una entidad reconocerá como ingresos de actividades ordinarias el importe del precio de la transacción (que excluye las estimaciones de la contraprestación variable que están limitadas de acuerdo con los parágrafos de esta norma (International Accounting Standards Boards, 2014).

Del mismo modo para determinar el precio de la transacción en este caso el contrato de obras civil o arquitectónica el estándar internacional lo determina como "El precio de la transacción es el importe de la contraprestación a la que una entidad espera tener derecho a cambio de transferir los 
bienes o servicios comprometidos con cliente, excluyendo los importes recaudados en nombre de terceros (International Accounting Standards Boards, 2014)"

De igual forma para poder definir el precio de la transacción es elemental identificar la naturaleza y los efectos que afectan en la fijación de la transacciones los cuales son: “contraprestación variable, limitaciones de las estimaciones de la contraprestación variable, existencia de un componente de financiación significativo en el contrato, contraprestaciones distintas al efectivo y contraprestación por pagos a realizar al cliente" (International Accounting Standards Boards, 2014).

Ahora bien, como mencionamos anteriormente las obligaciones de desempeño se generan a la hora del que el contratante y el contratista firman el contrato y este genera compromisos y obligaciones de desempeño que se pueden desarrollar en un tiempo determinado como en el transcurso de la ejecución de la obra. Es necesario saber asignar el precio de la transacción a estas obligaciones el cual no lo estipula la norma que:

El objetivo cuando se asigna el precio de la transacción es que una entidad distribuya el precio de la transacción a cada obligación de desempeño (a cada bien o servicio que sean distintos) por un importe que represente la parte de la contraprestación a la cual la entidad espera tener derecho a cambio de transferir los bienes o servicios comprometidos con el cliente (International Accounting Standards Boards, 2014).

Así mismo existen varios métodos de asignación de precio de la transacción dependiendo la naturaleza del negocio como son: Asignación basada en precios de venta independientes, Asignación de un descuento, Asignación de la contraprestación variable (International Accounting Standards Boards, 2014).

De igual forma es preciso tener en cuenta que este tipo de contratos cuya duración es superior a un año dependiendo su naturaleza, es de vital importancia tener en cuenta que los precios unitarios de estos contratos (APUS) varíen debido a las fluctuaciones del mercado o que el contratante considera que los precios de las transacciones varíen por otras razones que considere factible, ahora bien el estándar internacional define que hay que tener en cuenta para considerarse las variaciones de precio en las transacciones. 
Después del comienzo del contrato, el precio de la transacción puede cambiar por varias razones, incluidas la resolución de sucesos inciertos u otros cambios en circunstancias que modifican el importe de la contraprestación a la que una entidad espera tener derecho a cambio de los bienes o servicios comprometidos (International Accounting Standards Boards, 2014).

Una entidad asignará a las obligaciones de desempeño del contrato los cambios posteriores en el precio de la transacción sobre la misma base que al comienzo del contrato. Por consiguiente, una entidad no reasignará el precio de la transacción para reflejar los cambios en los precios de venta independientes después del inicio del contrato. Los importes asignados a una obligación de desempeño satisfecha se reconocerán como ingresos de actividades ordinarias, o como una reducción en los ingresos de actividades ordinarias, en el periodo en que el precio de la transacción cambie (International Accounting Standards Boards, 2014).

Una entidad asignará un cambio en el precio de la transacción en su totalidad a una o más, pero no a todas, las obligaciones de desempeño o a bienes o servicios distintos prometidos en una serie que forma parte de una obligación de desempeño única, de acuerdo con el párrafo 22(b) solo si se cumplen los criterios del párrafo 85 al distribuir la contraprestación variable (International Accounting Standards Boards, 2014).

Ahora bien cabe aclara la hora de ejecutar un contrato de construcción e ingeniería civil el contratista en su labor debe analizar el presupuesto por actividades (APUS) de obra en donde se detalla todos los ingresos costos y castos que se pueden incurrir a la hora de ejecución de la misma, los costos por su párate son una parte primordial para el contratista a la hora de ejecutar el contrato por lo cual debe realizar un estudio minucioso de estos dentro del presupuesto como al momentos que debe realizar el contratista a la hora de realizar el proceso de licitación para poder participar en la ejecución del contrato. Así mismo la NIIF 15 define el concepto de consto incrementales en la obtención de un contrato como: "Una entidad reconocerá como un activo los costos incrementales de obtener un contrato con un cliente si la entidad espera recuperar dichos costos" (International Accounting Standards Boards, 2014). 
"Los costos incrementales de obtener un contrato son los costos en que incurre una entidad para obtener un contrato con un cliente en los que no habría incurrido si el contrato no se hubiera obtenido" (International Accounting Standards Boards, 2014).

También nos estipula que los costos que los costos incurridos en la obtención de un contrato son aquellos que:

Se habría incurrido independientemente de si se obtuvo el contrato o no, se reconocerán como un gasto cuando tengan lugar, a menos que sean explícitamente imputables al cliente, con independencia de si se ha obtenido o no dicho contrato (International Accounting Standards Boards, 2014).

De igual forma la norma internacional define como los costos que se deben incurrir a la hora de ejecutar un contrato de construcción e ingeniería civil para la norma internacional los costos para cumplir un contrato son aquellos que : "una entidad reconocerá un activo por los costos incurridos para cumplir un contrato solo siempre que dichos costos cumplan todos los criterios estipulados en el estándar" (International Accounting Standards Boards, 2014).

Cierto es que en este tipo de contratos de construcciones poseen ciertos factores de depreciación y amortización los cuales la norma internacional los define cuando: "Un activo reconocido de acuerdo con el párrafo 91 o 95 se amortizará de una forma sistemática que sea congruente con la transferencia al cliente de los bienes o servicios con los que se relaciona dicho activo" (International Accounting Standards Boards, 2014). O cuando una entidad contratante la utilizara para:

reflejar un cambio significativo en el calendario esperado de transferencia de la entidad al cliente de los bienes o servicios con los que se relaciona el activo. Dicho cambio se contabilizará como un cambio en una estimación contable, de acuerdo con la NIC 8 (International Accounting Standards Boards, 2014).

Así mismo una entidad medirá el deterioro "de valor en el resultado del periodo en la medida en que el importe en libros de un activo reconocido de acuerdo con el párrafo 91 o 95 supere" (International Accounting Standards Boards, 2014). 
Los siguientes incisos expresados en el estándar:

(a) "el importe pendiente de la contraprestación que la entidad espera recibirá cambio de los bienes o servicios con los que se relaciona el activo; menos" (International Accounting Standards Boards, 2014).

(b) "los costos relacionados directamente con la provisión de esos bienes o servicios y que no se han reconocido como gastos" (International Accounting Standards Boards, 2014).

\subsubsection{Presentación.}

Del mismo modo la norma internacional estipula que información se debe presentar en los estados financieros cuando:

Una de las partes de un contrato haya cumplido, una entidad presentará el contrato en el estado de situación financiera como un activo del contrato o un pasivo del contrato, dependiendo de la relación entre el desempeño de la entidad y el pago del cliente. Una entidad presentará los derechos incondicionales a recibir la contraprestación como una cuenta por cobrar separada (International Accounting Standards Boards, 2014).

Así mismo la información a revelar en los estados financieros de un contrato, subcontrato ejecutado por un contratista mediante consorcios y o uniones temporales será aquella que estipule la normativa NIIF 15 con el objetivo de:

Revele información suficiente que permita a los usuarios de los estados financieros comprender la naturaleza, importe, calendario e incertidumbre de los ingresos de actividades ordinarias y flujos de efectivo que surgen de contratos con clientes. Para lograr ese objetivo, una entidad revelará información cualitativa y cuantitativa sobre los aspectos estipulados en la normativa NIIF15 (International Accounting Standards Boards, 2014). 


\section{Marco Metodológico}

Esta investigación es de tipo cualitativa y cuantitativa combinando modalidades exploratorias y descriptivas con el fin de alcanzar cada uno de los objetivos. El proceso investigativo estará enmarcado en utilizar instrumentos como encuestas y métodos vivenciales dando respuesta al objetivo de la presente investigación.

La investigación a realizar contiene fases exploratorias, descriptivas, explicativas y propositivas, a partir de las cuales se propone realizar un análisis a la NIIF 15 en el sector de la construcción que contratan con entidades públicas.

Esta investigación estará basada en el método de caso, de acuerdo a la práctica contable de las empresas colombianas que manejan contratos relacionados con la construcción.

El método a utilizar iniciara con un recorrido teórico sobre el rubro de la construcción en Colombia, observando los principales factores que inciden en el sector; lo que conllevara al investigador a analizar las condiciones actuales y las implicaciones de la NIIF 15, para lo cual se abordaran las siguientes fases:

Fase 1. Revisión teórica sobre el estado actual de las empresas de la construcción.

Fase 2. Análisis actual de la administración contable en el sector de la construcción que contratan con entidades públicas.

Fase 3. Analizar las implicaciones de la NIIF 15 para las empresas de la construcción. 


\section{Desarrollo del proceso metodológico}

Formuladas las fases del proceso metodológico en el ítem anterior, se procede a realizar el desarrollo a cada fase.

\subsection{Desarrollo fase 1}

La presente fase aborda una revisión teórica sobre el estado actual de las empresas de la construcción en Colombia y su comportamiento en la economía durante los últimos años.

\subsubsection{Estado Actual de las empresas de la construcción en Colombia.}

En Colombia el sector de la construcción es un motor fundamental en la economía colombiana en los últimos años ha jugado un papel importante en el crecimiento en el país.

Con el fin del que el lector tenga una mejor perspectiva sobre el sector de la construcción en los últimos años y tenga una visión de cómo las empresas contratistas han contribuido con el desarrollo y crecimiento del país los últimos tres años, es pertinente mencionar los aspectos más relevantes del sector de la construcción de obras civiles y arquitectónicas en Colombia y que aspectos positivos y negativos ha traído para la economía colombiana.

Es importante mencionar que las empresas contratistas en Colombia por medio de licitaciones realizan contratos con el Estado, logrado satisfacer las necesidades a la población colombiana mejorando la calidad de vida de los colombianos. Ahora bien, las empresas contratistas en Colombia realizan diferentes tipos de proyectos de construcción; con el fin de lograr satisfacer las necesidades de la sociedad, la economía y el Estado entre las cuales podemos encontrar:

Proyectos de construcción verticales, son aquellas que tienen relación con obras cuya ejecución se realiza desde un punto de nivel de la superficie, hacia arriba rompiendo la ley de la gravedad y se clasifican con el fin de satisfacer una necesidad de tipo social, económico, productivo como son escuelas, bibliotecas, centros de desarrollo infantil entre otros (Paladino, s.f.). 
De igual forma los proyectos de construcción horizontales se definen como aquellas obras que se construyen partiendo desde un punto fijo sobre la superficie terrestre y se va construyendo sobre la misma superficie hacia otro punto fijo, estas obras se visualizan cuando la empresas contratista realizan mejoramiento de vías, adecuación de redes de alcantarillado, construcción de caminos, redes de oleoductos, sistemas de drenaje, construcción de caminos rurales entre otros (Paladino, s.f.).

Basándose en lo anterior es pertinente mencionar los importantes avances y acontecimientos de empresas contratistas que han realizado obras de construcción de ingeniería civil y arquitectónica en Colombia los últimos tres años, la cual se ha caracterizado por desarrollar importantes avances en las obras a nivel nacional las cuales han traído beneficios a la población directamente relacionada; así mismo las empresas contratistas que licitan con el Estado ha generado polémicas de todo tipo de índole los cuales se mencionaran a continuación de manera general.

Comencemos por evocar el estado de las empresas contratistas en el año 2015 y que impactos realizaron en este año en materia de infraestructura y desarrollo del sector, de antemano es importante resaltar que a partir de año 2012 el gobierno ha realizado el proceso de diálogos de

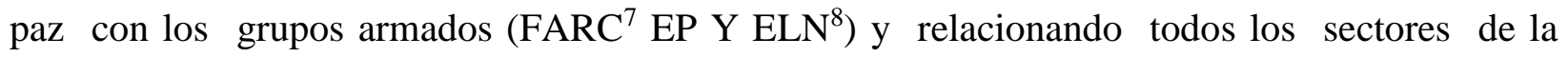
economía con estrategias de gobierno con el fin de alcanzar, establecer y mantener una paz estable y duradera dentro de los ejes del plan de desarrollo nacional del 2014 al 2018.

Como se mencionó anteriormente las empresas contratistas del sector de la construcción en el año 2015 evolucionaron en materia de infraestructura en varios campos, entre los cuales es pertinente mencionar algunas obras que tuvieron mayor impacto en este periodo como el desarrollo y avance de los proyectos de vías $4 \mathrm{G}^{9}$; los cuales iniciaron obra en el 2013 por medio de concesiones las cuales revolucionaran la infraestructura vial en Colombia, con en el objetivo de mejorar la competitividad del país, disminuyendo el tiempo, costo de las personas, facilidad del comercio permitiendo la mayor conectividad del país en zonas retiradas beneficiando los demás sectores

\footnotetext{
${ }^{7}$ Fuerzas Armadas Revolucionarias de Colombia

${ }^{8}$ Ejército de Liberación Nacional

${ }^{9}$ Concesiones Viales de Cuarta Generación
} 
de la economía en su desarrollo

Ahora bien, en un comunicado emitido por la vicepresidencia en el 2015 se señala que:

10 de los proyectos se encuentran con actas de inicio, 9 en proceso de adjudicación y 9 obras en ejecución de la primera ola del proyecto 4G, en el mismo el entonces vicepresidente German Vargas Lleras menciona que los proyectos de la segunda ola 4G se encuentran en procesos de adjudicación (Viceprecidencia, 2015).

Con base a lo anterior es importante mencionar la labor de las conceciones y contratistas que estan realizando obras para beneficio del pais con proyectos correspondientes a la primera ola del las vias $4 \mathrm{G}$, la cual se conforma por importantes proyectos de infrastructura vial entre los cuales es importante mecionar:

Conexión al pacífico 1, obra de bolobolo - ancon sur la cual se compone de $42 \mathrm{kl}$ en dobles calzadas, 42 puentes y 2 tuneles de doble tubo ejecutado por la consecionaria covipacifico s.a.s, los diseños fueron contratados por el Consorcio Integral S. A. - Iceacsa Colombia la cual es una empresa dedicada a la ingenieria de consulta la cual se encarga en dar soluciones integrales de ingenieria para la entidades públicas y privadas, participando en todas las fases de desarrollo de los proyectos arquitectonicos y civiles.

Este proyecto se encuentra ubicado en el departamento de antioquia entre los municipios de Venecia, Titiribí, Amagá, Caldas, La Estrella y Sabaneta. Su punto de inicio es el corregimiento de Bolombolo y se conectará en el punto conocido como "cuatro palos" con la doble calzada existente hasta el sector conocido como Ancón Sur del municipio de Sabaneta (Consecionaria Covipacifico S.A.S, 2015)

Otro de los proyectos de la primera ola es el denominado proyecto de Honda-Puerto SalgarGirardot cuyo objeto es la consturccion, rehabilitacion, mejoramiento y mantenimiento del corredor honda-Puerto salgar y Girardot.

Es importante resaltar que la obra anteriormente mencionada esta siendo ejecutada por contratistas relevantes como Mario Albertos Huertas Cotes, denominado uno de los contratistas mas poderosos de colombia tras una experiencia de 40 años de infraestructura vial que ha 
contribuido en grandes proyectos como el de la Avenida Boyacá, Cordoba, Suba y la ampliacion de la Autopista Norte (Huertas \& Alberto, 2016).

Dicho lo anterior se considera de suma importancia mencionar que ventajas y desventajas e impactos han traido dichas obras en el periodo 2015; según el ingeniero Carlos Jacks Presidente de la empresa Cemex en Colombia en artículo publicado en el Periodico La Republica expresa que gracias a estos proyectos Colombia se convertirá en un país más competitivo en la región, ya que no solo apalancará al sector de la construcción, comercio y agricultura sino toda la economía en general asi como el bienestar de la población (Janks, 2015, pág. 1), adicionalmente resalta que:

Partiendo de proyecciones realizadas por el Ministerio de Hacienda, el efecto directo que tendrían los proyectos 4G durante su construcción en el PIB, sería de 1,56\% anual a partir de este año. Lo que tendrá un efecto positivo durante los siguientes cuatro años (Janks, 2015).

Para finalizar janks señala algunos beneficios que traerá la contrucción de estas obras de infraestructura en colombia ayudará a la generación de empleo durante la ejecución, competitividad y crecimiento del país (Janks, 2015, pág. 1).

De igual es importante resaltar que "En el actual Plan Nacional de Desarrollo, se estima que la inversión privada en infraestructura será cercana $\$ 24$ billones, los cuales serán asignados a la construcción de carreteras, aeropuertos, ferrocarriles y puertos” (Janks, 2015, pág. 1).

Asi mismo este megaproyecto tambien se ha visto afectado por diferentes causas como es el caso de la contrucción de la via perimetral de oriente, una autopista 4G que pasará por los municipios de Cáqueza, Ubaque, La Calera, Guasca, Sopó, Briceño y Choachí, proyecto ejecutado por el Grupo Empresarial GRODCO, la cual en su ejecución esta proyectado la generacion significativa de puestos de trabajo.

Entre otros desarrollos arquitectonicos y en infraestructura que Colombia presenció en varios Departamentos de la nación en el año 2015, se puede mencionar el proceso de licitación para la modernización de los aeropuertos de el Eden ubicado en Armenia y en el aeropuerto Benito 
Salas ubicado en Neiva, proyecto el cual esta apoyado por el ANI. Algunas características que tiene este mega proyecto de los aeropuertos es buscar la ampliación de plataformas, construcción y adecuacion de nuevos accesos para los pasajeros entre otras mejoras (Agencia Nacional de Infraestructura (ANI), 2015).

A todo lo anterior es pertinente mencionar que en el año 2015 el sector de la construcción fue un factor primordial en la economía de la nación ya que como se mencionó este cumple con los ejes y las estrategias establecidas en el plan de desarrollo nacional DNP 2014- 2018, así mismo las entidades descentralizadas se han velado por lograr satisfacer las necesidades de la población mediante contrataciones públicas, generando puestos de trabajo y garantizando la preservación del medio ambiente.

Por otro lado, en los siguientes apartados para el año 2016 se puede evidenciar que los contratistas y el sector de la construcción presentan gran dinamismo mediante obras de gran relevancia para la economía del país, gracias a los mega proyectos de infraestructura que se han ejecutado bajo el gobierno, obteniendo un número significativo de licencias aprobadas para la ejecución y construcción de proyectos arquitectónicos y civiles. Considerándose para los economistas y el $\mathrm{DANE}^{10}$ un indicador que presento gran dinamismo a diferencia de otros sectores de la economía como la minería con la caída del petróleo en este periodo y las actividades de servicios.

Así mismo el DANE en uno de sus informes comunica cuales fueron los enfoques del sector de la construcción algunos fueron: la iniciativa e impulso y ejecución del proyecto mi casa ya ahorradores desarrollado por el ministerio de vivienda la cual está destinada para 2.265 familias de escasos recursos en la ciudad de Bogotá y al resto del país gracias a la fomentación de subsidios de vivienda; además del campo de la vivienda el sector de la construcción en este periodo también se desarrolló contribuyendo al sector comercial en la construcción de oficinas, bodegas de comercio y en el sector del turismo realizando grandes aportes, en la construcción de hoteles y mejoramiento de vías y aeropuertos (Flórez, 2016).

Entre los grandes avances arquitectónicos y de infraestructura es importante resaltar algunas obras

\footnotetext{
${ }^{10}$ Departamento Administrativo Nacional de Estadística.
} 
las cuales trajeron grandes beneficios a la nación como son la finalización de la obra doble calzada Bogotá- Tunja. Este proyecto de infraestructura vial que inicio labores en el año 2002 y que tras 14 años de ejecución finalizo y fue inaugurado el vicepresidente German Vargas Lleras.

Según la Agencia Nacional de Infraestructura se indica que:

Este proyecto conecta el del Departamento de Boyacá con el departamento de Cundinamarca quedan completamente conectados por el norte reduciendo notablemente los tiempos de desplazamiento entre estas dos regiones y sus municipios aledaños. Este es un megaproyecto que une a la zona industrial de Boyacá con Bogotá y que le va a cambiar la cara a la infraestructura del país, destacó el vicepresidente, quien resaltó que durante la ejecución de estas obras se generaron más de 2.000 empleos directos e indirectos (Agencia Nacional de Infraestructura (ANI), 2016).

De lo anterior es preciso señalar que la construcción del mega-proyecto vial fue ejecutado por el consorcio solarte representado por el ingeniero Carlos Alberto solarte el cual ha tenido gran prestigio en la nación y durante 48 años ha participado en importantes licitaciones de construcción e infraestructura con la nación. Así mismo entre los beneficios que trae la construcción de este proyecto de reducir los tiempos de trayecto entre esos dos Departamentos facilitando el comercio de grandes y pequeños empresarios por la capital de la nación, de igual forma el sector turístico del departamento de Boyacá también se ha visto beneficiado ya que el proyecto mejora el tránsito por el puente de Boyacá y sus monumentos siendo una fuente de inspiración de cultura y turismo colombiano.

Con base a lo anterior se puede determinar que el año 2016 el sector de la construcción jugó un papel primordial en el crecimiento y desarrollo de la nación y por medio de la apertura de nuevas licitación las empresas contratistas obtuvieron gran dinamismo en el sector respecto a los otros indicadores del PIB; impulsado por la generación de vivienda de interés prioritario, la constante carrera capitalista y expansión que se ve en las grandes capitales de la nación, creando la necesidad de mejorar la infraestructura de la ciudades como la construcción en el sector hotelero, mejoramiento de aeropuertos y construcción de nuevos centros comerciales.

Ahora bien, debido al incremento de apertura de licitaciones por parte del gobierno muchos contratistas con el paso del tiempo se han visto obligados por optar nuevas estrategias y mecanismos y alternativas a la hora de realizar proyectos arquitectónicos y de ingeniería civil 
como es la implementación de Building Information Modeling (BIM) ${ }^{11}$ (El Pais, 2016).

De igual forma otro de los modelos de innovación que están implementando los contratistas en Colombia es el modelo innova 2020 cuyo surgimiento se dio al ver que el gremio en los últimos años ha realizado consultas técnicas y especializadas en innovación a la hora de ejecutar un contrato de construcción el cual se compone de planes estratégicos de I+D+I ( Investigación, Desarrollo e Innovación) en el campo de la construcción para así mismo producción productos, materiales y servicios a la hora de ejecutar obras arquitectónicas y civiles en todas sus fases. Cabe mencionar algunos casos de firmas constructoras que por medio de la implementación de estas estrategias han desarrollado productos y herramientas que facilitan la ejecución de labores de empresas dedicadas a este rubro como son la empresa del valle del Cauca Forsa la cual a través de los años ha prestado servicios de soluciones integrales en el campo de obras de arquitectónicas y de ingeniería civil gracias a su constante innovación en los productos y servicios que ofrece, dándose a conocer internacionalmente por creación de sus innovadoras y practicas formaletas. Otra empresa que ha obtenido gran participación en el mercado gracias a la implementación de planes estratégicos $\mathrm{I}+\mathrm{D}+\mathrm{I}$ es la firma Quimiconstruccion la cual se ha dedicado al desarrollo de químicos utilizados en la construcción como lignosulfato de calcio la cual reduce la utilización de agua en la ejecución de obras civiles y arquitectónicas demostrando un gran compromiso con el medio ambiente (El Pais, 2016).

Asimismo, cabe señalar un modelo implementado por las empresas contratistas en este periodo el cual se denomina construcción liviana en seco conocido como Drywall considerado como un material practico versátil, económico y amigable con el ecosistema facilitando la construcción de viviendas promocionadas por el gobierno a través de subsidios (El Pais, 2016).

Ahora bien, en el año 2017 el sector de la construcción presento gran dinamismo y uno de los factores que aportaron fue el factor del sector de la vivienda a través de subsidios otorgados por el gobierno siguiendo las estrategias estipuladas en el plan de desarrollo 2014- 2018.

\footnotetext{
${ }^{11}$ Según (Eastman, 1999) Es una representación digital de los procesos de construcción de edificios para facilitar el intercambio y la interoperabilidad de la información de proyectos en forma digital. Tomado de (Torres et al., 2014).
} 
Así mismo a principios del año 2017 según la cámara de comercio Camacol $^{12}$ el sector paso por un periodo de transición y estabilización, presentando un impacto en cuanto la construcción y compra de vivienda por la reforma tributaria (Diario El País, 2017).

De igual forma señala la presidenta de CAMACOL Sandra Forero Ramírez que:

Con la implementación de la reforma tributaria es sector se complicó en cuanto al otorgamiento del beneficio de la exención del impuesto a la renta, con el nuevo sistema se procede a eliminarlo y, por lo tanto, la promoción de proyectos sería nula (Catelli, 2017).

Adicionalmente es pertinente señalar que con la implementación de la reforma tributaria afectaba a todas las empresas dedicadas al sector de la construcción ya que con los incrementos de la materia prima a la hora de la ejecución de un contrato de construcción de obras civiles y arquitectónicas elevando los costos, así mismo la presidenta de la cámara de la construcción colombiana CAMACOL expreso que:

Para un país como Colombia la preservación de los beneficios para el desarrollo de la Vivienda de Interés Social (VIS), son el pilar central en la promoción de proyectos y el cierre financiero de los hogares en la adquisición de vivienda. Eliminar esta exención no solo haría nula la posibilidad de ofertar nuevos proyectos por la inviabilidad financiera que se generaría, sino que limitaría los efectos redistributivos de la vivienda social sobre la población, particularmente en materia de superación de la pobreza, formalización en la tenencia de la propiedad y acceso a servicios básicos; efectos que han sido ampliamente demostrados en los últimos años (Catelli, 2017).

Así mismo el director de estudios económicos del gremio de la construcción Edwin Chiriví Bonilla expreso en un artículo publicado en el Periódico Colombiano que: para inicios del año 2017 el sector presentara estabilización y gran dinamismo en el transcurso del año, de igual forma los factores que se ven involucrados en el sector como la generación de empleo interno y externo y el crecimiento de entidades relacionadas en el sector como cementeras, ladrilleras y empresas especializadas como laboratorios entre otras. Por otra parte, señala que, con la implementación de la reforma tributaria, las tasas de interés y la debilidad de confianza de los consumidores. (Ortiz, 2017).

\footnotetext{
${ }^{12}$ Cámara de la Construcción Colombiana.
} 
Por otra parte, el viceministro de hacienda Andrés Escobar Arango, señalo que: "con la implementación de la reforma tributaria lograra que las cuentas fiscales de la nación se estabilicen y que, de esta manera, la actividad edificadora se vea afectada positivamente" (Ortiz, 2017).

De igual forma es importante resaltar que para el actual gobierno y siguiendo los ejes y estrategias del plan nacional de desarrollo 2014- 2018 resalta el cumplimiento ameno de sus pilares (paz, equidad y educación) ya que se asume como instrumento de igualdad social y crecimiento de la nación.

De igual forma otra de las obras que se evidenciaron en el periodo 2017 fue la finalización de la ampliación del aeropuerto José María Córdoba, concesión realizada por la Agencia Nacional de Infraestructura ANI, este ambicioso proyecto permitirá a los colombianos y en especial al departamento de Antioquia incrementar la movilización y permitir promover el comercio, la generación de empleo y el turismo a nivel nacional e internacional.

De igual forma el presidente de la Agencia nacional de infraestructura ANI Dimitri Zaninovich en una entrevista realizada por caracol radio expreso su opinión con la finalización del proyecto: Estamos muy contento con los avances de las obras del aeropuerto de Rionegro y que lo van a poner a la altura de lo que es Medellín, estamos incrementando cinco posiciones para los vuelos nacionales e internacionales, estamos ampliando las áreas en 12 mil metros, más área de plataforma, toda una transformación del aeropuerto, que sigue consolidando a Medellín (Caracol Radio, 2017).

Ahora bien, es pertinente resaltar que el año 2017 el sector de la construcción como las empresas contratistas presentaron grandes fluctuaciones a nivel nacional entre las cuales cabe mencionar la caída del precio del petróleo, el incremento de la materia prima debido a la reforma tributaria con su incremento en la tasa IVA, la desaceleración económica del país y por otro lado las revelaciones de corrupción en la contratación que salió a la luz pública en este periodo que hizo que disminuyera el nivel de confianza hacia los contratistas y el sector por parte de los contratantes.

Mas, sin embargo, el departamento nacional de estadística DANE ha expresado que los proyectos 
de construcción de vivienda siguen siendo uno de los factores que estabilizaron el sector en dicho periodo, así mismo CAMACOL mantiene que el sector de la construcción es uno de los sectores más dinámicos en materia de generación de empleo ya que produce 40.000 puestos de trabajo por año a nivel nacional (Ruiz, 2017).

Cabe señalar que este sector a lo largo de los años se ha considerado como uno de los más innovadores y vanguardistas de la economía, colombiana, gracias a su constante crecimiento y participación en obras estatales con el objetivo de mejorar la calidad de vida de los colombianos, exigiendo a los contratistas a tener un compromiso de ofrecer calidad a la hora de realizar una obra de civil o arquitectónica; llevándolos a la generación de estrategias y creación productos y procesos para la ejecución de proyectos.

Así mismo el arquitecto y conferencista español experto en materias de innovación en el 4 foro constructor realizado en la ciudad de Bucaramanga, señala que a pesar de los acontecimientos en que se ha visto involucrado el gremio de la construcción en Colombia en los últimos años, como casos de corrupción y fluctuaciones económicas que se ha visto reflejado, resalta que grandes ciudades como Medellín, Bogotá y Bucaramanga los contratistas están en las ciudades que tienen la capacidad de realizar obras sostenibles (Ruiz, 2017).

Como se mencionó anteriormente en este periodo el gremio de la construcción paso por grandes polémicas al darse a la luz pública diferentes casos de corrupción en la contratación como el caso de la empresa multinacional brasileña ODEBRECHT la cual realizo multimillonarios sobornos realizados a 12 países entre esos Colombia , con el fin de quedarse con contratos de infraestructura y energía como la adjudicación de obras como son la ruta del sol y el proyecto de recuperación de la navegabilidad del rio Magdalena entre otras, los cuales se vieron involucrados en estos hechos altos exfuncionarios de los gobiernos de Uribe y Juan Manuel Santos ,congresistas, funcionarios de la agencia nacional de infraestructura, empresarios, miembros de partidos políticos y de la rama judicial (Diario El Tiempo, 2017).

Así mismo también se considera pertinente mencionar otro polémico caso de corrupción en Colombia como es el caso del Carrusel de la Contratación el cual se dio a la luz pública en el 
año 2010 y hasta la fecha aún se siguen evidenciando los efectos de este particular caso en la ciudad capitalina el cual durante la administración del exalcalde Samuel Moreno Rojas en las cuales se evidenciaron multimillonarias comisiones de altos funcionarios políticos a empresarios como la empresa GRUPO NULE la cual en este periodo estaba realizado distintas obras de carácter público, como es la obra tercera fase del Transmilenio la cual durante su ejecución presento injustificables retrasos, como en otras las cuales le habían sido adjudicadas y cuyos anticipos fueron desviados, considerándose como un caso de detrimento patrimonial del distrito (Revista Dinero, 2013).

De los casos anteriores es preciso afirmar que durante la historia de Colombia se han presenciado interminables casos de corrupción los cuales magnifica la economía del país y el sector de la construcción no está libre de este gran fenómeno, el cual ha generado una falta de confianza por parte de las instituciones en el momento de ceder contratos de construcción.

El gobierno a través de los años ha tomado medidas con el objetivo de disminuir el nivel de corrupción en la contratación pública como fue el surgimiento e implementación del sistema electrónico de contratación pública en el año 2015 SECOP, con el fin de obtener una base de datos en donde los contratistas y contratantes conozcan los correctos procesos de contratación con entidades de orden nacional, subnacional y otras entidades como son INVIAS ${ }^{13}, \mathrm{ANI}^{14}, \mathrm{CAR}^{15}$ y los sistemas de trasporte masivo en las ciudades (Melendez, 2017).

Así mismo a finales del año 2016 la Cámara Colombiana de la Infraestructura (CCI) aseguro que ya existe una estrategia con el fin de minimizar los casos de corrupción en la contratación pública como el CASO ODEBRECHT, el cual genero un gran impacto económico.

Según el artículo denominado Proyecto de ley crearía 'antídoto' contra la corrupción en la contratación pública expresa que el presidente de CCI con la aprobación de la propuesta de contratación pliego tipo vinculante por parte de la comisión primera del Senado, busca reformar

\footnotetext{
${ }^{13}$ Instituto Nacional de Vías.

${ }^{14}$ Agencia Nacional de Infraestructura.

${ }^{15}$ Corporación Autónomas Regionales.
} 
el estatuto de contratación de la administración pública; estandarizando los procesos con el objetivo que sean definitivos y de uso obligatorio, documento que para los funcionarios corruptos no podrá crear pliegos discrecionales, sino tendrán que cumplir con el proyecto, de igual forma al crear una estrategia anti-corrupción en la contratación pública se brinda una oportunidad transparente en la cual puedan participar las pequeñas y grandes regiones del país democráticamente en los procesos de contratación (Diario El Portafolio, 2016).

\subsubsection{El sector de la construcción en cifras años $2015-2017$.}

Ahora bien, después de haber mencionado los avances económicos, de desarrollo, de innovación, polémicas y demás fluctuaciones que presento el gremio de la construcción en los periodos 2015, 2016, y 2017. Se considera de suma importancia realizar un análisis detallado de este sector, con el objetivo de visualizar los factores y comportamientos del sector y como las empresas contratistas contribuyen en la economía del país.

Con base a lo anterior es preciso iniciar con el comportamiento que presento el sector de la construcción en el producto interno bruto PIB en estos tres periodos mencionados anteriormente como muestra el siguiente grafico realizado por el DANE:

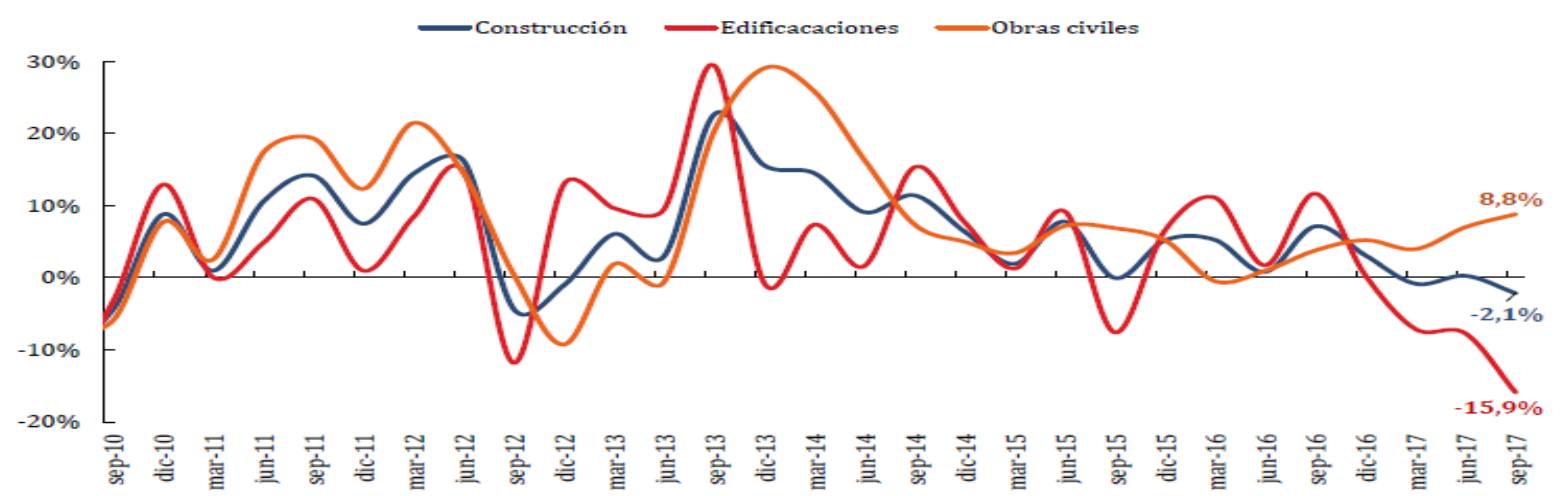

Figura 1. Variación anual del valor agregado Construcción Tercer Trimestre 2017. Adaptado de "Informe de actividad edificadora" de CAMACOL, por DANE y DEET, 2017. 
Tabla 1. Valor agregado sector construcción a precios constantes,

\begin{tabular}{|c|c|c|c|c|c|c|}
\hline \multicolumn{2}{|c|}{ Periodo } & \multirow{2}{*}{$\begin{array}{l}\text { Construcción } \\
\\
1,9\end{array}$} & \multirow{2}{*}{$\begin{array}{c}\text { Construcción de } \\
\text { edificaciones } \\
\text { completas y de } \\
\text { partes de } \\
\text { edificaciones; } \\
\text { acondicionamiento } \\
\text { de edificaciones } \\
1,3\end{array}$} & \multirow{2}{*}{\begin{tabular}{|}
$\begin{array}{c}\text { Construcción } \\
\text { de obras de } \\
\text { ingeniería } \\
\text { civil }\end{array}$ \\
3,4
\end{tabular}} & \multirow{2}{*}{$\begin{array}{r}\begin{array}{c}\text { Subtotal } \\
\text { Valor } \\
\text { Agregado }\end{array} \\
2,7\end{array}$} & \multirow{2}{*}{$\begin{array}{l}\text { PRODUCTO } \\
\text { INTERNO } \\
\text { BRUTO }\end{array}$} \\
\hline \multirow{5}{*}{ in } & $I$ & & & & & \\
\hline & II & 7,8 & 9,2 & 7,2 & 3,3 & 3,0 \\
\hline & III & $(0,0)$ & $(7,6)$ & 6,9 & 3,4 & 3,3 \\
\hline & IV & 5,2 & 6,6 & 5,2 & 3,7 & 3,4 \\
\hline & Anual & 3,7 & 2,1 & 5,7 & 3,3 & 3,1 \\
\hline \multirow{5}{*}{$\frac{\text { s. }}{2}$} & 1 & 5,3 & 11,1 & $(0,5)$ & 2,6 & 2,5 \\
\hline & II & 0,8 & 1,7 & 1,0 & 2,3 & 2,5 \\
\hline & III & 7,1 & 11,7 & 3,8 & 1,3 & 1,2 \\
\hline & IV & 3,1 & 0,3 & 5,2 & 1,5 & 1,7 \\
\hline & Anual & 4,1 & 6,0 & 2,4 & 1,9 & 2,0 \\
\hline \multirow{3}{*}{$\stackrel{\hbar}{\stackrel{5}{N}}$} & 1 & $(0,8)$ & $(7,1)$ & 4,0 & 1,2 & 1,3 \\
\hline & II & 0,3 & $(7,7)$ & 7,0 & 1,1 & 1,2 \\
\hline & III & $(2,1)$ & $(15,9)$ & 8,8 & 1,6 & 2,0 \\
\hline
\end{tabular}

NOTA: Datos de las series Desestacionalizadas - Tercer trimestre de 2017. Adaptado de "Colombia Construcción en Cifras febrero 2018” de CAMACOL, por DANE, 2018.

Con base a la Figura 1 y Tabla 1 se puede visualizar que el PIB del sector de la construcción presento grandes fluctuaciones en estos periodos como es en el primer trimestre del año 2015 a precios contantes el sector creció al 2,6 con misma relación del año 2014 más el subsector de construcción de obras civiles en este periodo, para finalizar este año el sector presento un crecimiento de un 3,4 en relación con el mismo trimestre del año 2014, cuyo subsector de obras civiles no tuvo mucha participación generando en este periodo un crecimiento del 3,3.

Para el año 2016 se puede evidenciar que sector del construcción en el producto interno bruto PIB respecto al trimestre anterior el sector de la construcción aumento en un 2,6 este comportamiento se debe al aumento de trabajos de obras de ingeniería civil, este comportamiento corresponde al aumento en la producción de edificaciones no residenciales en 3,1 y mantenimiento de reparaciones de edificaciones en un $0,6 \%$ en tanto disminuyo la construcción de edificaciones residenciales en un 0,3\% (Departamento Administrativo Nacional de Estadística (DANE), 2016).

Así mismo al finalizar el periodo 2016 sector de la construcción presento un decrecimiento esto se debe por la disminución en la construcción de edificaciones, por su parte la construcción de obras de ingeniería civil no disminuyó respecto al trimestre anterior el decrecimiento del valor agregado en la edificación, obedece a la diminución en edificaciones residenciales (Departamento 
Administrativo Nacional de Estadística (DANE), 2016).

Al finalizar este periodo que atravesó el sector de la construcción el cual sus subsectores presentaron grandes fluctuaciones, esto no disminuyo el crecimiento en tanto la construcción de edificaciones en un $6 \%$ de acuerdo, al DANE en el PIB nacional, a pesar de los desafíos económicos que se presentó a lo largo del año el sector como la disminución de la construcción de edificaciones no residenciales y el aumento de edificaciones no residenciales el cual si tuvo una importante participación en este periodo del $4,1 \%$ a comparación del año anterior que cerró en 3,7\% de igual forma al cierre del año 2016 las construcciones de ingeniería civil tuvieron un decrecimiento en comparación de año pasado este se debe al incremento de los precios de la materia prima, cemento, ladrillo, entre otros.

De igual forma el articulo denominado el Sector de edificaciones cerraría el 2017 con una caída de 5,7\% para el año 2017 se indica que el sector de la construcción tuvo una importante participación y presento grandes fluctuaciones cuyas causas, se debe al deterioro y la disminución de confianza en el sector después de los casos de corrupción, informó la presidenta de Camacol (Revista Dinero, 2017).

De igual forma es pertinente resaltar de acuerdo a la Tabla 1 que el primer trimestre tuvo un decrecimiento en comparación del primer trimestre del año 2016 pasando del 5,3\% al 0,8\% de igual forma debido a la debilidad de los compradores, el incremento de los precios en este periodo la construcción de edificaciones disminuyó considerablemente de 11,1 a 7,1 en el primer trimestre; en cambio para el primer trimestre del año 2017 la obras de construcción de ingeniería civil evidenciaron una considerable recuperación en $4 \%$ en comparación al trimestre inmediatamente anterior.

Ahora bien, se considera de suma importancia mencionar el nivel obras que ha que realizado el sector de la construcción en los periodos 2015 a 2017 en sus subsectores como son obras de ingeniería civil, edificación de viviendas, edificaciones, entre otras. Es pertinente iniciar con el subsector de obras de ingeniería civil realizadas a nivel nacional ya que las obras de ingeniería civil son se considera como un factor que incide en el crecimiento y desarrollo tanto económico como infraestructural del país, a continuación, se mencionaran los principales indicadores de este 
subsector en los últimos tres años.

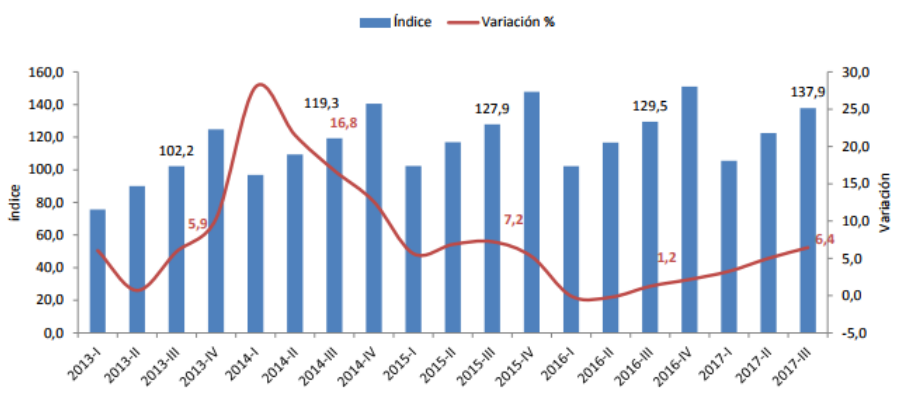

Figura 2. Índice y variación de los pagos. Adaptado del "Boletín técnico - Indicador de Inversión en Obras Civiles (III Trimestre de 2017)", por DANE, 2017.

Como se puede observar en el la Figura 2 se puede evidenciar que en el primer trimestre del año 2015 se registró un crecimiento de los pagos efectuados para la construcción de obras civiles de un 6,9\%, esto se debe por el comportamiento de vías de agua, puertos, represas, acueducto y alcantarillado que sumo un 24,4\% y sumo 3,2\% a la variación total (Departamento Administrativo Nacional de Estadística (DANE), 2015).

Al finalizar el año 2015 en su cuarto trimestre se pudo evidenciar en la Figura 2 que los pagos efectuados registraron un crecimiento de 2,0\% dicho resultado es debido al comportamiento del grupo de carreteras, calles, caminos y puentes, carreteras sobre elevadas túneles y construcción de subterráneos que creció en el 20,9 y sumo un 6,5\% la variación total. De igual forma las obligaciones adquiridas en este periodo registraron un decrecimiento frente a igual periodo en el año 2014 de 3,5 debido a construcciones para la minería y centrales generadoras eléctricas como tuberías para el transporte de larga y corta distancia, así mismo disminuyo las líneas de comunicaciones y energía en 26,9\% restando así 9,7 \% a la variación total (Departamento Administrativo Nacional de Estadística (DANE), 2016).

Ahora bien, el comportamiento en el año 2017 las obras de construcción civil presentaron el siguiente comportamiento en el índice y variación de pagos, en el primer trimestre registro un crecimiento de 3,3\% frente al trimestre del año inmediatamente anterior y presento una variación de $2,7 \%$ este comportamiento es procedente al el crecimiento de $12,3 \%$ que tuvo las obras Carreteras, calles, caminos, puentes, carreteras sobre elevadas, túneles y construcción de subterráneos aportando 4,7 puntos porcentuales de variación, así mimo la obras Construcciones 
para la minería, centrales generadoras eléctricas y tuberías para el transporte presentaron en este primer trimestre un decrecimiento de 5,1\% con una variación de 1,2 puntos porcentuales (Departamento Administrativo Nacional de Estadística (DANE), 2017).

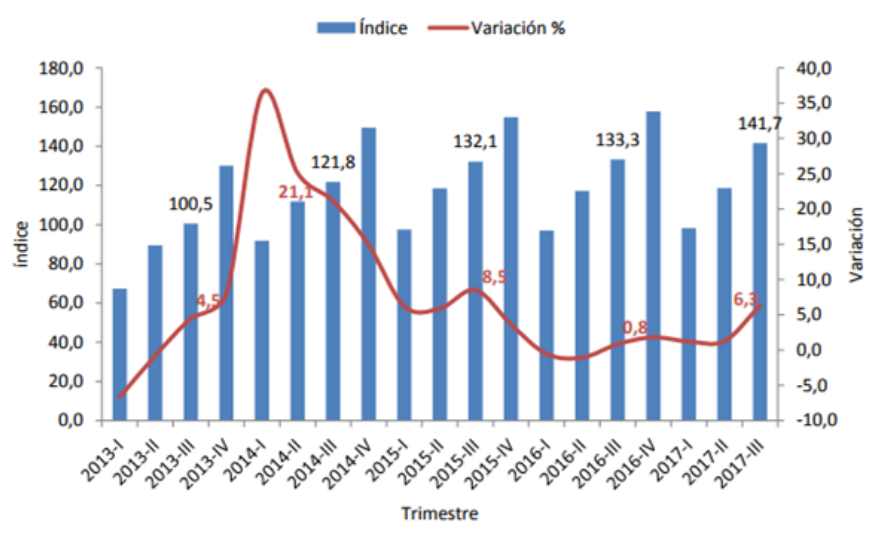

Figura 3. Índice y variación año corrido de las obligaciones en obras civiles, Adaptado de "Boletín técnico Indicador de Inversión en Obras Civiles (III Trimestre de 2017)”, por DANE, 2017.

Así mismo las obligaciones adquiridas en obras civiles en la Figura 3 para el primer trimestre del año 2015 registro un incremento de 7,9\% correspondiente a la construcción de calles caminos, puentes, túneles, y construcción de subterráneos que creció en 11,1 \% y sumo 4,6\% en la variación total (Departamento Administrativo Nacional de Estadística (DANE), 2015).

Para el año 2016 las Figuras 2 y 3 muestran un comportamiento con grandes fluctuaciones de igual forma en el primer trimestre de este periodo se registró un crecimiento de $0,2 \%$ frente al primer trimestre del año 2015, debido al incremento en obras correspondiente a vías férreas y pistas de aterrizaje mientras que las construcciones para la minería, centrales eléctricas y tubería para el transporte de agua presento un decrecimiento de 7,7\% con una variación de $24 \%$. Así mismo las obligaciones adquiridas en este periodo registro un decrecimiento de $0,9 \%$ frente al mismo trimestre del año 2015 debido a construcciones para la minera, centrales generadoras de energía eléctrica y tuberías para el transporte de agua presento una diminución de $26,4 \%$ y resto $8,9 \%$ a la variación total (Departamento Administrativo Nacional de Estadística (DANE), 2016).

De igual forma al finalizar el año 2016 como se puede evidenciar en las Figuras 2 y 3 las obras 
civiles en el cuarto trimestre; en cuanto al el indicador de pagos se registró un incremento de $3,9 \%$ frente al mismo trimestre del año 2015 y en la variación del año presento un 2,2\% debido al incremento en la construcción de carreteras, calles, caminos , puentes, carreteras sobre elevadas túneles y construcción de subterráneos con un porcentaje de $6 \%$ y una variación de $2,4 \%$ y el decrecimiento de obras para construcciones para la minería, centrales generadoras eléctricas y tuberías para el transporte de 8,1\% y una variación de 2,4\%; En cuanto a las obligaciones adquiridas en este periodo se registró un crecimiento de 3,5\% frente al mismo trimestre del año 2015 y tuvo un incremento del 1,8\% de variación transcurrida en el año debido al crecimiento que tuvo la construcción de carreteras, calles, caminos, puentes, carreteras sobre elevadas, túneles y construcción de subterráneos de 7\% con una variación de 2,5\% del año en curso así mismo las construcciones para la minería y centrales generadoras eléctricas y tuberías para el transporte a larga y corta distancia, líneas de comunicaciones y energía presentaron un decrecimiento de 6,5\%. De igual forma como se puede evidenciar en la Figura 2 y 3 Índice y variación año corrido de los pagos en obras civiles en el año 2017 se observa un alza, así mismo las obligaciones percibidas en este primer trimestre por obras civiles revelan un registro un crecimiento de $1,2 \%$ frente a trimestre del año inmediatamente anterior y aumento 2,1 puntos porcentuales de variación correspondiente a Carreteras, calles, caminos, puentes, carreteras sobre elevadas, túneles y construcción de subterráneos contribuyendo en crecimiento de un 16,6\% y una variación de 5,9\% a diferencia de la obras correspondientes a construcción de vías férreas, pistas de aterrizaje y sistemas de transporte masivo el cual presento una disminución de un 12,3\% con una variación de negativa de 0,3 puntos porcentuales.

A todo lo anterior se puede visualizar que en los periodos 2015 a 2017 las empresas contratistas que ejecutaron obras de construcción civil tuvieron gran participación en el sector. Así mismo en este rango de periodos se puede observar las fluctuaciones en tanto pagos realizados por entidades gubernamentales como las obligaciones asumidas por los contratistas como es el periodo 2015 2016 en donde se evidencio un gran decrecimiento en tanto los pagos realizados por entidades gubernamentales como la disminución de obligaciones asumidas por los contratistas. Cabe resaltar que en este periodo el sector de la construcción paso por los escándalos de corrupción afectando de manera significativa el sector. 
En el periodo 2016- 2017 se pudo evidenciar en las Figuras 2 y 3 en donde los pagos y las obligaciones de las obras civiles presentan una lenta recuperación por consecuencia de la disminución de confianza en el sector, por los casos de corrupción que se mencionaron anteriormente.

Ahora bien, es importante mencionar el nivel y desarrollo que tuvo las obras correspondientes a edificaciones que se realizaron en el periodo 2015 - 2017 para así poder observar la evolución producción y etapas que presentaron las obras.

En las siguientes Tablas se podrá visualizar la variación y contribución trimestral que tuvo las obras de edificación en los periodos 2015- 2017:

Tabla 2. Variación y contribución trimestral, por estado de obra, según áreas de cobertura Año 2015.

\begin{tabular}{|c|c|c|c|c|c|c|c|c|c|c|c|c|c|c|c|c|}
\hline & \multicolumn{4}{|c|}{ Variación VI 2014 - I Trimestre 2015} & \multicolumn{4}{|c|}{ Variación I Trimestre 2015-II Trimestre 2015} & \multicolumn{4}{|c|}{ Variación II Trimestre 2015-III Trimestre 2015} & \multicolumn{4}{|c|}{ variación III trimestre 2015-IV trimestre 2015} \\
\hline & \multicolumn{2}{|c|}{ Áreas Culminadas } & \multicolumn{2}{|c|}{ Áreas En Proceso } & \multicolumn{2}{|c|}{ Áreas Culminadas } & \multicolumn{2}{|c|}{ Áreas En Proceso } & \multicolumn{2}{|c|}{ Áreas Culminadas } & \multicolumn{2}{|c|}{ Áreas En Proceso } & \multicolumn{2}{|c|}{ áreas culminadas } & \multicolumn{2}{|c|}{ áreas en proceso } \\
\hline Áreas De Cobertura & Variación & $\begin{array}{c}\text { Contribución } \\
\text { Puntos } \\
\text { Porcentuales }\end{array}$ & Variación & $\begin{array}{c}\text { Contribución } \\
\text { Puntos } \\
\text { Porcentuales }\end{array}$ & Variación & $\begin{array}{l}\text { Contribución } \\
\text { Puntos } \\
\text { Porcentuales }\end{array}$ & Variación & $\begin{array}{c}\text { Contribución } \\
\text { Puntos } \\
\text { Porcentuales }\end{array}$ & Variación & $\begin{array}{l}\text { Contribución } \\
\text { Puntos } \\
\text { Porcentuales }\end{array}$ & Variación & $\begin{array}{c}\text { Contribución } \\
\text { Puntos } \\
\text { Porcentuales }\end{array}$ & variación & $\begin{array}{c}\text { contribución } \\
\text { puntos } \\
\text { porcentuales }\end{array}$ & variación & $\begin{array}{c}\text { contribución } \\
\text { puntos } \\
\text { porcentuales }\end{array}$ \\
\hline Total & $-12,5$ & $-12,5$ & 3,2 & 3,2 & $-0,2$ & $-0,2$ & 3,5 & 3,5 & $-2,1$ & $-2,1$ & 3,6 & 3,6 & 25,7 & 25,7 & $-0,4$ & $-0,4$ \\
\hline Bogotá & $-23,0$ & $-6,7$ & 3,8 & 1,1 & $-6,6$ & $-1,7$ & 2,9 & 0,9 & 17,5 & 4,2 & 0,3 & 0,1 & 7,5 & 2,2 & $-6,4$ & $-1,8$ \\
\hline Medellin AM & $-34,0$ & $-5,8$ & 6,7 & 1,1 & 39,1 & 5,0 & 0,5 & 0,1 & $-4,2$ & $-0,7$ & 3,5 & 0,6 & 24,4 & 4,2 & 5,2 & 0,9 \\
\hline Cundinamarca & $-22,1$ & $-3,5$ & 5,3 & 0,5 & $-39,7$ & $-5,6$ & 12,0 & 1,1 & 19,3 & 1,6 & 3,6 & 0,3 & 82,1 & 8,5 & $-1,0$ & $-0,1$ \\
\hline Cali A.U & 4,5 & 0,3 & $-4,4$ & $-0,2$ & $-43,1$ & $-3,5$ & 7,3 & 0,4 & 25,6 & 1,2 & 5,5 & 0,3 & $-17,3$ & $-1,0$ & 2,7 & 0,1 \\
\hline Barranquilla A.U & $-29,5$ & $-2,2$ & 6,5 & 0,6 & $-0,4$ & 0,0 & 14,6 & 1,4 & 30,5 & 1,8 & 2,3 & 0,2 & 4,6 & 0,4 & 9,8 & 1,0 \\
\hline Bucaramanga A.M & 53,2 & 3,5 & $-3,8$ & $-0,4$ & 4,4 & 0,5 & $-5,7$ & $-0,5$ & $-56,7$ & $-6,8$ & 9,3 & 0,8 & 97,1 & 5,2 & $-6,6$ & $-0,6$ \\
\hline Pereira A.U & $-29,6$ & $-0,8$ & $-7,2$ & $-0,1$ & 14,1 & 0,3 & 4,1 & 0,1 & $-6,8$ & $-0,2$ & $-6,1$ & $-0,1$ & 37,1 & 0,9 & 19,2 & 0,2 \\
\hline Armenia A.U & 33,9 & 0,3 & 10,8 & 0,1 & $-34,2$ & $-0,5$ & 17,6 & 0,2 & 117,8 & 1,1 & 18,6 & 0,3 & $-8,3$ & $-0,2$ & 12,2 & 0,2 \\
\hline Cartagena A.U & 60,1 & 1,1 & 5,4 & 0,3 & 72,9 & $-0,5$ & $-0,8$ & 0,0 & $-27,8$ & $-1,6$ & 6,6 & 0,3 & 28,9 & 1,2 & $-1,6$ & $-0,1$ \\
\hline Ibagué A.U & $-0,4$ & 0,0 & 3,3 & 0,1 & $-8,8$ & 2,4 & 6,3 & 0,1 & 61,3 & 1,1 & 17,2 & 0,4 & 30,9 & 0,9 & 17,0 & $-0,4$ \\
\hline Cúcuta A.M & 18,3 & 0,3 & 10,4 & 0,2 & 4,9 & $-0,2$ & 8,3 & 0,1 & $-27,9$ & $-0,7$ & 7,3 & 0,1 & 56,7 & 1,1 & 4,6 & 0,1 \\
\hline Manizales A.U & 51,9 & 0,8 & $-7,0$ & $-0,1$ & $-36,0$ & 0,1 & 1,0 & 0,0 & 15,2 & 0,3 & 17,8 & 0,2 & 0,8 & 0,0 & 2,3 & 0,0 \\
\hline Villavicencio A.U & 30,7 & 0,8 & $-9,6$ & $-0,3$ & 45,8 & 1,8 & $-33,3$ & $-0,9$ & $-61,1$ & $-3,6$ & $-1,4$ & 0,0 & 6,1 & 0,1 & 1,2 & 0,0 \\
\hline Neiva A.U & $-20,6$ & $-0,4$ & 6,9 & 0,1 & 20,2 & 0,4 & 18,9 & 0,3 & 12,6 & 0,3 & $-0,2$ & 0,0 & 35,4 & 0,8 & $-10,2$ & $-0,2$ \\
\hline Pasto A.U & $-2,1$ & 0,0 & 7,5 & 0,1 & 90,7 & 1,1 & $-3,4$ & $-0,1$ & $-18,2$ & $-0,4$ & 4,9 & 0,1 & 33,2 & 0,6 & 0,7 & 0,0 \\
\hline Popayán A.U & $-24,5$ & $-0,2$ & 9,3 & 0,1 & 78,1 & 0,7 & 28,2 & 0,3 & 17,7 & 0,3 & 0,0 & 0,0 & 37,4 & 0,7 & 10,3 & 0,1 \\
\hline
\end{tabular}

NOTA: Datos del “Boletín técnico - Censo Edificaciones”, por DANE, 2015.

Ahora bien se puede evidenciar en la Tabla 2 el comportamiento que tuvieron las obras de edificaciones en el primer trimestre del año 2015, se pueden comparar los resultados de las áreas culminadas y en proceso del último trimestre del año anterior con el primer trimestre del año 2015 se puede evidenciar un crecimiento de 3,2\%, por su parte el área de obras culminadas disminuyo un $12,5 \%$ este resultado se dio a la sumatoria de las ciudades de Bogotá, el área metropolitana de Medellín, y los municipios que comprenden el departamento de Cundinamarca (Departamento Administrativo Nacional de Estadística (DANE), 2015). 
Para el segundo trimestre del año 2015 en comparación del primero del mismo año se pudo evidenciar que las obras de edificaciones en la área de proceso incremento en 3,5\% incremento comprendido por el departamento de Cundinamarca, la ciudad de Bogotá los cuales aportaron 3,4 puntos porcentuales a la variación total del trimestre, más sin embargo el segundo trimestre del año 2015 presento una disminución $0,2 \%$ en el área de obras culminadas, resultado dado por las áreas urbanas de Cali con-43,1\% con una efecto de negativo de 3,5 puntos porcentuales en la contribución general y el área urbana de Manizales con un 36,0\% con un efecto negativo de 1 punto porcentual en la contribución general (Departamento Administrativo Nacional de Estadística (DANE), 2015).

En comparación del segundo y tercer trimestre del año 2015 se puede evidenciar un incremento en el área de obras en proceso de un 3,6 \% cuyo resultado fue dado por las áreas de Bucaramanga, Medellín e Ibagué. Por su parte se evidencia en la Tabla 2 que las áreas de obras culminadas el tercer trimestre disminuyo 2,1\% resultado dado por las áreas urbanas de Villavicencio, Cartagena, Pasto (Departamento Administrativo Nacional de Estadística (DANE), 2015).

De igual forma el comportamiento del cuarto trimestre del año 2015 en comparación con el anterior se puede observar que el área de procesos de edificaciones disminuyo en 0,4\% resultado evidenciado en las áreas de Bogotá, las áreas urbanas de Bucaramanga e Ibagué restando así 2,8 puntos porcentuales a la variación total del trimestre. Sin embargo, en este cuarto trimestre de año 2015 se evidencio en crecimiento en el área de obras culminadas en un 25,7\% resultado dado por las áreas de cubertura de Bucaramanga, el área metropolitana de Cúcuta con una variación de $56,7 \%$ presentando una contribución de 1,1 punto porcentual y Cundinamarca con una variación de $82,1 \%$ dando como resultado 8,5 puntos porcentuales en la culminación de obras de edificación (Departamento Administrativo Nacional de Estadística (DANE), 2016).

Ahora bien, es pertinente mencionar el comportamiento de las obras de edificación en el transcurso del año 2016 en sus áreas de culminación y ejecución. 
Tabla 3. Variación y contribución trimestral, por estado de obra, según áreas de cobertura Año 2016.

\begin{tabular}{|c|c|c|c|c|c|c|c|c|c|c|c|c|c|c|c|c|}
\hline \multirow{3}{*}{ Áreas De Cobertura } & \multicolumn{4}{|c|}{ Variación VI 2015 - I Trimestre 2016} & \multicolumn{4}{|c|}{ Variación I Trimestre 2016-II Trimestre 2016} & \multicolumn{4}{|c|}{ Variación II Trimestre 2016-III Trimestre 2016} & \multicolumn{4}{|c|}{ variación III trimestre 2016-IV trimestre 2016} \\
\hline & \multicolumn{2}{|c|}{ Áreas Culminadas } & \multicolumn{2}{|c|}{ Áreas En Proceso } & \multicolumn{2}{|c|}{ Áreas Culminadas } & \multicolumn{2}{|c|}{ Áreas En Proceso } & \multicolumn{2}{|c|}{ Áreas Culminadas } & \multicolumn{2}{|c|}{ Áreas En Proceso } & \multicolumn{2}{|c|}{ áreas culminadas } & \multicolumn{2}{|c|}{ áreas en proceso } \\
\hline & Variación & $\begin{array}{c}\text { Contribución } \\
\text { Puntos } \\
\text { Porcentuales }\end{array}$ & Variación & $\begin{array}{c}\text { Contribución } \\
\text { Puntos } \\
\text { Porcentuales }\end{array}$ & Variación & $\begin{array}{c}\text { Contribución } \\
\text { Puntos } \\
\text { Porcentuales }\end{array}$ & Variación & $\begin{array}{c}\text { Contribución } \\
\text { Puntos } \\
\text { Porcentuales }\end{array}$ & Variación & $\begin{array}{c}\text { Contribución } \\
\text { Puntos } \\
\text { Porcentuales }\end{array}$ & Variación & $\begin{array}{c}\text { Contribución } \\
\text { Puntos } \\
\text { Porcentuales }\end{array}$ & variación & $\begin{array}{c}\text { contribución } \\
\text { puntos } \\
\text { porcentuales }\end{array}$ & variación & $\begin{array}{c}\text { contribución } \\
\text { puntos } \\
\text { porcentuales }\end{array}$ \\
\hline Total & $-11,3$ & $-11,3$ & 1,2 & 1,2 & $-1,7$ & $-0,17$ & 3,0 & 3,0 & $-4,4$ & $-4,4$ & 2 & 2 & 3,2 & 32,4 & -5 & -5 \\
\hline Bogotá & $-2,0$ & $-0,5$ & 0,0 & 0,0 & 0,6 & 0,2 & $-1,2$ & $-0,3$ & $-18,9$ & $-5,3$ & 0,7 & 0,2 & 62,3 & 14,8 & $-5,5$ & $-1,4$ \\
\hline Medellin AM & $-14,3$ & $-2,4$ & 3,0 & 0,6 & $-15,1$ & $-2,5$ & 8,4 & 1,6 & 7,4 & 1,1 & 4,9 & 1,0 & 40,4 & 6,5 & $-4,7$ & $-0,9$ \\
\hline Cundinamarca & $-17,4$ & $-2,6$ & 0,4 & 0,0 & 8,4 & 1,2 & 4,1 & 0,4 & $-4,8$ & $-0,7$ & $-0,6$ & $-0,1$ & 21,2 & 3,3 & $-7,9$ & $-0,7$ \\
\hline Cali A.U & 95,9 & 3,7 & $-3,8$ & $-0,2$ & $-40,2$ & $-3,4$ & 9,3 & 0,5 & 41,9 & 2,2 & 6,7 & 0,4 & 37,1 & 2,9 & $-7,0$ & $-0,4$ \\
\hline Barranquilla A.U & 33,4 & 2,2 & 0,0 & 0,0 & $-11,3$ & $-1,1$ & 3,3 & 0,4 & $-20,3$ & $-1,8$ & $-1,6$ & $-0,2$ & 84,7 & 6,3 & $-8,3$ & $-0,9$ \\
\hline Pereira A.U & $-58,0$ & $-1,6$ & 23,9 & 0,4 & 57,0 & 0,7 & 8,1 & 0,1 & 114,3 & 2,3 & $-12,7$ & $-0,2$ & $-52,0$ & $-2,4$ & 7,4 & 0,1 \\
\hline Armenia A.U & $-19,8$ & $-0,3$ & 5,5 & 0,1 & 73,9 & 1,1 & $-0,3$ & 0,0 & $-58,4$ & $-1,5$ & 18,2 & 0,4 & 83,6 & 0,9 & $-1,8$ & 0,0 \\
\hline Cartagena A.U & $-28,0$ & $-1,2$ & 2,5 & 0,1 & $-25,2$ & $-0,9$ & 5,7 & 0,3 & 15,4 & 0,4 & 8,2 & 0,4 & 60,0 & 1,9 & $-0,4$ & 0,0 \\
\hline Ibagué A.U & $-60,1$ & $-1,9$ & 23,0 & 0,5 & 55,0 & 0,8 & 13,4 & 0,3 & $-10,9$ & $-0,2$ & 7,8 & 0,2 & 38,5 & 0,8 & $-8,1$ & $-0,2$ \\
\hline Cúcuta A.M & $-20,7$ & $-0,5$ & $-1,3$ & 0,0 & $-2,8$ & $-0,1$ & $-5,1$ & $-0,1$ & 82,7 & 1,7 & $-19,7$ & $-0,3$ & $-46,3$ & $-1,8$ & $-10,7$ & $-0,1$ \\
\hline Manizales A.U & $-52,4$ & $-0,8$ & 17,1 & 0,3 & 91,5 & 0,8 & 0,6 & 0,0 & 10,4 & 0,2 & $-5,8$ & $-0,1$ & $-48,8$ & $-0,9$ & 0,4 & 0,0 \\
\hline Villavicencio A.U & $-46,3$ & $-0,9$ & 0,5 & 0,0 & $-30,2$ & $-0,4$ & 0,3 & 0,0 & 85,1 & 0,7 & 0,3 & 0,0 & 105,4 & 1,7 & $-24,8$ & $-0,4$ \\
\hline Neiva A.U & $-47,3$ & $-1,2$ & $-2,9$ & 0,0 & 19,6 & 0,3 & 12,0 & 0,2 & 45,8 & 0,9 & $-6,5$ & $-0,1$ & $-44,9$ & $-1,3$ & $-0,6$ & 0,0 \\
\hline Pasto A.U & $-59,9$ & $-1,2$ & 11,3 & 0,2 & 212,7 & 1,9 & 1,4 & 0,0 & $-40,4$ & $-1,2$ & 8,2 & 0,2 & $-5,0$ & $-0,1$ & $-3,9$ & $-0,1$ \\
\hline Popayán A.U & $-72,9$ & $-1,5$ & 8,2 & 0,1 & 353,0 & 2,3 & $-9,5$ & $-0,1$ & $-46,3$ & $-1,4$ & 3,6 & 0,0 & $-24,3$ & $-0,4$ & $-4,2$ & $-0,1$ \\
\hline
\end{tabular}

NOTA: Datos del “Boletín técnico - Censo Edificaciones”, por DANE, 2016.

Para el primer trimestre del año 2016 se puede evidenciar las obras de edificaciones la fase de áreas en proceso aumento 1,2\% en comparación al trimestre anterior del año 2015 resultado dado por las áreas urbanas de Medellín, Ibagué, Pereira sumando 1,5 puntos porcentuales a la variación total. Por otro lado las fase de culminación de obras de edificios disminuyo 11,3\% resultado dado por las áreas urbanas de Pereira presentando una variación negativa de 58,0\% y 1,6 puntos porcentuales, el área urbana de Popayán presentando una variación negativa de 71,9\% con 1,5 puntos porcentuales, el área urbana de Villavicencio presentando una variación negativa de 46,3\% con 0,9 puntos porcentuales en el total de la obras culminadas en este periodo (Departamento Administrativo Nacional de Estadística (DANE), 2016).

Ahora bien, el segundo trimestre el censo de obras de edificaciones presentaron el siguiente comportamiento respecto al primer trimestre del año 2015, evidenciándose un crecimiento de 3,0\% en la fase de obras en proceso, resultado correspondiente a las obras en las áreas metropolitanas de Medellín y Cali las cuales sumaron 2,1 puntos porcentuales en la variación total del trimestre. Por otro lado, la fase de culminación de obras de edificación presento una disminución de 1,7\% resultado dado por el área metropolitana de Bucaramanga (Departamento Administrativo Nacional de Estadística (DANE), 2016).

Así mismo el tercer trimestre de comparado con el segundo trimestre del año 2016, mostro un crecimiento las obras en la fase de proceso aumentando 2,0\% respecto al trimestre anterior resultado dado por las áreas de cobertura de Medellín sumando 1,0 punto porcentual a la variación general del trimestre. Mas sin embargo la fase de culminación de obras presento una disminución 
de $4,4 \%$ resultado dado por las áreas de cobertura de Armenia en un 58,4\% con 1,5 punto porcentual, Popayán con una disminución de 46,3\% en obras sin culminar mostrando 1,4 punto porcentual a la variación total (Departamento Administrativo Nacional de Estadística (DANE), 2016).

En cuanto el cuarto trimestre en el censo realizado por el DANE a las edificaciones en todos sus procesos. Al comparar los resultados del tercer trimestre y cuarto trimestre del año 2016 por las fases de obra (en proceso y culminada) se pudo evidenciar el comportamiento. En la fase de obra en proceso se demuestra una disminución de 5,0\% respecto al trimestre anterior resultado dado por el área urbana de Bogotá el cual resto 1,4 \% como el área de Barranquilla el cual resto 0,9\% a la variación total. En contraparte la culminación de obras en ente trimestre evidencio un crecimiento de 32,4\% (Departamento Administrativo Nacional de Estadística (DANE), 2017) .

Ahora bien, se considera de suma importancia mencionar el comportamiento que tuvo las obras de edificaciones en las áreas de cobertura seleccionadas en la Tabla 4 durante el año 2017.

Tabla 4.Variación y contribución trimestral, por estado de obra, según áreas de cobertura Año 2017.

\begin{tabular}{|c|c|c|c|c|c|c|c|c|c|c|c|c|}
\hline & \multicolumn{4}{|c|}{ Variación VI 2016 - I Trimestre 2017} & \multicolumn{4}{|c|}{ Variación I Trimestre 2017-II Trimestre 2017} & \multicolumn{4}{|c|}{ Variación II Trimestre 2017-III Trimestre 2017} \\
\hline & \multicolumn{2}{|c|}{ Áreas Culminadas } & \multicolumn{2}{|c|}{ Áreas En Proceso } & \multicolumn{2}{|c|}{ Áreas Culminadas } & \multicolumn{2}{|c|}{ Áreas En Proceso } & \multicolumn{2}{|c|}{ Áreas Culminadas } & \multicolumn{2}{|c|}{ Áreas En Proceso } \\
\hline Áreas De Cobertura & Variación & $\begin{array}{c}\text { Contribución } \\
\text { Puntos } \\
\text { Porcentuales }\end{array}$ & Variación & $\begin{array}{c}\text { Contribución } \\
\text { Puntos } \\
\text { Porcentuales }\end{array}$ & Variación & $\begin{array}{c}\text { Contribución } \\
\text { Puntos } \\
\text { Porcentuales }\end{array}$ & Variación & $\begin{array}{c}\text { Contribución } \\
\text { Puntos } \\
\text { Porcentuales }\end{array}$ & Variación & $\begin{array}{c}\text { Contribución } \\
\text { Puntos } \\
\text { Porcentuales }\end{array}$ & Variación & $\begin{array}{c}\text { Contribución } \\
\text { Puntos } \\
\text { Porcentuales }\end{array}$ \\
\hline Total & $-31,6$ & $-31,6$ & 3,9 & 3,9 & 0,9 & 0,9 & 2,5 & 2,5 & 2,9 & 2,9 & $-0,6$ & $-0,6$ \\
\hline Bogotá & $-43,5$ & $-12,7$ & 5,4 & 1,4 & 3,4 & 0,8 & 0,2 & 0,1 & $-7,7$ & $-1,9$ & $-1,1$ & $-0,3$ \\
\hline Medellín AM & $-54,0$ & $-9,2$ & 6,4 & 1,3 & 40,5 & 4,6 & 4,2 & 0,9 & 11,2 & 1,8 & 2,6 & 0,5 \\
\hline Cundinamarca & $-28,0$ & $-3,9$ & 3,5 & 0,3 & $-4,7$ & $-0,7$ & 4,0 & 0,4 & $-9,0$ & $-1,3$ & 0,2 & 0,0 \\
\hline Cali A.U & $-32,7$ & $-2,6$ & 13,5 & 0,8 & $-5,4$ & $-0,4$ & 16,5 & 1,0 & 24,2 & 1,8 & 0,1 & 0,0 \\
\hline Barranquilla A.U & $-29,1$ & $-3,0$ & 0,1 & 0,0 & $-26,6$ & $-2,9$ & 2,6 & 0,3 & 14,1 & 1,1 & $-3,4$ & $-0,3$ \\
\hline Bucaramanga A.M & 43,9 & 1,7 & $-5,7$ & $-0,4$ & $-29,6$ & $-2,4$ & $-5,0$ & $-0,4$ & 26,0 & 1,5 & $-3,1$ & $-0,2$ \\
\hline Pereira A.U & 47,7 & 0,8 & $-0,6$ & 0,0 & $-25,8$ & $-0,9$ & 6,6 & 0,1 & 7,9 & 0,2 & 2,6 & 0,0 \\
\hline Armenia A.U & $-33,3$ & $-0,5$ & 10,5 & 0,3 & 3,6 & 0,1 & $-1,4$ & 0,0 & 35,8 & 0,5 & $-10,2$ & $-0,3$ \\
\hline Cartagena A.U & $-16,9$ & $-0,7$ & 5,5 & 0,3 & 2,3 & 0,1 & 6,3 & 0,4 & 14,5 & 0,7 & $-4,0$ & $-0,2$ \\
\hline Ibagué A.U & $-51,2$ & $-1,1$ & 16,4 & 0,4 & 93,1 & 1,5 & 8,6 & 0,3 & 17,8 & 0,5 & $-1,9$ & $-0,1$ \\
\hline Cúcuta A.M & $-39,2$ & $-0,6$ & 6,0 & 0,1 & 54,6 & 0,8 & $-6,6$ & $-0,1$ & $-22,8$ & $-0,5$ & 14,4 & 0,2 \\
\hline Manizales A.U & 38,7 & 0,3 & $-1,7$ & 0,0 & $-6,8$ & $-0,1$ & 10,9 & 0,2 & 33,1 & 0,5 & 2,4 & 0,0 \\
\hline Villavicencio A.U & $-61,3$ & $-1,6$ & $-7,6$ & $-0,1$ & 61,4 & 0,9 & $-13,0$ & $-0,1$ & $-32,3$ & $-0,7$ & 6,6 & 0,1 \\
\hline Neiva A.U & 138,3 & 1,6 & $-27,8$ & $-0,5$ & $-44,6$ & $-1,8$ & $-26,2$ & $-0,3$ & $-10,1$ & $-0,2$ & 0,4 & 0,0 \\
\hline Pasto A.U & $-6,3$ & $-0,1$ & 2,4 & 0,0 & 111,6 & 2,0 & $-9,6$ & $-0,2$ & $-56,9$ & $-2,1$ & 1,7 & 0,0 \\
\hline Popayán A.U & 0,9 & 0,0 & 2,3 & 0,0 & $-40,9$ & $-0,6$ & 6,3 & 0,1 & 127,4 & 1,1 & $-7,0$ & $-0,1$ \\
\hline
\end{tabular}

NOTA: Datos del “Boletín técnico - Censo Edificaciones”, por DANE, 2017.

Para el primer trimestre del año 2017 se puede evidenciar que las obras de edificaciones en la fase de proceso aumentaron 3,9\% en comparación al trimestre anterior del año 2016 resultado dado por las aéreas de Bogotá, Cali e Ibagué mientras que obras culminadas en este trimestre presentan una diminución de 31,6\% respecto al trimestre anterior del año 2016, resultado dado por las áreas de 
cobertura de Cali, Cundinamarca e Ibagué (Departamento Administrativo Nacional de Estadística (DANE), 2017).

Ahora bien, para el segundo trimestre del 2017 el censo realizado por el DANE muestra un comportamiento si se compara con el trimestre anterior se puede evidenciar que el área de proceso presento un incremento de $2,5 \%$ respecto al trimestre anterior, resultado dado por el área urbana de Cali con un porcentaje de 16,5\% a la variación total de 1,0 punto porcentual. Así mismo el área de obras en culminación presento una variación de $0,9 \%$ en el segundo trimestre siendo Medellín la ciudad que más aporto a la variación con un 4,6 punto porcentual a la variación total (Departamento Administrativo Nacional de Estadística (DANE), 2017).

En cuanto al tercer trimestre del año 2017 el censo muestra un comportamiento comparado con el segundo trimestre del año 2017 señalando una disminución de 0,6\% en el área de proceso de obra en comparación con el trimestre anterior, cuyo resultado es la influencia del comportamiento de las obras en las áreas de Bogotá, Barranquilla y Armenia. Por su parte el área de obras culminadas mostro en el tercer trimestre del año 2017 una variación de 2,9\% siendo resultado de las obras realizadas en Medellín y Cali aportando gran porcentaje a la variación total con 3,6 puntos porcentuales (Departamento Administrativo Nacional de Estadística (DANE), 2017).

Ahora se considera pertinente mencionar que gracias al censo realizado por el Departamento Administrativo Nacional de Estadística DANE, en las edificaciones, su variación y contribución trimestral por el estado de obra a lo largo de los periodos 2015- 2017 se logra evidenciar que en el transcurso del año 2015 hubo una disminución de obras culminadas hasta el cuarto trimestre del mismo en donde el departamento de Cundinamarca, el área metropolitana de Bucaramanga tuvo gran participación. Es importante recordar que las obras civiles y arquitectónicas del sector de la construcción poseen longevidad en su desarrollo, ejecución y culminación siendo un factor el cual da estos resultados en el censo, así mismo se considera pertinente que es este periodo estallo las polémicas sobre casos de corrupción en el sector afectando, paralizando y prorrogando muchos proyectos de construcción dando como resultado los resultados en la culminación de obras.

En cuanto el año 2016 se puede evidenciar un comportamiento similar más sin embargo el sector 
presenta una recuperación debido a la falta de confianza en el sector disminuyendo así la variación de obras en proceso de ejecución en comparación con el año anterior, en donde las empresas contratistas podían ejecutar, licitar y culminar los proyectos de construcción con mayor agilidad. De igual forma en el transcurso del año 2017 presentan grandes fluctuaciones más sin embargo se considera como un periodo de transición en el sector de la construcción iniciando el primer trimestre con buen porcentaje en la ejecución de obras, mostrando tendencia a la baja, así mismo es importante mencionar que en el transcurso de los periodos 2015- 2016 como se muestra en las Tablas 2 y 3 y tres las áreas de coberturas estudiadas, las áreas de cobertura han ejecutado obras como también las han culminado dependiendo la participación del mercado en el sector como las necesidades de la población como es el caso de los de Cundinamarca, el área metropolitana de Medellín, área metropolitana de Cúcuta y Bucaramanga .

Con base a lo anterior se considera de suma importancia conocer los sectores y destinos en donde

\begin{tabular}{|c|c|c|c|c|c|c|c|c|c|c|c|c|c|c|c|c|}
\hline \multicolumn{17}{|c|}{ Áreas Culminadas Según Destinos Año 2015} \\
\hline \multirow{3}{*}{ Destino } & \multicolumn{4}{|c|}{ IV Trimestre 2014-I Trimestre 2015} & \multicolumn{4}{|c|}{ | trimestre 2015 - || trimestre 2015} & \multicolumn{4}{|c|}{ II Trimestre 2015 - III Trimestre 2015} & \multicolumn{4}{|c|}{ III trimestre 2015 - IV trimestre 2015} \\
\hline & \multicolumn{2}{|c|}{ Trimestres } & \multirow{2}{*}{$\begin{array}{c}\text { Variación } \\
\qquad \% \\
\end{array}$} & \multirow{2}{*}{$\begin{array}{c}\text { Contribución } \\
\text { Puntos } \\
\text { Porcentuales }\end{array}$} & \multicolumn{2}{|c|}{ trimestres } & \multirow{2}{*}{$\begin{array}{c}\text { variación } \\
\qquad \%\end{array}$} & \multirow{2}{*}{$\begin{array}{c}\text { Contribución } \\
\text { puntos } \\
\text { porcentuales }\end{array}$} & \multicolumn{2}{|c|}{ Trimestres } & \multirow{2}{*}{$\begin{array}{c}\text { Variación } \\
\% \\
\end{array}$} & \multirow{2}{*}{$\begin{array}{c}\text { Contribución } \\
\text { Puntos } \\
\text { Porcentuales }\end{array}$} & \multicolumn{2}{|c|}{ trimestres } & \multirow{2}{*}{$\begin{array}{c}\text { variación } \\
\%\end{array}$} & \multirow{2}{*}{$\begin{array}{c}\text { Contribución } \\
\text { puntos } \\
\text { porcentuales }\end{array}$} \\
\hline & IV - 2014 & 1-2015 & & & 1-2015 & $\|-2015$ & & & |1-2015 & III- 2015 & & & III- 2015 & IV-2015 & & \\
\hline Total & $4.766 .556,00$ & $4.185 .951,00$ & $-12,5$ & $-12,5$ & 4.185.951 & 4.178 .640 & $-0,2$ & $-0,2$ & 4.178 .640 & 4.090 .219 & $-2,1$ & $-2,1$ & 4.090 .219 & 5.141 .159 & 25,7 & 25,7 \\
\hline Apartamentos & $2.749 .797,00$ & $2.421 .107,00$ & -12 & $-6,9$ & 2.421 .107 & 2.376 .705 & $-1,8$ & $-1,1$ & 2.376 .705 & 2.398.946 & 0,9 & 0,5 & 2.398 .946 & 3.120 .126 & 30,1 & 17,6 \\
\hline Casas & $800.883,00$ & $634.971,00$ & $-20,7$ & $-3,5$ & 634.971 & 576.259 & $-9,2$ & $-1,4$ & 576.259 & 641.898 & 11,4 & 1,6 & 641.898 & 754.126 & 17,6 & 2,8 \\
\hline Oficinas & $157.862,00$ & $173.838,00$ & $-1,2$ & 0 & 173.838 & 157.558 & $-9,4$ & 0,4 & 157.558 & 232.562 & 47,6 & 1,8 & 232.562 & 192.027 & $-17,4$ & -1 \\
\hline Comercio & $284.004,00$ & $144.486,00$ & $-49,1$ & $-2,9$ & 144.486 & 413.512 & 186,2 & 6,4 & 413.512 & 118.232 & $-71,4$ & $-7,1$ & 118.232 & 360.039 & 204,5 & 5,9 \\
\hline Bodegas & $236.414,00$ & $214.769,00$ & $-9,2$ & $-0,5$ & 214.769 & 234.903 & 9,4 & 0,5 & 234.903 & 212.473 & $-9,5$ & $-0,5$ & 212.473 & 172.589 & $-18,8$ & -1 \\
\hline Educación & $109.714,00$ & $97.464,00$ & $-11,2$ & $-0,3$ & 97.464 & 62.976 & $-35,4$ & $-0,8$ & 62.976 & 113.308 & 79,9 & 1,2 & 113.308 & 149.509 & 31,9 & 0,9 \\
\hline Hoteles & $95.939,00$ & $51.662,00$ & $-46,2$ & $-0,9$ & 51.662 & 65.946 & 27,6 & 0,3 & 65.946 & 74.930 & 13,6 & 0,2 & 74.930 & 49.906 & $-33,4$ & $-0,6$ \\
\hline Hospitales & $64.956,00$ & $188.032,00$ & 189,5 & 2,6 & 188.032 & 78.719 & $-58,1$ & $-2,6$ & 78.719 & 50.878 & $-35,5$ & $-0,7$ & 50.878 & 39.555 & $-22,3$ & $-0,3$ \\
\hline Administración Publica & $70.790,00$ & $55.846,00$ & $-21,1$ & 0,3 & 55.846 & 25.211 & $-54,9$ & $-0,7$ & 25.211 & 82.949 & 229 & 1,4 & 82.949 & 84.220 & 1,5 & 0 \\
\hline Otros & $198.157,00$ & $203.776,00$ & 2,8 & 0,1 & 203.776 & 186.851 & $-8,3$ & $-0,4$ & 186.851 & 164.043 & $-12,2$ & $-0,5$ & 164.043 & 218.198 & 33 & 1,3 \\
\hline
\end{tabular}

se realizaron las obras culminadas en estos periodos, para ello se considera pertinente visualizar las siguientes tablas:

Tabla 5. Variación y contribución trimestral, por estado de obra, según áreas de cobertura Año 2015 por destino. NOTA: datos del "Boletín técnico - Censo Edificaciones", por DANE, 2015.

En la Tabla 5 variación Área culminada según destino en el primer trimestre del año 2015 se logra evidenciar un decrecimiento de $12,5 \%$ respecto al trimestre inmediatamente anterior, las edificaciones con destino a apartamentos, casas y comercio registraron disminuciones y restaron en conjunto 13,3 puntos porcentuales a la variación trimestral. Por el contrario, el destino de hospitales presento la mayor contribución y sumo 2,6 puntos porcentuales. Ahora bien, en el censo realizado en el primer trimestre 2015 del área culminada que el 73,0\% correspondió a vivienda es decir apartamentos y casas mientras que el 27,0\% restante se distribuyó con obras de distinto destino (Departamento Administrativo Nacional de Estadística (DANE), 2015). 
En el segundo trimestre de año 2015 se pudo evidenciar que el área culminada en comparación al trimestre anterior presento un decrecimiento de $0,2 \%$ debido a las edificaciones con destino a hospitales, casas y apartamentos registraron diminuciones. Por el contrario, el destino de obras de comercio presento la mayor contribución y sumo 6,4 puntos porcentuales.

Así mismo durante el segundo trimestre de año 2015 las obras de edificaciones culminadas correspondieron al 70,7\% a vivienda mientras que el 29,3\% se distribuyó en los diferentes destinos. Ahora bien, en el tercer trimestre del 2015 se puede observar un decrecimiento de 2,1\% con relación al segundo trimestre cuyo resultado es dado por obras con destino a comercio el cual presento mayor disminución en el trimestre de 7,1 a la variación total, por otro lado, las edificaciones que tuvieron buena representación en este trimestre fuero las obras destinadas a la construcción de oficinas con un 1,8 y casas con 1,5 puntos porcentuales la variación total (Departamento Administrativo Nacional de Estadística (DANE), 2015).

De igual forma durante el tercer trimestre del año 2015 las obras culminadas que tuvo mayor participación fue al momento de que el DANE realizará el censo fue la construcción de apartamentos con un 58,7\% mientras que la culminación de obras correspondientes a la construcción de hospitales y hoteles mostrando una baja participación de 1,2\% y 1,9 correspondientemente.

Ahora bien, al finalizar el cuarto trimestre del año 2015 en comparación del tercer trimestre del mismo periodo se logró evidenciar que las obras culminadas de este periodo presento un crecimiento de $25,7 \%$ cuyo resultado fue dado por el incremento en las culminaciones en las obras con destino a apartamentos, edificaciones de comercio sumando así 23,5\% a la variación porcentual por el contrario disminuyo el porcentaje correspondiente a la culminación de obras destinadas a la oficinas con un 1,0 punto porcentual, y bodegas con un 1,0 punto porcentual (Departamento Administrativo Nacional de Estadística (DANE), 2016).

Cierto es que en el transcurso de este cuarto trimestre el censo realizado por el DANE muestra que las obras culminadas corresponden a las edificaciones apartamentos con un 60,7\%, en segundo lugar, la culminación de obras correspondientes a casas y en tercer lugar obras relacionadas con el 
comercio (Departamento Administrativo Nacional de Estadística (DANE), 2016).

\begin{tabular}{|c|c|c|c|c|c|c|c|c|c|c|c|c|c|c|c|c|}
\hline \multicolumn{17}{|c|}{ Áreas Culminadas Según Destinos Año 2016} \\
\hline \multirow{3}{*}{ Destino } & \multicolumn{4}{|c|}{ IV Trimestre 2015 - I Trimestre 2016} & \multicolumn{4}{|c|}{ | trimestre 2016- || trimestre 2016} & \multicolumn{4}{|c|}{ II Trimestre 2016- III Trimestre 2016} & \multicolumn{4}{|c|}{ III trimestre 2016 - IV trimestre 2016} \\
\hline & Trim & & Variación & Contribución & trim & & variación & Contribución & Trim & & Variación & Contribución & & & variación & Contribución \\
\hline & IV-2015 & $1-2016$ & $\%$ & Puntos & 1-2016 & ॥-2016 & $\%$ & puntos & $\| 1-2016$ & III-2016 & $\%$ & Puntos & III-2016 & IV-2016 & $\%$ & puntos \\
\hline Total & 5.141 .159 & 4.560 .235 & $-11,3$ & $.11,3$ & 4.560 .235 & $4,482,223$ & $-1,7$ & $-1,7$ & $4,482,223$ & 4.286 .318 & $-4,4$ & $-4,4$ & 4.286 .318 & 5.675 .184 & 32,4 & 31,4 \\
\hline Apartamentos & 3.120 .126 & 2.493 .475 & $-20,1$ & $-12,2$ & 2.493 .475 & 2.604 .642 & 4,5 & 2,5 & 2.604 .642 & 2.400 .010 & $-7,9$ & $-4,6$ & 2.400 .010 & 3.005 .098 & 25,2 & 14,1 \\
\hline Casas & 754.126 & 701.587 & $-7,1$ & -1 & 701.587 & 729.556 & 4 & 0,6 & 729.556 & 852.992 & 16,9 & 2,8 & 852.992 & 734.328 & $-13,9$ & $-2,8$ \\
\hline Oficinas & 192.027 & 329.271 & 71,5 & 2,7 & 329.271 & 169.516 & $-48,5$ & $-3,5$ & 169.516 & 174.230 & 2,8 & 0,1 & 174.230 & 348.572 & 100,1 & 4,1 \\
\hline Comercio & 360.039 & 149.893 & $-58,4$ & $-4,1$ & 149.893 & 174.792 & 16,6 & 0,5 & 174.792 & 351.625 & 101,2 & 3,9 & 351.625 & 943.498 & 168,3 & 13,8 \\
\hline Bodegas & 172.589 & 366.501 & 112,4 & 3,8 & 366.501 & 288.959 & $-21,2$ & $-1,7$ & 288.959 & 159.553 & $-44,8$ & $-2,9$ & 159.553 & 212.173 & 33 & 1,2 \\
\hline Educación & 149.509 & 130.005 & -13 & $-0,4$ & 130.005 & 75.384 & -42 & $-1,2$ & 75.384 & 73.254 & $-2,8$ & 0 & 73.254 & 68.373 & $-6,7$ & $-0,1$ \\
\hline Hoteles & 49.906 & 45.897 & -8 & $-0,1$ & 45.897 & 82.051 & 78,8 & 0,8 & 82.051 & 28.575 & $-65,2$ & $-1,2$ & 28.575 & 45.885 & 60,5 & 0,4 \\
\hline Hospitales & 39.555 & 97.448 & 146,4 & 1,1 & 97.448 & 50.833 & $-47,8$ & -1 & 50.833 & 101.841 & 100,3 & 1,1 & 101.841 & 69.410 & $-31,8$ & $-0,8$ \\
\hline Administración Publica & 84.220 & 54.966 & $-34,7$ & $-0,6$ & 54.966 & 36.713 & $-33,2$ & $-0,4$ & 36.713 & 33.400 & -9 & $-0,1$ & 33.400 & 38.056 & 13,9 & 0,1 \\
\hline Otros & 218.198 & 192.192 & $-11,9$ & $-0,5$ & 192.192 & 269.784 & 40,4 & 1,7 & 269.784 & 110.908 & $-58,9$ & $-3,5$ & 110.908 & 209.821 & 89,2 & 2,3 \\
\hline
\end{tabular}

Tabla 6. Variación y contribución trimestral, por estado de obra, según áreas de cobertura Año 2016 por destino. NOTA: Datos del "Boletín técnico - Censo Edificaciones”, por DANE, 2016.

Así mismo en la Tabla 6 se puede observar que el censo realizado por el DANE correspondiente a obras culminadas en el primer trimestre del año 2016 en comparación con el cuarto trimestre del año 2015 muestra un decrecimiento de 11,3\% cuyo resultado se debe a la disminución del porcentaje en la culminación de obras correspondientes a apartamentos con 12,2 puntos porcentuales, comercio con 4,1 puntos porcentuales en la variación total. Así mismo incremento el porcentaje en la culminación de obras destinadas a edificaciones de bodegas con 3,8 punto porcentual y oficinas con 2,7 puntos porcentuales sumando 6,5 puntos porcentuales a la variación total realizada por el censo al comparar los dos trimestres (Departamento Administrativo Nacional de Estadística (DANE), 2016).

Del mismo modo el mimo censo realizado por el DANE muestra que las obras culminadas en este periodo los destinos que tuvieron mayor participación fue obras de edificación de apartamentos y casa sumando un $70,1 \%$ mientras un $29,9 \%$ restante corresponde a otros destinos (Departamento Administrativo Nacional de Estadística (DANE), 2016).

Ahora bien para el segundo trimestre del año 2015 y en comparación con el trimestre anterior se pudo evidenciar una disminución de 1,7\% respecto al trimestre anterior, resultado por la disminución en el porcentaje de culminación de obras destinadas en oficinas con 3,5\% afectando la variación total, asimismo se evidenció un incremento en el porcentaje de culminación de obras destinadas en apartamentos con 2,5\% puntos porcentuales a la variación total (Departamento Administrativo Nacional de Estadística (DANE), 2016).

En el transcurso del segundo trimestre se pudo evidenciar que de las obras culminadas en este 
periodo las obras que tuvieron mayor participación fueron la correspondientes a apartamentos con $58,1 \%$ y casa con un $16,3 \%$ al contrario se evidenció en este periodo $0,8 \%$ en la culminación de obras destinadas a la administración pública (Departamento Administrativo Nacional de Estadística (DANE), 2016).

Para el área culminada en el tercer trimestre de 2016 se observa un decrecimiento de 4,4 en comparación del trimestre anterior resultado dado en los porcentajes de las obras culminadas destinadas en apartamentos y bodegas con un 2,9 a la variación trimestral. Mas sim embargo en el mismo trimestre se presenció un incremento en los porcentajes de obras culminadas destinadas al comercio considerándose el principal crecimiento de este trimestre aportando 3,9 puntos porcentuales a la variación total (Departamento Administrativo Nacional de Estadística (DANE), 2016).

De igual forma en el transcurso del tercer trimestre del año 2016 el $79 \%$ de la obra culminada corresponde a apartamentos y casas con un 75,9\% mientras que dentro del $24,1 \%$ restante se evidencio un 0,7\% de obras culminadas destinadas a los hoteles (Departamento Administrativo Nacional de Estadística (DANE), 2016).

Para finalizar el año 2016 en el cuarto trimestre y en comparación con el trimestre anterior como se puede visualizar en la Tabla 6 las obras culminadas presenciaron un crecimiento en comparación al trimestre anterior resultado dado por el incremento de obras destinadas a 1 comercio y apartamentos aportando $27,9 \%$ a la variación total, más sin embargo; en este periodo se evidenció un disminución porcentual en la culminación de obras destinadas en casas, hospitales restando 3,6 puntos porcentuales a la variación total (Departamento Administrativo Nacional de Estadística (DANE), 2017).

Igualmente, en el trascurso del último trimestre del año 2016 en el censo realizado por el DANE el 65,9\% de las obras culminadas correspondieron a vivienda mientras que el 34,1\% se distribuyó en obras con destinos diferentes (Departamento Administrativo Nacional de Estadística (DANE), 2017). 
Tabla 7.Variación y contribución trimestral, por estado de obra, según áreas de cobertura Año 2017 por destino.

\begin{tabular}{|c|c|c|c|c|c|c|c|c|c|c|c|c|}
\hline \multirow{4}{*}{ Destino } & \multicolumn{12}{|c|}{ Áreas Culminadas Según Destinos Año 2017} \\
\hline & \multicolumn{4}{|c|}{ IV Trimestre 2016 - I Trimestre 2017} & \multicolumn{4}{|c|}{ | trimestre 2017 - || trimestre 2017} & \multicolumn{4}{|c|}{ II Trimestre 2017 - III Trimestre 2017} \\
\hline & \multicolumn{2}{|c|}{ Trimestres } & \multirow{2}{*}{$\begin{array}{c}\text { Variación } \\
\% \\
\end{array}$} & \multirow{2}{*}{$\begin{array}{c}\text { Contribución } \\
\text { Puntos }\end{array}$} & \multicolumn{2}{|c|}{ trimestres } & \multirow{2}{*}{$\begin{array}{c}\text { variación } \\
\%\end{array}$} & \multirow{2}{*}{$\begin{array}{c}\text { Contribución } \\
\text { puntos }\end{array}$} & \multicolumn{2}{|c|}{ Trimestres } & \multirow{2}{*}{$\begin{array}{c}\text { Variación } \\
\% \\
\end{array}$} & \multirow{2}{*}{$\begin{array}{c}\begin{array}{c}\text { Contribuciór } \\
\text { Puntos }\end{array} \\
\end{array}$} \\
\hline & IV-2015 & I- 2017 & & & I- 2017 & II-2017 & & & II-2017 & III - 2017 & & \\
\hline Total & 5.675 .184 & 3.881 .490 & $-31,6$ & $-31,6$ & 3.881 .490 & 3.916.249 & 0,9 & 0,9 & 3.916.249 & 4.028 .478 & 2,9 & 2,9 \\
\hline Apartamentos & 3.005 .098 & 2.120 .396 & $-29,4$ & $-15,6$ & 2.120 .396 & 2.278 .880 & 58,2 & 4,1 & 2.278 .880 & 2.284 .925 & 0,3 & 0,2 \\
\hline Casas & 734.328 & 579.159 & $-21,1$ & $-2,7$ & 579.159 & 589.998 & 15,1 & 0,3 & 589.998 & 695.638 & 17,9 & 2,7 \\
\hline Oficinas & 348.572 & 163.630 & $-53,1$ & $-3,3$ & 163.630 & 176.989 & 4,5 & 0,3 & 176.989 & 247.287 & 39,7 & 1,8 \\
\hline Comercio & 943.498 & 229.399 & $-68,3$ & $-11,3$ & 229.399 & 312.597 & 8 & 0,3 & 312.597 & 188.658 & $-39,6$ & $-3,2$ \\
\hline Bodegas & 212.173 & 243.392 & 14,7 & 0,6 & 243.392 & 177.693 & 4,5 & $-1,7$ & 177.693 & 157.655 & $-11,3$ & $-0,5$ \\
\hline Educación & 68.373 & 120.403 & 76,1 & 0,9 & 120.403 & 51.458 & 1,3 & $-1,8$ & 51.458 & 55.514 & 7,9 & 0,1 \\
\hline Hoteles & 45.885 & 41.516 & $-9,5$ & $-0,1$ & 41.516 & 73.840 & 1,9 & 0,8 & 73.840 & 86.346 & 16,9 & 0,3 \\
\hline Hospitales & 69.410 & 117.350 & 69,1 & 0,8 & 117.350 & 104.556 & 2,7 & $-0,3$ & 104.556 & 42.215 & $-59,6$ & $-1,6$ \\
\hline Administración Publica & 38.056 & 35.669 & $-6,2$ & 0 & 35.669 & 40.793 & 1 & 0,1 & 40.793 & 13.838 & $-66,1$ & $-0,7$ \\
\hline Otros & 209.821 & 160.546 & $-23,5$ & $-0,9$ & 160.546 & 109.445 & 2,8 & $-1,3$ & 109.445 & 256.402 & 134,3 & 3,8 \\
\hline
\end{tabular}

NOTA: Datos del “Boletín técnico - Censo Edificaciones”, por DANE, 2017.

Ahora bien en la Tabla 7 para el primer trimestre del año 2017 el porcentaje de obras culminadas en comparación con el cuarto trimestre del año 2016 se logró evidenciar en el censo realizado por el Departamento Administrativo Nacional de Estadística DANE un decrecimiento en comparación con el trimestre anterior de con un porcentaje de 31,6\% cuyo resultado es el porcentaje de las obras culminadas destinadas en apartamentos con un 15,6 puntos porcentuales y comercio con 11,3 puntos porcentuales restando en conjunto 26,9 a la variación trimestral. De igual forma en el transcurso del primer trimestre en el censo realizado muestra 69,5\% correspondientes a obras destinadas a vivienda, casas y apartamentos mientras que el $30,5 \%$ se a diferentes destinos.

Así mismo el segundo trimestre del año 2017 evidenció un crecimiento de 0,9\% en comparación con el trimestre anterior cuyo resultado es dado por la culminación de obras destinadas a la edificación de apartamentos con un 4,1 punto porcentual en la variación total por otro lado se observa una diminución en el porcentaje de obras culminadas destinadas a la educación con un 1,8 y bodegas con un 1,7 restándole a la variación total.

De igual forma en el transcurso del segundo trimestre del año 2017 se logra evidenciar que las obras culminadas destinadas a los apartamentos, casas y comercio tuvieron buena participación de $58,2 \%, 15,1 \%$ y $8,0 \%$ correspondiente. Al contrario de la culminación de obras destinadas a la administración pública con 1,0\%.

En el tercer trimestre del 2017 en el censo realizado por el Departamento Nacional de Estadística DANE se logró evidenciar un aumento de 2,9\% en comparación con el trimestre anterior, resultado 
por el porcentaje de las obras culminadas de otro destino las cuales incluyen obras religiosas, clubes, cines, teatros, estadios deportivos y oras áreas destinadas al esparcimiento con una contribución de 3,8 puntos porcentuales. Por el contrario, el porcentaje de culminación de obras presentaron disminución en la culminación de obras fueron aquellas destinadas al comercio disminuyendo la variación en 3,2 puntos porcentuales (Departamento Administrativo Nacional de Estadística (DANE), 2017).

Así mismo en el transcurso del censo realizado en el tercer trimestre del 2017 se puede evidenciar que culminaron y tuvieron mayor representación en este periodo fue las obras destinadas a los apartamentos y casas sumando un 74,0\% mientras que el 26,0\% restante corresponde a los sectores de oficinas, comercio, bodegas, educación, hoteles, hospitales, administración pública y otras edificaciones (Departamento Administrativo Nacional de Estadística (DANE), 2017).

Ahora bien, en las Tablas 5,6 y 7 correspondiente a los años 2015, 2016 y 2017 se puede observar un comportamiento bastante dinámico y las obras culminadas fueron prioritarias e influyeron en el estudio aquellas destinadas a edificaciones relacionadas con apartamentos, casas y oficinas las cuales a través de las fluctuaciones presentaron en los tres periodos buena participación en el mercado.

De igual forma es pertinente mencionar que al observar la Tabla 5 se logra evidenciar que el porcentaje de los primeros tres trimestres muestran una variación negativa en el $80 \%$ destinos relacionados en la tabla debido a que este periodo se vio influenciado por los polémicos casos de corrupción disminuyendo en el proceso de culminación de obras en civiles y arquitectónicas, hasta su lenta recuperación que se pudo documentar en el tercer trimestre del año 2015 gracias a la culminación de obras relacionadas con vivienda (casas y apartamentos). Así mismo en el transcurso del año 2016 estas obras presentaron grades fluctuaciones y se evidenció gran participación en la culminación de obras relacionadas con la edificación de oficinas, establecimientos de comercio y bodegas.

Para el año 2017 el censo realizado por el DANE evidenció que los tres primeros meses no se culminaron obras en comparación con el trimestre anterior, más sin embargo el segundo y tercer 
trimestre evidencia una recuperación en el porcentaje de variación en la culminación de obras relacionadas con la edificación de edificios y apartamentos teniendo coherencia con los resultados expresados en la Tabla 7 Variación y contribución trimestral, por estado de obra, según áreas de cobertura 2017.

Así mismo se logró evidenciar que a lo largo de los tres periodos 2015, 2016, y 2017 se realizaron y culminaron más obras relacionadas con la vivienda que con los otros destinos de la construcción teniendo menor participación la construcción y culminación de obras destinadas para la administración pública, hospitales, hoteles y educación.

Dicho lo anterior es importante tener presente el porcentaje de licencias de construcción que realizo el estado y cómo fue su comportamiento en estos tres periodos.

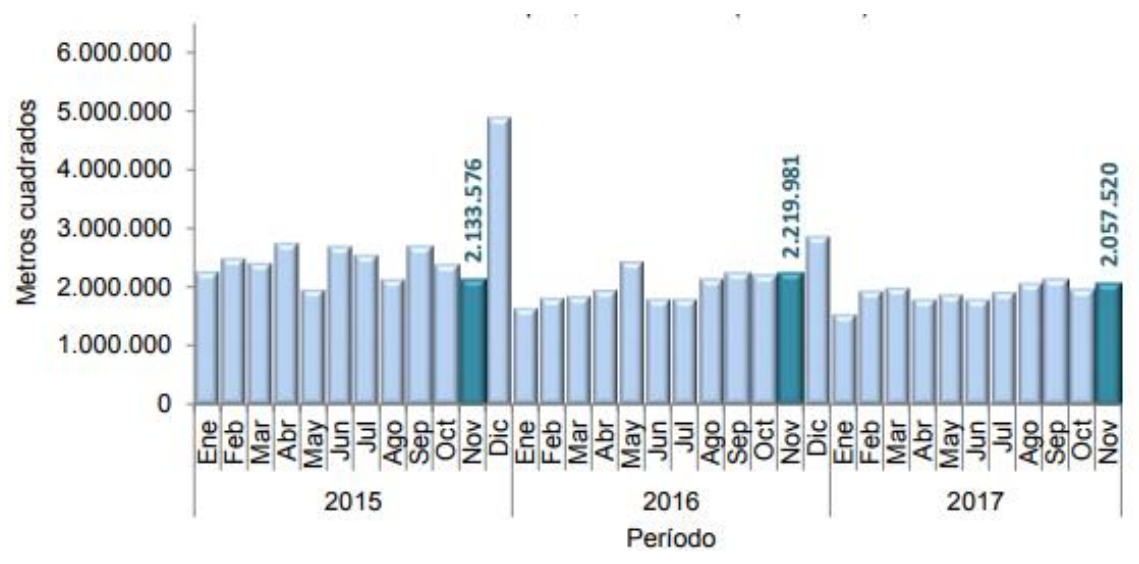

Figura 4. Área total licenciada 302 municipios año 2015 - 2017, Adaptado del "Boletín técnico - Licencias de construcción (diciembre 2017)”, por DANE, 2018.

Ahora bien la licencias de construcción hacen parte fundamental del proceso de licitación pública y privada, convirtiéndose en un instrumento de control a de las entidades gubernamentales con el objetivo de visualizar le crecimiento y desarrollo de las ciudades, así mismo comprender e implementar las normas de infraestructura con el fin de mantener en materia de estructura una construcción, así como las áreas verdes con el objetivo de preservar el medio ambiente así como para la construcción de obras civiles y arquitectónicas. 
Así mismo, en la Figura 4 se puede visualizar el comportamiento que ha tenido este indicador los últimos 3 años en Colombia expresado en metros cuadrados.

Para iniciar en el año 2015 se puede observar que el comportamiento del indicador muestra un decrecimiento en comparación con el último mes del año 2014 ya que el área aprobada en el mes de Enero fue inferior fue inferior al mes de Diciembre del año 2014 disminuyendo 27,0\% cuyo resultado fue dado principalmente a la diminución de licencias aprobadas en el Valle del Cauca restando 7 puntos porcentuales a la variación total, así mismo del total de áreas aprobadas en el mes de Enero del 2015 el $77 \%$ correspondió a licencias de construcción destinadas para vivienda mientras que el $23 \%$ al resto de los destinos.

Al finalizar el año 2015 se identificó que el indicador ELIC estadísticas de licencias de construcción, realizado por el Departamento Nacional de Estadística DANE evidencia que el mes de diciembre del 2015 se licenciaron 3.885.5486 m2 superando así el mes de diciembre del año 2014 resultado dado por licencias destinadas a la vivienda. Cabe resaltar que en el trascurso del año 2015 se aprobaron 26.742.749 metros cuadrados de las cuales el 18,1\% se aprobaron en la ciudad de Bogotá, en el Departamento de Cundinamarca el 14,1 y el 13,8\% en el Departamento de Antioquia como se puede evidenciar en la siguiente Figura 5.

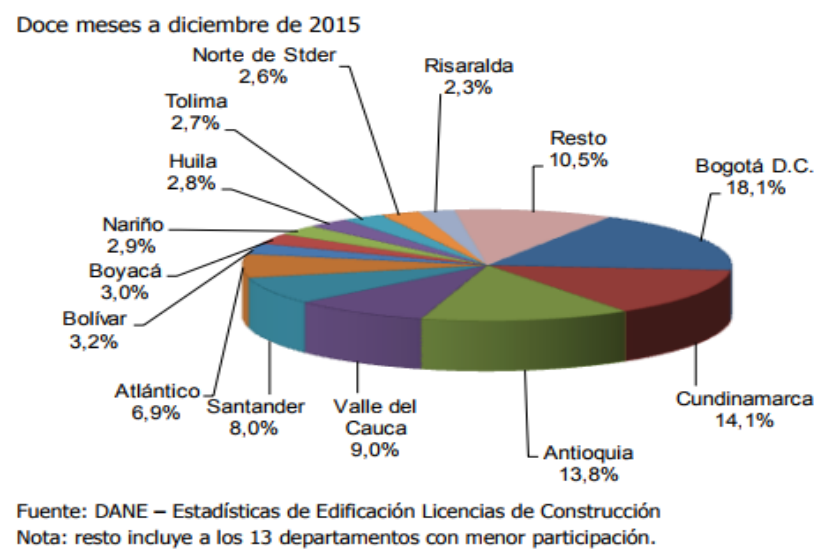

Figura 5. Participación aprobada según Departamentos y Bogotá D.C 88 municipios, doce meses a diciembre de 2015. Adaptado del “Boletín técnico-Licencias de construcción (diciembre 2015)”, por DANE, 2016.

Ahora a inicios del año 2016 el indicador señala una reducción de 61,5 \% en comparación de mes 
de diciembre del año 2015 los cuales se aprobaron 2.494,498 metros cuadrados. Este resultado fue debido a la diminución de áreas aprobadas del departamento de Cundinamarca en comparación a diciembre del año 2015 el cual reto 19,3 puntos porcentuales a la variación, así mismo los Departamentos de Antioquia y Santander los cuales restaron 91 y 89 puntos porcentuales. Por otro lado, en el transcurso del mes de enero se evidenció que del total del área aprobada 71,5\% se destinó a vivienda, mientras que el 28,5\% fue destinado a otros destinos.

Al finalizar el año 2016 se aprobaron en total 25,032.833 metros cuadrados lo cual señala una disminución en comparación del total licenciado en el año anterior, disminuyendo un 20,3\% concretándose en la ciudad de Bogotá y los Departamentos de Antioquia y Cundinamarca, así mismo los Departamentos de del valle del cauca y Atlántico tuvieron una considerable participación en el año 2016 sumando un 15,3 \% (Departamento Administrativo Nacional de Estadística (DANE), 2017).

Ahora bien, es pertinente mencionar los destinos de las obras que se aprobaron en el año 2016 continuación se logra evidenciar la variación que tuvo los destinos en comparación con el año 2015.

Tabla 8. Variación y contribución a la variación del área aprobada, según destinos 302 municipios doce meses a diciembre (2015-2016).

\begin{tabular}{|c|c|c|c|c|}
\hline \multirow{3}{*}{ Destinos } & \multirow{2}{*}{\multicolumn{2}{|c|}{$\begin{array}{c}\text { Metros cuadrados } \\
\text { Doce meses }\end{array}$}} & \multirow{3}{*}{$\begin{array}{c}\text { Variación } \\
\text { año corrido } \\
(\%)\end{array}$} & \multirow{3}{*}{$\begin{array}{c}\text { Contribución a la } \\
\text { variación (puntos } \\
\text { porcentuales) }\end{array}$} \\
\hline & & & & \\
\hline & 2015 & 2016 & & \\
\hline Vivienda & 22.880 .389 & 18.564 .273 & $-18,9$ & $-13,7$ \\
\hline Industria & 931.749 & 547.344 & $-41,3$ & $-1,2$ \\
\hline Oficina & 876.930 & 947.570 & 8,1 & 0,2 \\
\hline Bodega & 1.303 .371 & 815.859 & $-37,4$ & $-1,6$ \\
\hline Comercio & 2.883 .368 & 2.102 .767 & $-27,1$ & $-2,5$ \\
\hline Hotel & 478.910 & 387.111 & $-19,2$ & $-0,3$ \\
\hline Educación & 904.227 & 753.895 & $-16,6$ & $-0,5$ \\
\hline Hospital & 620.805 & 389.663 & $-37,2$ & $-0,7$ \\
\hline Administración pública & 148.154 & 224.863 & 51,8 & 0,2 \\
\hline Religioso & 101.001 & 71.059 & $-29,6$ & $-0,1$ \\
\hline Social-recreacional & 238.239 & 192.025 & $-19,4$ & $-0,1$ \\
\hline Otro* & 35.386 & 36.404 & 2,9 & 0,0 \\
\hline Total & 31.402 .529 & 25.032 .833 & $-20,3$ & $-20,3$ \\
\hline
\end{tabular}

NOTA: Datos del boletín técnico “licencias de construcción- ELIC diciembre 2016” de DANE, 2017. 
Como se logra evidenciar el año 2016 del área aprobada el destino de bodega disminuyó considerablemente en comparación con el año 2015 dejándolo en 37, 4 puntos porcentuales, la industria también presencio en este periodo una disminución considerable en comparación con el periodo pasado dejando una variación de 41,3 puntos siendo estos dos los factores que influyeron al resultado total del censo. Por otro lado, el destino de licencia de áreas aprobadas relacionadas con la administración pública en el año 2016 evidencio un crecimiento contribuyendo a la variación total de 51,8\% en comparación con el año anterior (Departamento Administrativo Nacional de Estadística (DANE), 2017).

Ahora bien, en el año 2017 se puede observar en la Figura 4 una diminución en el trascurso del año de licencias de construcción aprobadas en comparación con los años 2015 y 2016. Así pues, en el año corrido hasta noviembre del 2017 se observó un total de 21.143.287 metros cuadrados representando una diminución en comparación con el periodo anterior, de esta aérea aprobada en el año 2017 Bogotá resto 5,7 puntos porcentuales a la variación total. Por en el Departamento de Antioquia se evidenció un crecimiento de 1,4 puntos a la variación del año corrido.

Así mismo del área aprobada del año 2017 corrido se puede observar el comportamiento y variación que ha tenido esta en los diferentes destinos de la construcción como se muestra en la siguiente Figura.

\begin{tabular}{l|rr|rr}
\hline \multicolumn{1}{c}{ Destinos } & $\begin{array}{c}\text { Variación } \\
\text { año corrido } \\
\text { (\%) }\end{array}$ & $\begin{array}{c}\text { Contribución a la } \\
\text { variación (puntos } \\
\text { porcentuales) }\end{array}$ & $\begin{array}{c}\text { Distribución del } \\
\text { área aprobada }\end{array}$ \\
\hline Vivienda & $-2,7$ & & $-2,0$ & 75,7 \\
Oficina & $-46,3$ & $-1,7$ & 2,1 \\
Comercio & $-13,0$ & $-1,1$ & 7,5 \\
Industria & $-31,4$ & $-0,6$ & 1,5 \\
Hospital & $-32,3$ & $-0,6$ & 1,2 \\
Administración pública & $-51,3$ & $-0,5$ & 0,5 \\
Hotel & $-8,5$ & $-0,1$ & 1,5 \\
Religioso & $-25,6$ & 0,1 & 0,2 \\
Social-recreacional & 19,7 & 0,8 & 1,0 \\
Bodega & 24,2 & 1,2 & 4,3 \\
Educación & 39,4 & 0,0 & 4,3 \\
Otro* & 15,6 & $-4,6$ & 0,1 \\
Total & $-4,6$ & & 100,0 \\
\hline
\end{tabular}

Figura 6. Variación, contribución a la variación y distribución del área total aprobada 302 municipios año corrido a noviembre (2017 /2016), Adaptado del "Boletín técnico - Licencias de construcción (noviembre 2017)", por DANE, 2018. 
Como se logra visualizar en la Figura 6 contribución y distribución del área aprobada año 2016 2017 el área aprobada en el año corrido 2017 las licencias aprobadas para áreas destinadas a vivienda disminuyo considerablemente en 2,0 porcentuales, así mismo las oficinas con 1,7 y el comercio con 1,1 presentaron decrecimientos a comparación con el año anterior. Por otro lado, los destinos de las licencias de construcción aprobadas que presentaron un incremento en este periodo fue aquellas destinadas a la educación con 1,2 puntos porcentuales, las bodegas con 0,8 puntos porcentuales y a las licencias con destino social recreacional con 0,2 puntos porcentuales a la incrementando la variación total del año corrido (Departamento Administrativo Nacional de Estadística (DANE), 2018).

Mencionado lo anterior es considerable mencionar que el indicador ELIC estadísticas de edificación licencias de construcción durante los tres periodos 2015-2017 ha evidenciado un comportamiento con muchas fluctuaciones en donde los Departamentos de Cundinamarca, Antioquia, Cali tuvieron gran participación, así como las licencias de construcción aprobadas destinadas para la construcción de vivienda, oficina y comercio siendo los principales influyentes del indicador.

Ahora bien, en la Figura 4 se logra evidenciar que en el transcurso de los años 2015 al 2017 una disminución considerable en la aprobación de licencias para la construcción ya que es preciso recordar que a mediados del año 2015 se da a la luz pública los polémicos casos de corrupción en la contratación influyendo en la pérdida de confianza en los compradores y así mismo en la aprobación de licencias de construcción tanto a la entidad pública como a los contratistas.

Como se mencionó anteriormente el sector de la construcción es considerado un pilar fundamental de la economía colombiana, pues bien, se considera de suma importancia observar el grado de empleo que este ha generado a lo largo de los periodos 2015 al 2017 como se indica en la siguiente Tabla. 
Tabla 9. Número de ocupados totales, No ocupados en el sector de la construcción, tasa de ocupación y tasa de desempleo.

\begin{tabular}{|c|c|c|c|c|c|c|c|c|c|c|c|c|c|}
\hline & & \multicolumn{4}{|c|}{ Total Nacional } & \multicolumn{4}{|c|}{ Total Cabecera } & \multicolumn{4}{|c|}{ Total Zona Rural } \\
\hline & & $\begin{array}{c}\text { No. } \\
\text { ocupados }\end{array}$ & $\begin{array}{l}\text { Ocupados } \\
\text { construcción }\end{array}$ & $\begin{array}{c}\text { Tasa de } \\
\text { ocupación }\end{array}$ & $\begin{array}{c}\text { Tasa de } \\
\text { desempleo }\end{array}$ & $\begin{array}{c}\text { No. } \\
\text { ocupados }\end{array}$ & $\begin{array}{l}\text { Ocupados } \\
\text { construcción }\end{array}$ & $\begin{array}{c}\text { Tasa de } \\
\text { ocupación }\end{array}$ & $\begin{array}{c}\text { Tasa de } \\
\text { desempleo }\end{array}$ & $\begin{array}{c}\text { No. } \\
\text { ocupados }\end{array}$ & $\begin{array}{l}\text { Ocupados } \\
\text { construcción }\end{array}$ & $\begin{array}{c}\text { Tasa de } \\
\text { ocupación }\end{array}$ & $\begin{array}{c}\text { Tasa de } \\
\text { desempleo }\end{array}$ \\
\hline \multirow{4}{*}{2015} & Ene 15 - Mar 15 & 21.368 & 1.376 & $57,5 \%$ & $9,8 \%$ & 16.754 & 1.194 & $58,4 \%$ & $10,9 \%$ & 4.614 & 182 & $54,4 \%$ & $5,9 \%$ \\
\hline & Abr 15 - Jun 15 & 22.017 & 1.351 & $59,1 \%$ & $8,9 \%$ & 17.195 & 1.168 & $59,7 \%$ & $9,9 \%$ & 4.822 & 183 & $56,8 \%$ & $5,0 \%$ \\
\hline & Jul 15 - Sep 15 & 21.936 & 1.372 & $58,6 \%$ & $9,0 \%$ & 17.323 & 1.205 & $59,9 \%$ & $9,5 \%$ & 4.614 & 167 & $54,2 \%$ & $7,1 \%$ \\
\hline & Oct 15 - Dic 15 & 22.747 & 1.400 & $60,6 \%$ & $8,0 \%$ & 17.765 & 1.202 & $61,2 \%$ & $8,9 \%$ & 4.982 & 198 & $58,5 \%$ & $4,9 \%$ \\
\hline \multirow{4}{*}{2016} & Ene 16 - Mar 16 & 21.552 & 1.379 & $57,2 \%$ & $10,7 \%$ & 16.914 & 1.167 & $58,1 \%$ & $11,9 \%$ & 4.639 & 212 & $54,3 \%$ & $5,9 \%$ \\
\hline & Abr 16 - Jun 16 & 22.144 & 1.428 & $58,6 \%$ & $8,9 \%$ & 17.250 & 1.261 & $59,0 \%$ & $9,9 \%$ & 4.894 & 166 & $57,2 \%$ & $5,2 \%$ \\
\hline & Jul 16 - Sep 16 & 22.092 & 1.373 & $58,3 \%$ & $9,1 \%$ & 17.367 & 1.205 & $59,2 \%$ & $10,0 \%$ & 4.725 & 168 & $55,2 \%$ & $5,6 \%$ \\
\hline & Oct $16-$ Dicl6 & 22.837 & 1.409 & $60,0 \%$ & $8,2 \%$ & 17.782 & 1.205 & $60,4 \%$ & $9,2 \%$ & 5.055 & 205 & $58,9 \%$ & $4,4 \%$ \\
\hline \multirow{3}{*}{2017} & Ene 17 - Mar 17 & 21.755 & 1.319 & $57,0 \%$ & $10,6 \%$ & 17.081 & 1.170 & $57,8 \%$ & $11,7 \%$ & 4.673 & 149 & $54,4 \%$ & $6,5 \%$ \\
\hline & Abr 17 - Jun 17 & 22.578 & 1.354 & $59,0 \%$ & $9,0 \%$ & 17.551 & 1.174 & $59,1 \%$ & $10,2 \%$ & 5.027 & 179 & $58,4 \%$ & $4,4 \%$ \\
\hline & Jul 17 - Sep 17 & 22.329 & 1.359 & $58,1 \%$ & $9,3 \%$ & 17.476 & 1.175 & $58,7 \%$ & $10,4 \%$ & 4.853 & 184 & $56,3 \%$ & $5,3 \%$ \\
\hline
\end{tabular}

Fuente: DANE

NOTA: Datos del Informe de "Colombia construcción en cifras dic 2017”, por DANE, 2017. Por Luis Sebastián Avella Martínez, 2018

Ahora bien, cómo se puede observar en la Tabla 9 el número de ocupados en el sector de la construcción es mayor en el total de la cabecera que en la zona rural a lo largo de los años 2015 al 2017 lo cual es coherente ya que en estos periodos se realizaron mayores obras en las zonas urbanas que en las rurales lo cual requirió más mano de obra en comparación con la obra que se realizaron en la zona rural. Así mismo se puede evidenciar que en el trascurso del año 2015 el no de ocupados en el sector de la construcción incrementa disminuyendo la tasa de desempleo de 9,8\% a 8,0\% cerrado con 1400 ocupados en la construcción.

A en el año 2016 se puede evidenciar grandes fluctuaciones debido a que este indicador se ve influenciado por los escándalos relacionados con la corrupción en el sector de la construcción ya que disminuyo el número de ocupados en el primer trimestre del año 2016 pasando de 1.400 a 1.379 aumentando, así mismo la tasa de desempleo en comparación con el trimestre anterior quedando en $10,7 \%$ a nivel nacional, al finalizar este periodo se puede observar que para el cuarto trimestre del 2016 el número de ocupados en el sector de la construcción incrementa tanto en la zona rural como la zona de la cabecera cerrando el año con 1.409 puestos ocupados en el sector de la construcción y una tasa de desempleo de $8,2 \%$ ya que en este periodo culminaron más número de obras en comparación con los periodos 2015-2017.

Así mismo para el año 2017 muestra un decrecimiento de número de ocupados en comparación el con el último trimestre del año 2016 pasando de 1.409 a 1.319, así mismo incrementando la 
tasa de desemplea $10,06 \%$ debido a la estabilización de los eventos ocurridos en el sector el año pasado, de igual forma las ramas de la economía que aportaron en este primer trimestre del año 2017 fueron los sectores relacionados con la agricultura, la ganadería, la silvicultura, la pesca y actividades inmobiliarias, ahora bien para el segundo trimestre del año evidencia un incremento de número de ocupados en el sector de la construcción en comparación con el primer trimestre del año anterior disminuyendo así la tasa de desempleo pasando de 10,06\% a 9,0\%. Para el tercer trimestre del año 2017 se evidencia un incremento en el número de ocupados en el sector de la construcción en comparación del segundo trimestre del 2017 cerrado en junio del mismo año, pasando de 1.354 a 1.359 por su parte la tasa de desempleo incremento en comparación con el trimestre anterior pasado de $9,0 \%$ a $9,3 \%$ incremento generado por los otros sectores de la economía.

\subsubsection{Normatividad Colombiana para el sector de la construcción.}

Ahora bien, mencionado lo anterior se considera de suma importancia conocer la las leyes y normas que beben cumplir las empresas contratistas de Colombia con el fin de realizar actividades arquitectónicas y civiles con entidades públicas.

La ley 80 de 1993 por medio de la cual se expide el Estatuto General de Contratación de la Administración Pública cuyo objeto es disponer las reglas y principios que rigen los contratos de las entidades estatales. Adicionalmente la Ley 1150 de 2007 por medio de la cual se introducen medidas para la eficiencia y transparencia de la ley 80 de 1993 y se dictan otras disposiciones generales sobre la contratación con recursos públicos la cual está más enfocada a los procesos de contratación estatal, de igual forma el Decreto 1510 de 2013 por el cual se reglamenta el sistema de compras y contratación pública.

Los aspectos más relevantes que tocan estas normas son primordiales para que las empresas contratistas lleven a cabalidad a la hora de realizar una obra de construcción civil y arquitectónica como son el proceso de licitación. Para esto las empresas contratistas a la hora de ejecutar contratos de obras civiles y arquitectónicas con entidades públicas deberán aplicar en primera instancia las leyes anteriormente mencionadas en particular la ley 1150 de 2007 dentro del título 
primero de la eficiencia y transparencia, de esta estipula las modalidades de selección entre las cuales se puede mencionar la licitación pública ${ }^{16}$, selección abreviada ${ }^{17}$, concurso de méritos ${ }^{18}$, contratación directa ${ }^{19}$ y cuantía mínima. ${ }^{20}$

De igual manera es preciso señalar que mediante el Decreto 4170 del 2011 se crea la unidad administrativa especial Agencia Nacional de Contratación Pública denominada Colombia Compra Eficiente, entidad encargada en regular y direccionar los procedimientos de contratación pública en los oferentes y compradores; esta a su vez dentro de sus funciones tiene el desarrollo de la herramienta SECOP que es de gran utilidad ya que permite a los interesados en participar en ofertas publicadas por entidades gubernamentales.

Ahora bien, cabe resaltar que la ley 80 de 1993 señala que los consorcios y uniones temporales hacen parte fundamental a la hora de ejecutar un contrato civil o arquitectónico en el cual se puede encontrar en los artículos $6^{\circ}$ de la capacidad de contratar y $7^{\circ}$ de los consorcios y uniones temporales, de la ley 80 de 1993 en donde dictamina:

El artículo 6 de la Ley 80 de 1993 expresa sobre la capacidad para contratar que se "Pueden celebrar contratos con las entidades estatales las personas consideradas legalmente capaces en las disposiciones vigentes. También podrán celebrar contratos con las entidades estatales, los consorcios y uniones temporales" (Ley 80, 1993)

De igual forma la Ley 80 de 1993 en su Artículo $7^{\circ}$ define que los Consorcios y Uniones Temporales son:

Consorcio: cuando dos o más personas en forma conjunta presentan una misma propuesta para la adjudicación, celebración y ejecución de un contrato, respondiendo solidariamente de todas y cada

\footnotetext{
${ }^{16}$ La Ley 1150 del 2007 la define como el "Procedimiento mediante el cual la entidad estatal formula públicamente una convocatoria para que, en igualdad de oportunidades, los interesados presenten sus ofertas y seleccione entre ellas la más favorable" (Congreso de la república, 1993).

${ }^{17} \mathrm{La}$ ley 1150 del 2007 indica que "Corresponde a la modalidad de selección objetiva prevista para aquellos casos en que, por las características del objeto a contratar, las circunstancias de la contratación o la cuantía o destinación del bien, obra o servicio, puedan adelantarse procesos simplificados para garantizar la eficiencia de la gestión contractual" (Congreso de la república, 2007).

${ }^{18}$ El Decreto 019 del 2012 define como la "Modalidad para la selección de consultores o proyectos, en la que se podrán utilizar sistemas de concurso abierto o de precalificación. en este último caso, la conformación de la lista de precalificados se hará mediante convocatoria pública" (presidente de la república, 2012).

${ }^{19}$ Según ley 1150 del 2007.

${ }^{20}$ De acuerdo con la ley 1150 de 2012 reglamenta como aquella que no excede del 10 por ciento de la menor cuantía de la entidad independientemente de su objeto (Congreso de la república, 2007).
} 
una de las obligaciones derivadas de la propuesta y del contrato. En consecuencia, las actuaciones, hechos y omisiones que se presenten en desarrollo de la propuesta y del contrato, afectarán a todos los miembros que lo conforman. (Ley 80, 1993)

Unión Temporal: cuando dos o más personas en forma conjunta presentan una misma propuesta para la adjudicación, celebración y ejecución de un contrato, respondiendo solidariamente por el cumplimiento total de la propuesta y del objeto contratado, pero las sanciones por el incumplimiento de las obligaciones derivadas de la propuesta y del contrato se impondrán de acuerdo con la participación en la ejecución de cada uno de los miembros de la unión temporal (Ley 80, 1993)

De igual forma el decreto 1510 del 2013 reglamenta el sistema de compras y contratación pública mencionando en el artículo 1 los objetivos del Sistema de Compras y Contratación Pública señalando que "Las Entidades Estatales deben procurar el logro de los objetivos del sistema de compras y contratación pública definidos por Colombia Compra Eficiente” (Decreto 1510, 2013).

Así mismo las empresas dedicadas al sector de la construcción deben tener en cuenta las figuras involucradas a la hora de licitar, participar y ejecutar una obra de construcción como se indica en el artículo 2 del Decreto 1510 del 2013 entidades estatales, Colombia Compra Eficiente, oferentes en los procesos de contratación, los contratistas, los supervisores, los interventores y organizaciones de la sociedad civil y los ciudadanos (Decreto 1510, 2013).

Igualmente, para las empresas contratistas es de suma importancia la implementación del RUP ${ }^{21}$ como una herramienta fundamental tal como lo expresa el Capítulo 5 del decreto 1510 del 2013. Ahora bien se considera de suma importancia resaltar que vivimos en un mundo globalizado que constantemente está sufriendo cambios en materia contable y financiera, con la implementación de las Normas Internacionales de Información Financiera NIIF en Colombia las organizaciones tienen ventajas al converger con estos estándares tales como la mejor interpretación de los

\footnotetext{
21 "Es un registro de creación legal que llevan las cámaras de comercio, en el cual deben inscribirse las personas naturales o jurídicas nacionales o extranjeras domiciliadas o con sucursal en Colombia que aspiran a celebrar contratos con las entidades estatales" (Cámara de Comercio)
} 
estados financieros entre países, ofrecer información de alta calidad, así como la posibilidad de participar en un mercado más competitivo.

El gobierno de colombiano mediante la Ley 1314 del 2009 "Regulan los principios y normas de contabilidad e información financiera y de aseguramiento de información aceptados en Colombia, se señalan las autoridades competentes, el procedimiento para su expedición y se determinan las entidades responsables de vigilar su cumplimiento" (Ley 1314, 2009).

Para el sector de la construcción con el objetivo de llevar la contabilidad mediante estándares internacionales se establece la NIIF 15 denominada ingresos de actividades ordinarias precedentes con contratos con clientes, para lo cual se abordará más adelante en el presente estudio.

\subsection{Desarrollo fase 2}

La presente fase aborda un análisis actual de la administración contable en el sector de la construcción que contratan con entidades públicas, para lo cual se aborda un caso según tratamiento contable tradicional.

\subsubsection{Análisis Actual de la Administración Contable del Sector de la Construcción que Contrata con Entidades Públicas.}

Colombia se encuentra en proceso de implementar estándares internacionales de contabilidad en las organizaciones, proceso que ha tenido varias implicaciones para las empresas de diferentes sectores de la economía en especial al sector de la construcción, este sector esta direccionado por una serie de normas y leyes vigentes que contribuyen para que se lleve el adecuado manejo contable. Ahora bien, Colombia antes de entrar en convergencia a estándares internacionales de contabilidad no tenía una norma específica que reglamentara la contabilización de las empresas dedicadas a la construcción e ingeniería, por lo cual el tratamiento contable de este tipo de operaciones durante los últimos años se ha venido realizando bajo normas locales Decreto 2649 de 1993 y Decreto 2650 de 1993.

La anterior afirmación es basada de acuerdo a un previo estudio realizado en la presente 
investigación, que indica que el 82,4\% de las empresas encuestadas del sector de la construcción, continúan aplicando prácticas tradicionales bajo Decreto 2649 de 1993, el 11,8\% aplica actualmente NIC 11 y el 5,9\% aplica prácticas contables bajo NIIF 15.

De lo anterior a continuación se señala el tratamiento contable general para los contratos de construcción realizados con entidades públicas bajo practicas actuales en Colombia, hecho que nos permitirá analizar el contexto y estudiar las implicaciones que tiene el estándar internacional NIIF 15.

Ahora bien, es de resaltar que las empresas colombianas que se dedican a realizar contratos de construcción con entidades públicas mediante la conformación de consorcios y uniones temporales como lo expresa la Ley 80 de 1993, tienen que cumplir con los requisitos precontractuales que se exigen en el pliego de condiciones a la hora de realizar la licitación con una entidad estatal.

Para el desarrollo de esta investigación se tomará como ejemplo la contabilización de un contrato celebrado entre la unión temporal Mejores Vías 2015 y la agencia de infraestructura del meta AIM cuyo objeto es "Construcción y mejoramiento de la vías urbanas y corredor vial que comunica de la zona urbana con el malecón turístico en el municipio de Acacias - Meta" por un valor de $\$ 10.000 .000 .000$.

Es preciso mencionar que el consorcio está conformado por dos personas naturales y dos personas jurídicas cuya participación como se puede observar en la Tabla 10:

Tabla 10. Acta de Conformación Unión Temporal Mejores Vías 2015

Unión Temporal Mejores Vías 2015

\begin{tabular}{|c|c|}
\hline \multicolumn{2}{|c|}{ Unión Temporal Mejores Vías 2015 } \\
\hline Nombre & Porcentaje de participación \\
\hline $\begin{array}{c}\text { Construcciones Eficientes } \\
\text { de Colombia S.A.S }\end{array}$ \\
\hline Ingemax S.A.S & $20 \%$ \\
\hline Tiburcio Angarita Prieto & $15 \%$ \\
\hline Agapito Méndez Zapata & $15 \%$ \\
\hline
\end{tabular}

NOTA: Firmas integrantes de la Unión temporal Mejores vías, por Luis Sebastián Avella, Martínez, 2018 
Cuyo contrato fue celebrado entre las partes el 5 de septiembre del 2014 con ocho 8 meses para su ejecución e iniciando obras según acta de inicio el día 8 de octubre del 2015.

- Ahora bien, dentro del contrato celebrado con la entidad estatal se estipula una cláusula en donde relaciona la forma de pago del anticipo equivalente al 50\% del valor del contrato mediante un contrato de fiducia mercantil con una entidad bancaria

- Así mismo como lo estipula el Artículo No 91 de la ley 1474 de 2011 en donde estipula la constitución de un contrato fiduciario en para el manejo de los recursos que se reciban como anticipo. (Ley 1474, 2011)

Para este ejercicio el consorcio y la entidad estatal acordaron conformar el contrato fiduciario con la entidad bancaria banco Los millonarios para el manejo del anticipo.

Ahora bien, el tratamiento contable que tiene la unión temporal se muestra a continuación:

Tabla 11. Registro Contable No 1, Unión Temporal Mejores Vías 2015

\begin{tabular}{|l|c|c|}
\hline \multicolumn{3}{|c|}{ Unión Temporal Mejores Vías 2015 } \\
\hline \multicolumn{1}{|c|}{ Cuenta } & Debito & Crédito \\
\hline 1245 Derechos Fiduciarios & 5.000 .000 .000 & \\
\hline 2815 Ingresos Recibidos para terceros & & 5.000 .000 .000 \\
\hline
\end{tabular}

NOTA: Datos contables de la Unión temporal Mejores vías, por Luis Sebastián Avella, Martínez, 2018

Como se logra evidenciar en la contabilización en la Tabla 11 correspondiente al anticipo de la unión temporal se manejaron las cuentas 1245 Derechos Fiduciarios la cual hace mención a los recursos recibidos con el propósito de cumplir la finalidad del contrato y en contra partida en el crédito la cuenta 2815 Ingresos Recibidos para terceros, la cual hace referencia a los recursos que se reintegraran a la hora de terminar la obra al contratante y este dispondrá de él siguiendo las cláusulas y condiciones contractuales. 
- Ahora bien, a medida que la unión temporal va ejecutando la obra del objeto contractual esta va cobrando cortes de obra mediante ordenes de operación de fiducia hasta lograr completar el cincuenta por ciento del anticipo del contrato.

- Para este caso la Unión Temporal Mejores Vías 2015 mediante contratos con proveedores, y terceros acuerdan la realización de actividades pertinentes a la ejecución del objeto contractual algunos de ellos son:

- El 15 de octubre la unión temporal mejores vías 2015 celebro un contrato con la empresa Arenas Y Gravas La Calidad del Meta S.A.S, con el objeto de suministro, transporte e instalación de 500 metros grava y transporte de arena de rio por un valor de $\$ 630.000 .000$ la cual se le dará un anticipo del $60 \%$ valor del contrato.

- El 15 de octubre la unión temporal mejores vías 2015 realizo un contrato con la empresa concretos Beta y Asociados S.A con el objeto de suministro y transporte de 1400 bultos de cemento de alta calidad por valor de $\$ 850.000 .000$.

- El 20 de octubre la Unión Temporal Mejores vías 2015 celebro un contrato con la empresa El Herrero Colombiano S.A por el suministro y transporte de 700 metros de hierro por un valor de \$ 480.000 .000 en cuya clausula señala que la unión temporal abonara un 50\% como anticipo por el valor del contrato.

- De igual forma la unión temporal al 30 de noviembre obtuvo unos gastos de administración por un valor de $\$ 80.400 .000$ correspondientes a la Tabla no 12 que se muestra a continuación:

Tabla 12.Gastos Administrativos, Unión Temporal Mejores Vías 2015

\begin{tabular}{|c|l|c|}
\hline \multicolumn{3}{|c|}{$\begin{array}{c}\text { Gastos Administrativos Union temporal Mejores } \\
\text { Vias 2015 }\end{array}$} \\
\hline No & \multicolumn{1}{|c|}{ Cargos } & Valor \\
\hline 1 & Director de Obra & $\$ 9.000 .000$ \\
\hline 1 & Residente de Obra & $\$ 7.400 .000$ \\
\hline 1 & Inspector de Obra & $\$ 7.000 .000$ \\
\hline 20 & Ayudantes de Obra & $\$ 32.000 .000$ \\
\hline 1 & HSEQ & $\$ 4.000 .000$ \\
\hline 2 & Celador de Obra & $\$ 4.000 .000$ \\
\hline & Seguridad Social & $\$ 17.000 .000$ \\
\hline \multicolumn{2}{|c|}{ Total } & $\$ 80.400 .000$ \\
\hline
\end{tabular}

NOTA: Cuantía por cargo dentro de la Unión Temporal Mejores vías, por Luis Sebastián Avella, Martínez, 2018 
De acuerdo a las actividades mencionadas anteriormente y los gastos administrativos señalados en la Tabla 12 por la Unión Temporal Mejores Vías 2015 se realiza una orden de operación No 001 con el banco los millonarios el día 30 de noviembre y el departamento de contabilidad realiza los siguientes registros contables:

Tabla 13.Registro Contable No 2, Orden de Operación 001 Unión Temporal Mejores Vías 2015.

\begin{tabular}{|l|l|c|c|}
\hline \multicolumn{1}{|c|}{ Cuenta } & \multicolumn{1}{|c|}{ Tercero } & Debito & Crédito \\
\hline 1245 Derechos Fiduciarios & Fiduciaria Los Millonarios & & 378.000 .000 \\
\hline 1330 Anticipos y Avances & Arena y Gravas La Calidad del Metas S.A.S & 378.000 .000 & \\
\hline 1245 Derechos Fiduciarios & Fiduciaria Los Millonarios & & 850.000 .000 \\
\hline 2205 Proveedores Nacionales & Concretos Beta y Asociados S. A & 850.000 .000 & \\
\hline 1245 Derechos Fiduciarios & Fiduciaria Los Millonarios & & 240.000 .000 \\
\hline 1330 Anticipos y Avances & E1 Herrero Colombiano S. A & 240.000 .000 & \\
\hline 1245 Derechos Fiduciarios & Fiduciaria Los Millonarios & & 80.400 .000 \\
\hline 1105 caja General & Unión Temporal Mejores vías 2015 & 80.400 .000 & \\
\hline & Sumas Iguales & 1.548 .400 .000 & 1.548 .400 .000 \\
\hline
\end{tabular}

NOTA: Cuantía de los registros contables de la Unión Temporal Mejores Vías, por Luis Sebastián Avella, Martínez, 2018

Como se logra evidenciar en los registros contables que señala la Tabla 13, la unión temporal acredita la cuenta 1245 Derechos Fiduciarios correspondiente al anticipo determinados por el contrato con la entidad estatal, conforme se va ejecutando las actividades contractuales hasta llegar al $100 \%$ del anticipo pactado.

En el primer movimiento de la orden de operación 001 se percibe el manejo de la cuenta 1330 Anticipos y avances con la empresa Arenas Y Gravas La Calidad del Meta S.A.S ya que se determinó por medio de una cláusula contractual la unión temporal mejores vías 2015 un anticipo equivalente al $60 \%$ del valor del contrato.

Seguidamente el segundo movimiento que se registra contablemente correspondiente a la orden de operación No 001 acreditando la cuenta correspondiente a derechos fiduciarios 1245 contra la cuenta 2205 proveedores nacionales debido al contrato realizado entre la empresa Concretos Beta y Asociados S.A y la unión temporal mejores vías 2015 por suministro de cemento para la ejecución del objeto contractual. 
Así mismo el cuarto movimiento realizado en la operación fiduciaria No 001 por la unión temporal mejores vías 2015 corresponde a los gastos administrativos de nómina durante los meses de octubre y noviembre que asumió la unión temporal por lo tanto en el registro contable se implementan las cuentas 1245 contra la cuenta 1105 de La Unión Temporal Mejores Vías 2015. De acuerdo con el caso anterior la unión temporal Mejores vías 2015 realiza ordenes operación para lograr ejecutar las actividades contractuales hasta lograr cumplir con el 50\% del anticipo y liquidar el contrato fiduciario.

Ahora bien, la unión temporal debe seguir realizando actividades correspondientes para la ejecución del objeto contractual para esto la unión temporal mejores vías 2015 mediante cortes parciales de obra va cobrando a la entidad estatal los recursos necesarios.

De acuerdo a lo anterior la unión temporal mejores vías 2015 realiza compras de los materiales necesarios para la ejecución optima del objeto contractual como se logra evidenciar en la siguiente tabla:

Tabla 14.Compras de Materiales Primer Corte Unión Temporal Mejores Vías 2015.

\begin{tabular}{|cccl|}
\hline \multicolumn{4}{|c|}{ Resumen Materiales 1 Corte } \\
Materiales & Cantidades & Valor \\
\hline Cemento & 850 bultos & $\$$ & 300.000 .000 \\
Arena & $250 \mathrm{~m}$ & $\$$ & 150.000 .000 \\
Grava & $250 \mathrm{~m}$ & $\$$ & 120.000 .000 \\
Hierro & $280 \mathrm{~m}$ & $\$$ & 230.000 .000 \\
Adoquin & 1.700 Unidades & $\$ 1$ & 12.000 .000 \\
Sardinel & 2.000 Unidades & $\$ 1$ & 120.000 .000 \\
tubos de alcantarillado & 700 Unidades & $\$$ & 150.000 .000 \\
\hline \multicolumn{3}{|c}{ Total } & $\$ 1.182 .000 .000$ \\
\hline
\end{tabular}

NOTA: Cantidades y costos de materiales, por Luis Sebastián Avella, Martínez, 2018

Ahora bien, se procede a realizar el registro contable de la compra de los materiales los cuales se 
cancelaron de contado como se puede visualizar en el siguiente Tabla 15 el registro contable de las compras mencionadas anteriormente:

Tabla 15. Registro contable No 3, Compras de materiales primer corte unión temporal mejores vías 2015.

\begin{tabular}{|l|c|c|}
\hline \multicolumn{3}{|c|}{ Unión Temporal Mejores Vías 2015 } \\
\hline \multicolumn{1}{|c|}{ Cuenta } & Debito & Crédito \\
\hline 140505 Materias Primas Cemento & 300.000 .000 & \\
\hline 140510 Materias Primas Arena & 150.000 .000 & \\
\hline 140515 Materias Primas Grava & 120.000 .000 & \\
\hline 140520 Materias Primas Hierro & 230.000 .000 & \\
\hline 140525 Materias Primas Adoquín & 112.000 .000 & \\
\hline 140530 Materias Primas Sardinel & 120.000 .000 & \\
\hline 140535 Materias Primas Tubos de Alcantarillado & 150.000 .000 & \\
\hline 236540 Retención en la Fuente Por Compras Generales & & 295.500 .000 \\
\hline 110505 Caja General & & 886.500 .000 \\
\hline Sumas Iguales & 1.182 .000 .000 & 1.182 .000 .000 \\
\hline
\end{tabular}

NOTA: Registros contables de los materiales, por Luis Sebastián Avella, Martínez, 2018

Ahora cómo se logra visualizar en la Tabla 15 con el registro contable la unión temporal maneja la subcuenta 1405 Materias primas de la cuenta 14 inventario. Esto se debe que la obra no ha finalizado y se encuentra en ejecución, así mismo se le aplica la tarifa de retención que corresponda.

De igual forma a medida que la obra está en ejecución los materiales del inventario se van utilizando y los registros contables para la unión temporal van hacer los siguientes:

- El 20 de diciembre la unión temporal mejores vías 2015 durante la ejecución del objeto contractual utilizo el $60 \%$ de los siguientes materiales:

Tabla 16.Registro Contable No 4, Salida De Materia Prima Del Inventario Unión Temporal Mejores Vías 2015. 


\begin{tabular}{|l|c|c|}
\hline \multicolumn{2}{|c|}{ Unión Temporal Mejores Vías 2015 } \\
\hline \multicolumn{1}{|c|}{ Cuenta } & Debito & Crédito \\
\hline 140505 Materias Primas Cemento & & 180.000 .000 \\
\hline 140510 Materias Primas Arena & & 90.000 .000 \\
\hline 140515 Materias Primas Grava & & 72.000 .000 \\
\hline 140520 Materias Primas Hierro & & 138.000 .000 \\
\hline 140525 Materias Primas Adoquín & & 67.200 .000 \\
\hline 140530 Materias Primas Sardinel & & 72.000 .000 \\
\hline 140535 Materias Primas Tubos de Alcantarillado & & 90.000 .000 \\
\hline 142005 Contratos en Ejecución & 709.200 .000 & \\
\hline Sumas Iguales & $\mathbf{7 0 9 . 2 0 0 . 0 0 0}$ & $\mathbf{7 0 9 . 2 0 0 . 0 0 0}$ \\
\hline
\end{tabular}

NOTA: Registros contables de inventario, por Luis Sebastián Avella, Martínez, 2018

Como se puede evidenciar en el registro contable en la Tabla 16, las materias primas se acreditan la cuenta 1405 contra la cuenta contratos en ejecución 1420.

Se considera de suma importancia tener en cuenta el factor humano el cual labora en la ejecución del objeto contractual está conformado de la siguiente manera al 30 de diciembre del 2015:

Tabla 17. Gastos Administrativos Unión Temporal Mejores Vías 2015 a diciembre.

\begin{tabular}{|c|l|c|}
\hline \multicolumn{3}{|c|}{ Gastos Administrativos Union temporal Mejores Vias } \\
2015 a Diciembre \\
\hline No Trabajadores & \multicolumn{1}{|c|}{ Cargos } & Valor \\
\hline 1 & Director de Obra & $\$ 4.500 .000$ \\
\hline 1 & Residente de Obra & $\$ 3.700 .000$ \\
\hline 1 & Inspector de Obra & $\$ 3.500 .000$ \\
\hline 20 & Ayudantes de Obra & $\$ 16.000 .000$ \\
\hline 1 & HSEQ & $\$ 2.000 .000$ \\
\hline 2 & Celador de Obra & $\$ 2.000 .000$ \\
\hline \multicolumn{2}{|c|}{ Total } & $\mathbf{3 1 . 7 0 0 . 0 0 0}$ \\
\hline
\end{tabular}

NOTA: Cuantía por cargo dentro de la Unión Temporal Mejores vías, por Luis Sebastián Avella, Martínez, 2018

Con base a lo anterior la unión temporal mejores vías 2015 realizo el correspondiente nomina aplicando las tarifas correspondientes a la Ley 3743 de 1950 expresadas en el primer y segundo capítulo del Código Sustantivo Del Trabajo. 
Tabla 18. Comprobante De Pago Nomina General Unión Temporal Mejores Vías 2015 Periodo Diciembre.

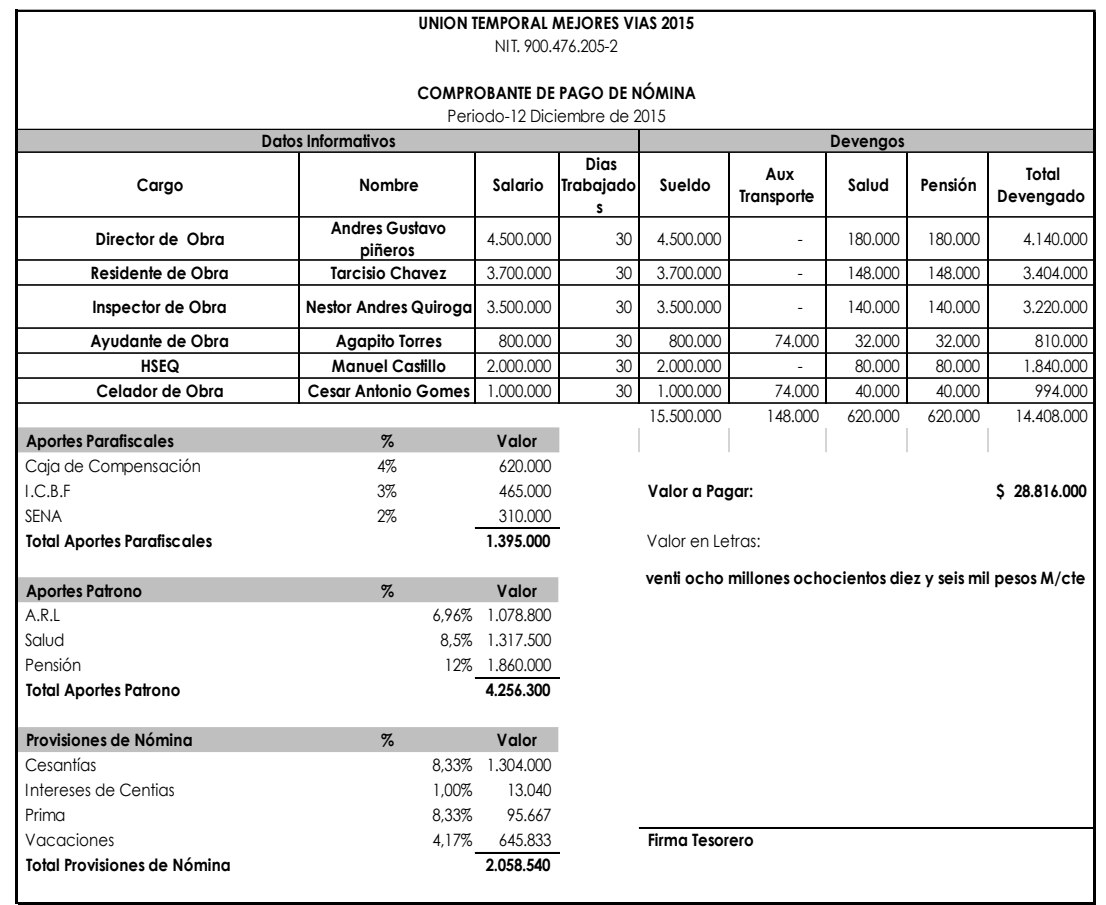

NOTA: Discriminación de la nómina de la Unión temporal Mejores vías, por Luis Sebastián Avella, Martínez, 2018

Teniendo como base la nómina anterior en la Tabla 18 para este caso se realizará el registro contable de un empleado para este caso la nómina del ayudante de obra Agapito Torres. 
Tabla 19. Comprobante De Pago Nomina Empleado Agapito Torres, Unión Temporal Mejores Vías 2015 Periodo Diciembre.

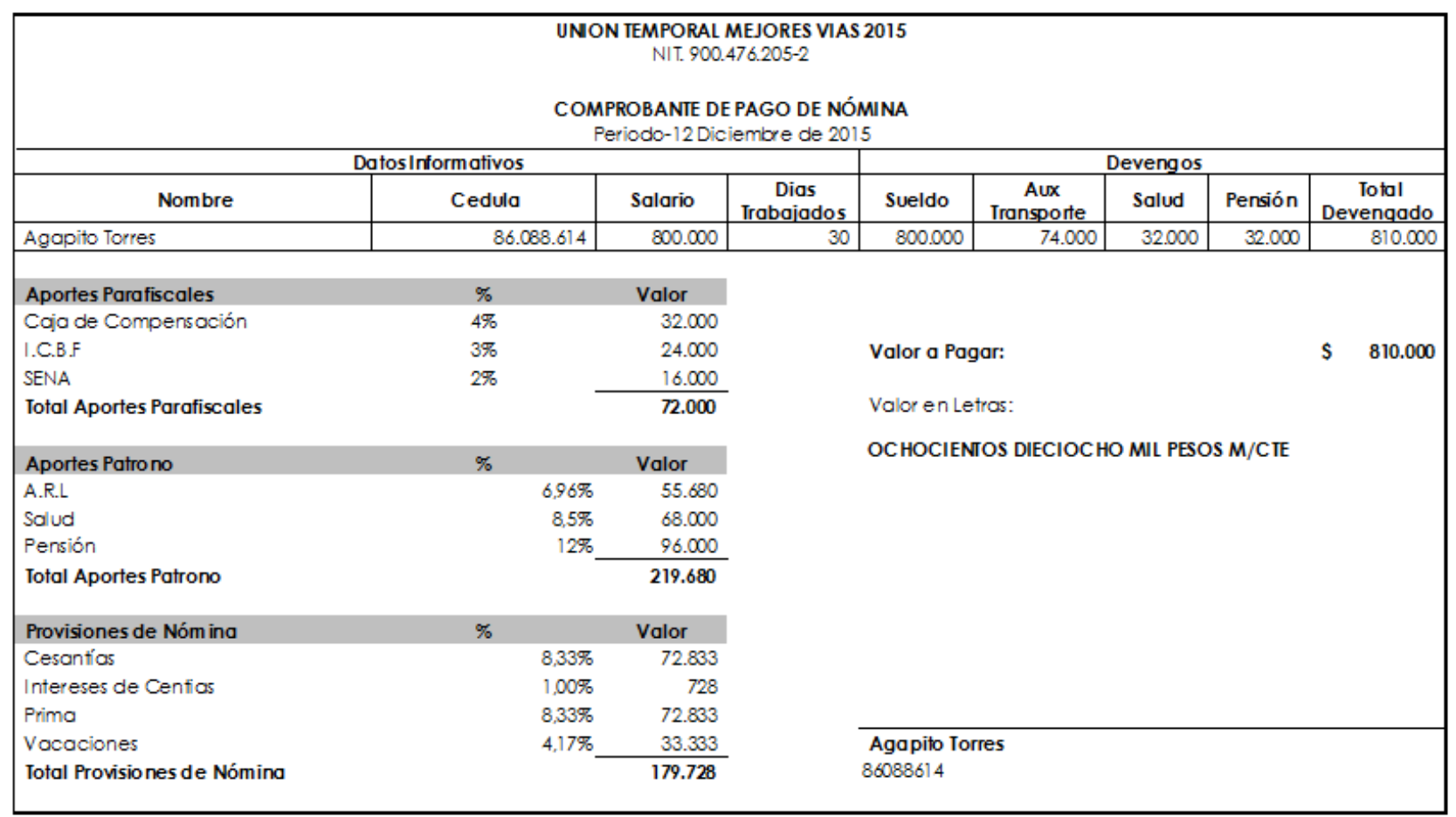

NOTA: Discriminación de la nómina de la Unión temporal Mejores vías, por Luis Sebastián Avella, Martínez, 2018

Como se logra visualizar en la Tabla 19 de nómina del ayudante de obra Agapito Torres se aplican porcentajes de ley correspondientes a las prestaciones sociales y parafiscales en la contabilidad de la unión temporal mejores vías 2015. 
Tabla 20. Registro Contable No 5, Nomina Periodo Diciembre Empleado Agapito Torres Unión Temporal Mejores Vías 2015.

\begin{tabular}{|c|c|c|c|}
\hline \multicolumn{4}{|c|}{$\begin{array}{c}\text { Unión Temporal Mejores Vías } 2015 \\
\text { Comprobante de Nomina } \\
\text { Diciembre } 2015\end{array}$} \\
\hline Cuenta & Tercero & Debito & Crédito \\
\hline 510506 Sueldos & Agapito Torres & 800.000 & \\
\hline 510527 Auxilio de Transporte & Agapito Torres & 74.000 & \\
\hline 237005 Aporte a Salud & Eps El Moribundo & & 32.000 \\
\hline 238030 Aportes a Pensión & El Abuelo Colombiano & & 32.000 \\
\hline 250501 Salario por Pagar & Agapito Torres & & 810.000 \\
\hline 510568 Aportes a ARP & Arl La Pierna Rota & 55.680 & \\
\hline 237006 Aportes a ARP & Arl La Pierna Rota & & 55.680 \\
\hline 510568 Aportes Salud & Eps El Moribundo & 68.000 & \\
\hline 237005 Aportes a Salud & Eps El Moribundo & & 68.000 \\
\hline 510570 Aportes a Fondos de Pensión y Cesantías & El Abuelo Colombiano & 96.000 & \\
\hline 238030 Aportes Pensión & El Abuelo Colombiano & & 96.000 \\
\hline 510572 Aportes a Cofrem & Cofrem & 32.000 & \\
\hline 237010 Aporte a Cofrem & Cofrem & & 32.000 \\
\hline 510575 Aporte a ICBF & ICBF & 24.000 & \\
\hline 237010 Aportes a ICBF & ICBF & & 24.000 \\
\hline 510578 Aportes a SENA & SENA & 16.000 & \\
\hline 237010 Aportes a SENA & SENA & & 16.000 \\
\hline 510530 Cesantías & El Abuelo Colombiano & 72.833 & \\
\hline 261005 Cesantías & El Abuelo Colombiano & & 72.833 \\
\hline 510533 Intereses de Cesantías & El Abuelo Colombiano & 728 & \\
\hline 261010 Interese Sobre Cesantías & El Abuelo Colombiano & & 728 \\
\hline 510536 Prima de Servicios & Agapito Torres & 72.833 & \\
\hline 261020 Prima & Agapito Torres & & 72.833 \\
\hline 510539 Vacaciones & Agapito Torres & 33.333 & \\
\hline 261015 Vacaciones & Agapito Torres & & 33.333 \\
\hline \multicolumn{2}{|l|}{ Sumas Iguales } & 1.345 .407 & 1.345 .407 \\
\hline
\end{tabular}

NOTA: Registro contables de parafiscales y seguridad social de la Unión Temporal Mejores vías, por Luis Sebastián Avella, Martínez, 2018

Ahora bien, como se logra visualizar en el anterior registro contable expresado en la Tabla 20 de nómina de uno de los empleados que labora en La Unión Temporal Mejores Vías 2015, en el ejercicio las cuentas correspondientes a gastos de nómina 5105 Gastos de personal y en contra partida las cuentas correspondientes a las retenciones y aportes de nómina 2370 y 2610.

De igual forma es importante mencionar que las obras de construcción poseen otros costos y gastos elementales para su ejecución entre los cuales se pueden clasificar como CIF, tal como se señala en la siguiente información: 
- La unión Temporal mejores vías 2015 alquila por 3 meses maquinaria amarilla correspondiente a retroexcavadora hidráulica 320 , rana 210 , motoniveladora $120 \mathrm{~K}$, bomba de concreto por un valor de $1.750 .000 .000 \mathrm{~m} /$ cte a la empresa SU MOTOR S.A.

- De igual forma la empresa cobra honorarios por el manejo de operarios de maquinaria pesada correspondiente a $12.400 .000 \mathrm{~m} / \mathrm{cte}$.

- Así mismo la unión temporal tomo por arriendo una casa con bodega en la cual dispondrá para la oficina administrativa y almacenamiento de materiales para la ejecución del objeto contractual por un valor de 1.500 .000 durante 6 meses y sus servicios mensuales correspondientes a:

1. Agua y alcantarillado por valor de 112.000 mensual

2. Luz por valor de 240.000 mensual

3. Teléfono e internet 350.000 mensual

De acuerdo a la información anterior la unión temporal mejores vías 2015 procede a realizar los correspondientes registros contables con se observa a continuación. Tabla 21.

Tabla 21.Registro Contable No 6, CIF 1, Unión Temporal Mejores Vías 2015.

\begin{tabular}{|l|c|c|}
\hline \multicolumn{3}{|c|}{ Unión Temporal Mejores Vias 2015 } \\
\hline \multicolumn{1}{|c|}{ Cuenta } & Debito & Crédito \\
\hline 142010 Contratos en Ejecución CIF & 1.750 .000 .000 & \\
\hline 233515 Alquiler de Maquinaria Amarilla & & 1.715 .000 .000 \\
\hline 236530 Retención Bienes Muebles & & 35.000 .000 \\
\hline Sumas Iguales & $\mathbf{1 . 7 5 0 . 0 0 0 . 0 0 0}$ & $\mathbf{1 . 7 5 0 . 0 0 0 . 0 0 0}$ \\
\hline
\end{tabular}

NOTA: Cuantías No.6, CIF 1, por Luis Sebastián Avella, Martínez, 2018

Para este movimiento es pertinente recordar que la tarifa de retención por bienes mueble equivale al 2\% e implementado las cuentas 1420 correspondiente a contratos en ejecución contra la cuenta por pagar correspondiente al alquiler del bien mueble. Tabla 22. 
Tabla 22.Registro Contable No 7, CIF 2, Unión Temporal Mejores Vías 2015.

\begin{tabular}{|l|c|c|}
\hline \multicolumn{3}{|c|}{ Unión Temporal Mejores Vías 2015 } \\
\hline \multicolumn{1}{|c|}{ Cuenta } & Debito & Crédito \\
\hline 142010 Contratos en Ejecución CIF & 12.400 .000 & \\
\hline 233520 Honorarios de Obras & & 11.036 .000 \\
\hline 236535 Retencion Honorarios de Obra & & 1.364 .000 \\
\hline Sumas Iguales & 12.400 .000 & 12.400 .000 \\
\hline
\end{tabular}

NOTA: Cuantías No.7, CIF 2, por Luis Sebastián Avella, Martínez, 2018

Ahora bien, como se logra percibir en el anterior registro expresado en la Tabla 22 se implementaron las cuentas correspondientes a los contratos en ejecución contra la cuenta por pagar a los prestadores de servicios con su respectiva retención para esto es preciso señalar que equivale al $11 \%$.

Tabla 23.Registro Contable No 8, CIF 3, Unión Temporal Mejores Vías 2015.

\begin{tabular}{|l|c|c|}
\hline \multicolumn{3}{|c|}{ Unión Temporal Mejores Vías 2015 } \\
\hline \multicolumn{1}{|c|}{ Cuenta } & Debito & Crédito \\
\hline 142010 Contratos en Ejecución CIF & 1.500 .000 & \\
\hline 233540 Arrendamientos bienes inmuebles & & 1.447 .500 \\
\hline 236540 Retención arrendamiento bien inmueble & & 52.500 \\
\hline Sumas Iguales & 1.500 .000 & 1.500 .000 \\
\hline
\end{tabular}

NOTA: Cuantías No.8, CIF 3, por Luis Sebastián Avella, Martínez, 2018

Como se logra observar en la Tabla 23 la cuenta por pagar a terceros correspondiente a servicio de arrendamiento de la casa- bodega al crédito contra la cuenta 1420 contratos en ejecución.

Así mismo es pertinente mencionar que durante la ejecución de contratos de construcción de obras civiles y arquitectónicas contraen costos como son compras de materiales fundamentales para la ejecución del objeto contractual y gastos de administración como son la nómina, servicios públicos y asesorías de profesionales.

De acuerdo a lo anterior se realizarán los correspondientes registros contables que incurrió la unión temporal mejores vías 2015 en la casa - bodega arrendada en el mes de diciembre. 
Tabla 24.Registro Contable No 9, CIF 4, Unión Temporal Mejores Vías 2015.

\begin{tabular}{|l|c|c|}
\hline \multicolumn{3}{|c|}{ Unión Temporal Mejores Vias 2015 } \\
\hline \multicolumn{1}{|c|}{ Cuenta } & Debito & Crédito \\
\hline 513525 Acueducto y alcantarillado & 112.000 & \\
\hline 513530 Energia Eléctrica & 240.000 & \\
\hline 513535 Telefonia e internet & 350.000 & \\
\hline 110505 Caja General & & 702.000 \\
\hline Sumas Iguales & 702.000 & 702.000 \\
\hline
\end{tabular}

NOTA: Cuantías No.9, CIF 4, por Luis Sebastián Avella, Martínez, 2018

Ahora bien, para finalizar la unión temporal mejores vías 2015 decide realizar un cobro equivalente al $25 \%$ de ejecución del objeto contractual mediante la siguiente factura anexada al acta parcial ante la entidad como se logra evidenciar a continuación. 


\begin{tabular}{|c|c|c|c|}
\hline \multirow{4}{*}{ 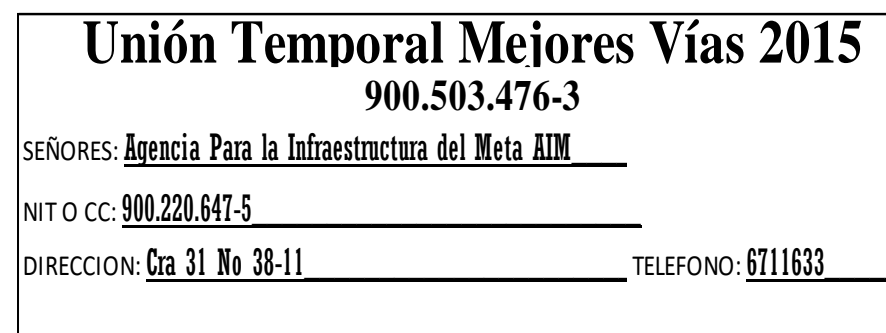 } & \multicolumn{3}{|c|}{$\begin{array}{l}\text { FACTURA DE VENTA } \\
\text { NO '001 }\end{array}$} \\
\hline & \multicolumn{3}{|c|}{$\mathrm{FECHA}$} \\
\hline & DIA & MES & AÑOO \\
\hline & 30 & 12 & 2015 \\
\hline
\end{tabular}

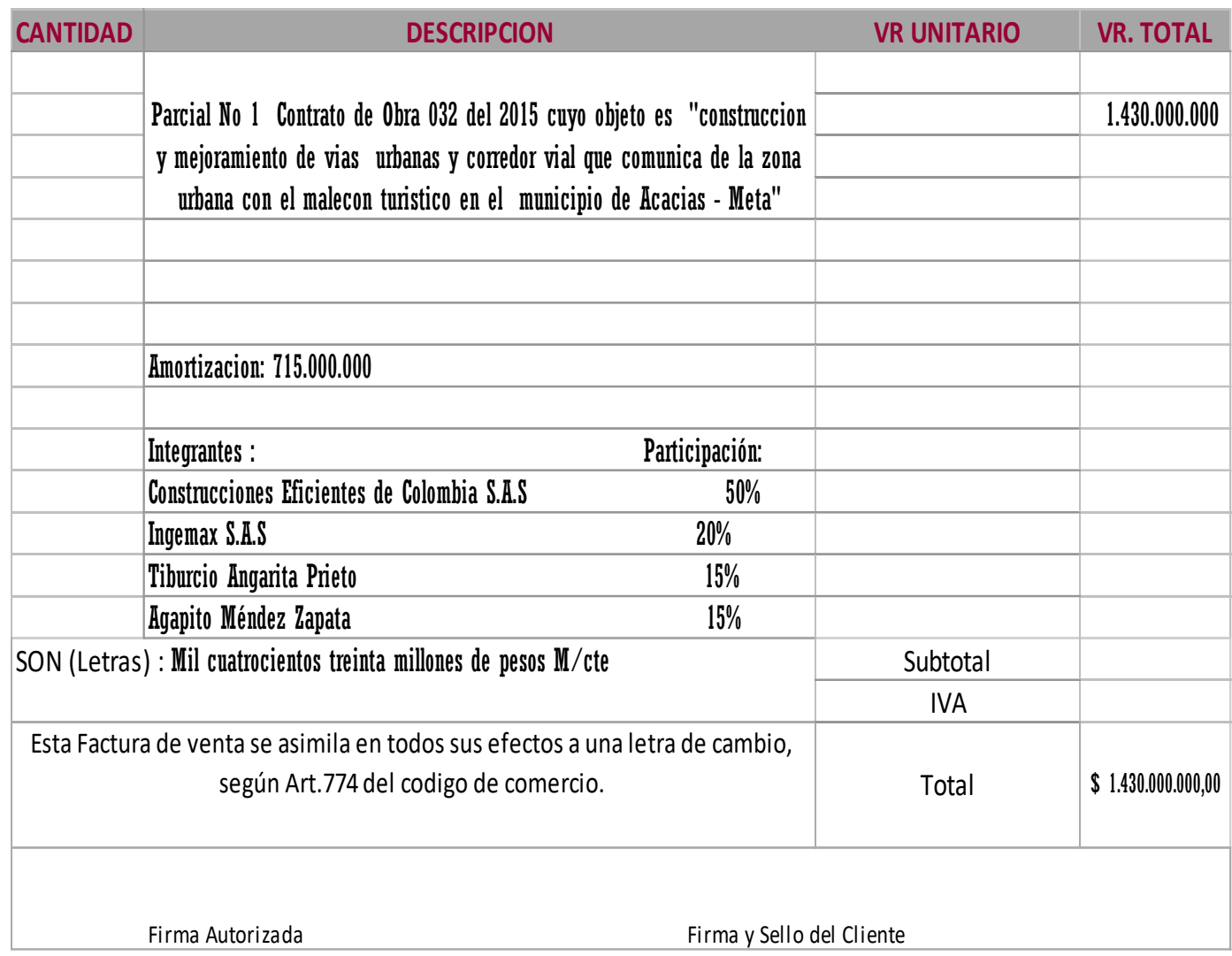

Figura 7. Factura De Venta 001 Parcial No 1 Unión Temporal Mejores Vías 2015., por Luis Sebastián Avella, Martínez, 2018.

Como se logra evidenciar en el ejercicio, la factura anexada por la unión temporal mejores vías 2015 en la cual cobran todos los costos y gastos significativos para la efectiva ejecución del objeto contractual, como algunos como casos que se mencionaron anteriormente.

De igual forma en la factura se logra identificar un cobro por un valor de $\$ 1.430 .000 .000$ y este valor se amortiza ya que al inicio de la obra se recibió un anticipo del 50\% correspondiente por el valor del contrato por lo tanto en cada parcial que la unión temporal mejores vías 2015 realizara la correspondiente amortización hasta completar el valor del anticipo. 
En segunda instancia la unión temporal no declara el impuesto de renta y complementarios como lo expresa el artículo 20 de la ley 1819 del 2016 que los contratos de colaboración empresarial tales como consorcios y uniones temporales, no son contribuyentes al impuesto de renta y complementarios (Direccion de Impuestos y Aduanas Nacionales (DIAN), 2017).

En cuanto el impuesto de valor agregado IVA ya que como se expresa en el artículo 100 de la Ley 21 de 1992 los contratos que se celebren con entidades públicas o territoriales de orden departamental y municipal está excluido de IVA razón por la cual en el ejercicio en la factura la unión temporal no puede hacer el cobro de este impuesto.

Ahora bien, es permitente señalar como la unión temporal mejores vías 2015 se procede a realizar el correspondiente registro contable de la factura 001 a la entidad estatal una vez esta sea aprobada.

Tabla 25.Registro Contable No 10, Factura 001 Parcial 1, Unión Temporal Mejores Vías 2015.

\begin{tabular}{|l|c|c|}
\hline \multicolumn{3}{|c|}{ Unión Temporal Mejores Vías 2015 } \\
\hline \multicolumn{1}{|c|}{ Cuenta } & Debito & Crédito \\
\hline $\begin{array}{l}\text { 413010 Construcción de Edificios y Obras } \\
\text { de Ingenieria Civil }\end{array}$ & & 1.430 .000 .000 \\
\hline 130505 Clientes Nacionales & 1.430 .000 .000 & \\
\hline Sumas Iguales & 702.000 & 702.000 \\
\hline
\end{tabular}

NOTA: Cuantías No.10, Factura 001 parcial, por Luis Sebastián Avella, Martínez, 2018

Como se puede evidenciar en la Tabla 25 se acredita la cuenta 413010 la cual corresponde a la cuenta relacionada con contratos de edificios y obras de ingeniería civil contra la cuenta por cobrar a clientes nacionales 130505 en este caso la AIM.

Ahora bien, el 15 de enero de 2016 la agencia para la infraestructura del meta AIM realiza la correspondiente viabilidad de la parcial y realiza el correspondiente pago a la unión temporal mejores vías 2015 mediante el siguiente comprobante de egreso. 


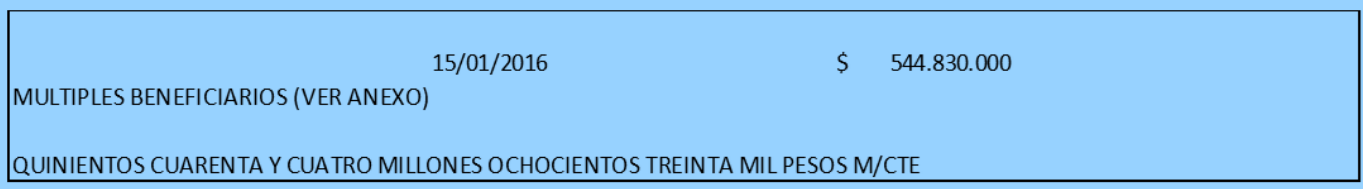

AGENCIA PARA LA INFRAESTRUCTURA DEL META - AIM

CRA 31 NO 38-41 EDIFICIO NIZA CENTRO

NIT : 900220547-5

COMPROBANTE DE EGRESO NO 407

VILLAVICENCIO

BENEFICIARIO: MULTIPLES BENEFICIARIOS

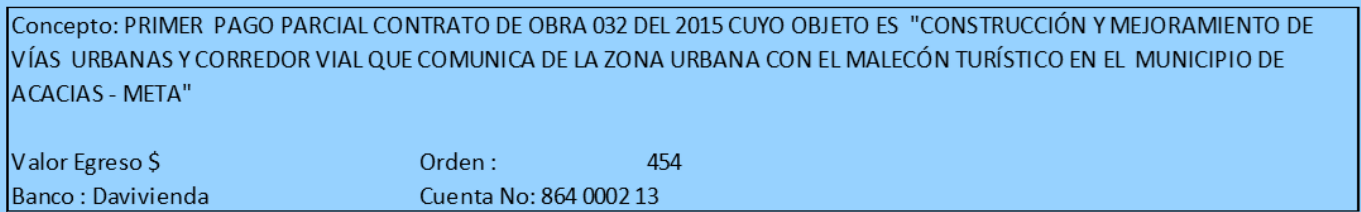

Banco : Davivienda

Cuenta No: 864000213

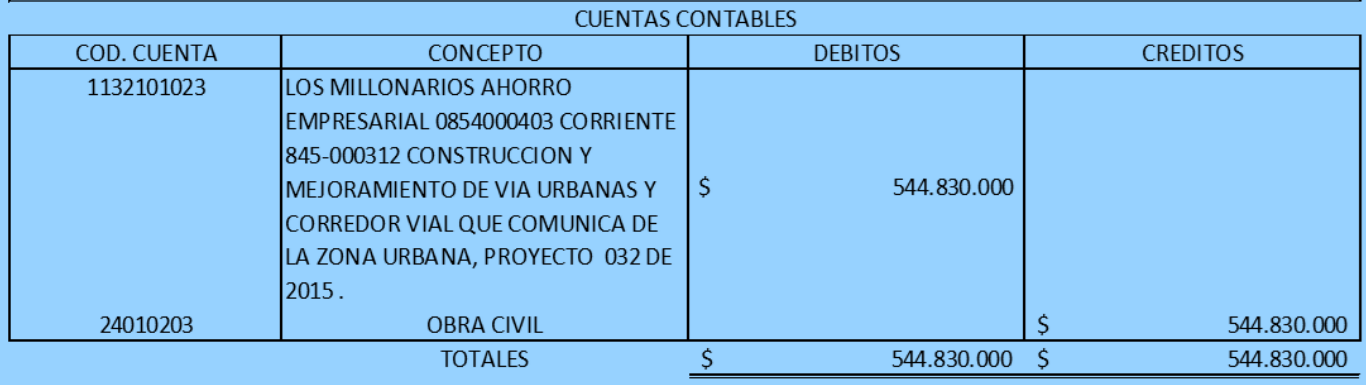

\begin{tabular}{|l|c|c|c|}
\hline \multicolumn{5}{|c}{ CUENTAS DE PLANEACION Y PREACION Y PRESUPUESTO } \\
\hline COD. CUENTA & CONCEPTO & DEBITOS & CREDITOS \\
\hline
\end{tabular}

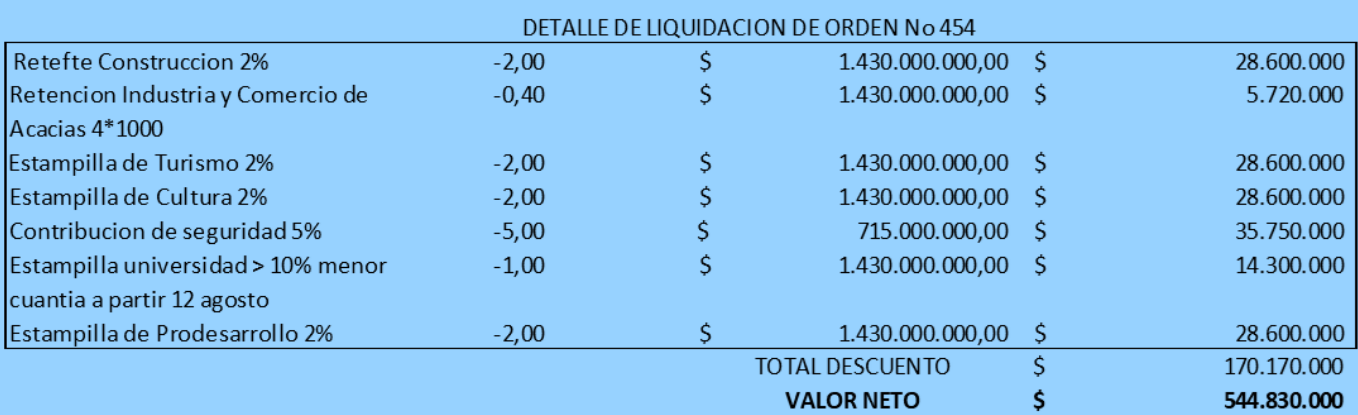

RICARDO ENRIQUE FLORES

ELABORO
SARA MARCELA ANGARITA TORRES

TESORERO

Figura 8. Comprobante De Egreso 407 Parcial No 1 a Favor de La Unión Temporal Mejores Vías 2015, por Luis Sebastián Avella, Martínez, 2018

Como se puede visualizar en la Figura 8 correspondiente al comprobante de egreso No 407 girado a por la agencia para la infraestructura del meta AIM para la Unión Temporal Mejores Vías 2015; 
El día 15 de enero del 2016 hace el siguiente registro contable en un comprobante de ingreso.

Tabla 26. Registro Contable No 11, Comprobante de Egreso 407, Unión Temporal Mejores Vías 2015.

\begin{tabular}{|c|c|c|}
\hline \multicolumn{3}{|c|}{ Unión Temporal Mejores Vías 2015} \\
\hline Cuenta & Debito & Crédito \\
\hline 13050501 Clientes & & 1.430 .000 .000 \\
\hline 61301511 Pro Universidad & 14.300 .000 & \\
\hline 13550501 Impuesto de Renta & 28.600 .000 & \\
\hline 61301502 Pro Turismo & 28.600 .000 & \\
\hline 61301504 Pro Cultura & 28.600 .000 & \\
\hline 61301503 Pro Desarrollo & 28.600 .000 & \\
\hline 61301502 Fondo Local de Seguridad & 35.750 .000 & \\
\hline 13551002 Anticipo Industria y Comercio & 5.720 .000 & \\
\hline 28051001 Anticipo Obras Ingeniería Civil & 715.000 .000 & \\
\hline 11200501 El Millonario Cta Ahorros No 096 & 544.830 .000 & \\
\hline Sumas Iguales & 1.430 .000 .000 & 1.430 .000 .000 \\
\hline
\end{tabular}

NOTA: Cuantía de egresos de la Unión Temporal Mejores Vías, por Luis Sebastián Avella, Martínez, 2018

Como se evidenciar en la Tabla 26 correspondiente al registro contable del comprobante de egreso No 407 se registran en las cuentas pertinentes todos los descuentos correspondientes a estampillas que se le pagan al gobierno, retención en la fuente y retención al impuesto de industria y comercio dependiendo de las tarifas que maneje el municipio, como se logra evidenciar en el registro contable se acredita la cuenta 13050501 correspondiente a clientes nacionales contra las cuentas correspondientes a los descuentos como son las estampillas pro turismo, pro cultura, pro desarrollo debitadas bajo la cuenta 6130 costos de construcción ya que para poder ejecutar el objeto contractual el municipio exige que se realicen estos aportes.

Así mismo en este caso la entidad contratante posee un convenio con el municipio en donde se está ejecutando la obra civil la cual va deduciendo en cada parcial que se cobre un anticipo correspondiente al impuesto de industria y comercio y así mismo la retención en la fuente correspondiente a contratos de construcción utilizando las cuentas 1355 cuentas correspondiente 1355 anticipos de impuestos y contribuciones o saldos a favor al débito.

De igual forma es pertinente mencionar que en el comprobante de egreso no $407 \mathrm{y}$ en el registro contable contables se debita la cuenta correspondiente a la amortización del $50 \%$ del valor inicial de la factura equivalente al anticipo del contrato bajo la cuenta 280510 anticipos y avances recibidos con naturaleza debito para el caso. 
Para finalizar el registro es importante mencionar el saldo cuyo resultado se calcula después de aplicar los descuentos y retenciones de ley se registran bajo la cuenta 112005 cuenta de ahorros con movimiento débito.

Ahora bien, en Colombia el gran porcentaje de los contratos de construcción que se ejecutan bajo recursos de entidades públicas poseen demoras en la ejecución de los objetos contractuales ya sea por índoles administrativos del contratante, del contratista o causas fortuitas.

Para este ejercicio la unión temporal mejores vías 2015 solicito una prórroga de 6 meses a la entidad contratante debido a la falta de diseños y el mal clima la cual fue aprobada por la interventoría y la entidad contratante para poder ejecutar el $60 \%$ del contrato restante.

De igual forma, para el ejercicio planteado los integrantes que conforman la unión temporal mejores vías 2015 solicitan un certificado de ingresos y retenciones que tuvo la unión temporal con el fin de recopilar la información para sus correspondientes obligaciones tributarias como se logra evidenciar en el certificado tributario. 


\title{
El represe ntante legal y Contad or Público de UNION TEMPORAL MEJORES VIAS 2015
}

\author{
Nit. 900.476.205-2
}

Según lo establecido en el artícul o 18 del estatuto tributario "Los contratos de col aboraci ón empresarial tales como consorcios, uni ones temporales, no son contribuyentes del impuesto sobre la renta y complementarios. Las partes en el contrato de colaboración empresarial, deberán declarar de manera independiente los activos, pasivos, ingresos, costos y deducciones que les correspondan, de acuerdo con su participaci ón en los activos, pasivos, ingresos, Costos y gastos incurridos en desarrollo del contra to de col aboraci ón empresarial. Para efectos tri butarios, las parter deberán llevar un registro sobre las mismo

\section{SE PERMITE CERTIFICAR QUE:}

1. Que mediante documento privado se constituyó la UNION TEMPORAL MEIORES VIAS 2015 para la ejecución del Contrato de obra 032 DEL 2015 Cuyo obje to es: "construccion y mejoramiento de vias urbanas y corredor vial que comunica de la zona urbana con el malecon turistico en el municipio de Acacias - Meta

2. Que mediante el documento de conformación de la UNION TEMPORAL MEJORES VIAS 2015 firmado el día treinta (30) de diciembre de 2015, los porcentajes de participación Son:

\begin{tabular}{|c|l|c|c|}
\hline ITEM & \multicolumn{1}{|c|}{ NOMBRES Y APELUDOS - RAZÓN SOCIAL } & IDEN TIFICACIÓN & \% PARCITIP \\
\hline 1 & Construcciones Eficientes de Colombia S.A.S & 900.846 .597 & $50 \%$ \\
\hline 2 & Ingemax S.A.S & 900.918 .354 & $20 \%$ \\
\hline 3 & Tiburcio Angarita Prieto & 86.076 .443 & $15 \%$ \\
\hline 4 & Agapito Méndez Zapata & 80.467 .098 & $15 \%$ \\
\hline
\end{tabular}

3. Que del dia 01 de enero al 31 de dicie mbre de 2015 , los valores registrados y acumulados en contabilidad son los siguientes:

\begin{tabular}{|l|l|l|r|r|r|}
\hline Código & \multicolumn{1}{|c|}{ NOMBRE } & ANT & \multicolumn{1}{c|}{ Déblto } & \multicolumn{1}{c|}{ Crédito } & \multicolumn{1}{c|}{ SALDO } \\
\hline 4 & INGRESOS & & & 0,00 & 0,00 \\
\hline 41 & OPERACIONALES & & & 0,00 & 0,00 \\
\hline 4130 & CONSTRUCCION & & & 0,00 & 0,00 \\
\hline 413010 & Construccion Edif. YObras Civ & & & 0,00 & 0,00 \\
\hline 41301001 & Construccion De EdifYObras C & & & 0,00 & 0,00 \\
\hline
\end{tabular}

\begin{tabular}{|c|l|r|r|c|}
\hline ITEM & \multicolumn{1}{|c|}{ NOMBRES Y APELUDOS-RAZÓN SOCIAL } & VALOR & PORCENTAJE & PARTICIPACION \\
\hline 1 & Construcciones Eficientes de Colombia S.A.S & 0,00 & $50 \%$ & - \\
\hline 2 & Ingemax S.A.S & 0,00 & $20 \%$ & - \\
\hline 3 & Tiburcio Angarita Prieto & 0,00 & $15 \%$ & - \\
\hline 4 & Agapito Méndez Zapata & 0,00 & $15 \%$ & - \\
\hline & & & $100 \%$ & - \\
\hline
\end{tabular}

\begin{tabular}{|c|c|c|c|c|c|}
\hline Códlgo & NOMBRE & ANT & Déblto & Crédito & SALDO \\
\hline 5 & GASTOS & & & & 0,00 \\
\hline 6 & COSTO DE VENTAS & & 3.200 .000 .000 & & $3.200 .000 .000,00$ \\
\hline & TOTAL & $0, \infty$ & $3.200 .000 .000,00$ & 0,00 & $3.200 .000 .000,00$ \\
\hline
\end{tabular}

\begin{tabular}{|c|l|c|c|r|}
\hline ITEM & \multicolumn{1}{|c|}{ NOMBRES Y APELUDOS - RAZÓN SOCIAL } & VALOR & PORCENTAJE & PARTICIPACION \\
\hline 1 & Construcciones Eficientes de Colombia S.A.S & $3.200 .000 .000,00$ & $50 \%$ & 1600.000 .000 \\
\hline 2 & Ingemax S.A.S & $3.200 .000 .000,00$ & $20 \%$ & 640.000 .000 \\
\hline 3 & Tiburcio Angarita Prieto & $3.200 .000 .000,00$ & $15 \%$ & 480.000 .000 \\
\hline 4 & Agapito Méndez Zapata & $3.200 .000 .000,00$ & $15 \%$ & 480.000 .000 \\
\hline & & & $100 \%$ & 3.200 .000 .000 \\
\hline
\end{tabular}

4. Que las retenciones practicadas por la GOBERNACIÓN DEL META con corte al 31 de diciembre del 2017 fue ron:

\begin{tabular}{|c|c|r|r|r|r|}
\hline Código & Cuenta & \multicolumn{1}{c|}{ SadoAnt. } & \multicolumn{1}{c|}{ Débito } & \multicolumn{1}{c|}{ Crédito } & Nuevo Sal do \\
\hline 13551001 & Industria y Comercio & 0,00 & 0,00 & 0,00 & 0,00 \\
\hline 13551501 & Retencion En La Fuente a títul o de renta & 0,00 & 0,00 & 0,00 & 0,00 \\
\hline & TOTAL & 0,00 & 0,00 & 0,00 & 0,00 \\
\hline
\end{tabular}

\begin{tabular}{|c|l|r|r|r|}
\hline ITEM & \multicolumn{1}{|c|}{ NOMBRES Y APELUDOS - RAZÓN SOCIAL } & VALOR & PORCENTAJE & PARTICIPACION \\
\hline 1 & Construcciones Eficientes de Colombia S.A.S & 0,00 & $50 \%$ & 0,00 \\
\hline 2 & Ingemax S.A.S & 0,00 & $20 \%$ & 0,00 \\
\hline 3 & Tiburcio Angarita Prieto & 0,00 & $15 \%$ & 0,00 \\
\hline 4 & Agapito Mendez Zapata & 0,00 & $15 \%$ & 0,00 \\
\hline & & & $100 \%$ & - \\
\hline
\end{tabular}

Para efectos de impuesto de INDUSTRIA Y COMERCIO ICO se pagará en cabeza de la UNION TEMPORAL MEJORES VIAS 2015 en los plazos correspondientes establecidos por la Admi nistración Tributaria. NOTA: NO se han pagado las retenciones en la fuente que practicó el LA UNION TEMPORAL MEJORES VIAS 2015 los distintos proveedores con quienes tuvo relaciones comerciales; esto por disposiciones de la gerencia de la empresa, excl uyendo de responsabilidad el departamento contable.

Dada en el munici pio de Villavicencio de partamento del Meta, a los veintidós (22) dlas del mes de febrero de dos mil diecisiete (2016)

JORGE REINALDO TORRES REPRESENTANTE LEGAL

C.C. No 80.567 .545 de VIll avicenclo (Meta)
CAMILA VACA CONTADOR PÚBLICO

TP 267454-7

Figura 9. Certificado De Ingresos Y Retenciones Unión Temporal Mejores Vías 2015 Periodo 2015, por Luis Sebastián Avella, Martínez, 2018 
Como se evidencia en el certificado de ingresos y retenciones emitido por la unión temporal Mejores vías 2015 se pude detallar los principales movimientos que tuvo en el periodo 2015 para el conocimiento y fines pertinentes a cada uno de los partícipes de la unión temporal.

Como se logra evidenciar la unión temporal en el año 2015 no tuvo ingresos por lo cual en el certificado no expresa valor en este certificado ya que el único recurso que recibió la unión temporal mejores vías para ejecutar el proyecto fue el porcentaje correspondiente al valor del anticipo.

De igual forma para tener coherencia con el ejercicio los cada uno de los unionistas que participan en la unión temporal mejores vías 2015 realizan el siguiente registro contable para su contabilidad y la preparación de obligaciones tributarias, como se mencionó anteriormente los contratos de colaboración no presentan declaración renta y complementarios más si los unionistas y consorciados de acuerdo a la participación que tengan, que se reflejara en las cuentas 413095 actividades conexas es decir ingresos por participación en consorcios y uniones temporales igual para los costos y los gastos las cuentas 613015 acondicionamiento de edificios por participación de consorcios y uniones temporales.

Ahora bien, para finalizar el ejercicio en el cual se trató los principales registros contables que tuvo una unión temporal en la ejecución del objeto contractual.

Para la contabilización del ejercicio antes mencionado bajo los principios y normas generalmente aceptados en Colombia bajo el decreto 2649 y 2650 el tratamiento contable se puede registrar de dos formas dependiendo la perspectiva del contador sobre los gastos administrativos ya sea a los costos indirectos de fabricación o discriminando los costos de los gastos; estas decisiones están en plena libertad del departamento contable del consorcio o unión temporal siempre y cuando no vulnere las normas vigentes.

\subsection{Desarrollo fase 3}

La presente fase analiza las implicaciones del estándar internacional de contabilidad NIIF 15 para 
las empresas de la construcción y aborda casos prácticos del tratamiento contable, en especial de empresas que licitan con entidades públicas.

\subsubsection{Análisis las implicaciones de la NIIF 15 para las empresas de la construcción.}

Para analizar las implicaciones que trae la implementación del estándar internacional NIIF 15 en el sector de la construcción de las empresas que licitan con entidades estatales; se abordarán algunos expertos en la materia.

El consejero Dr. Luis Henry Moreno Moya perteneciente Consejo Técnico de Contaduría Pública, menciona las etapas de aplicación y consideraciones a tener en cuenta a la hora de implementar este estándar internacional de las NIIF 15 entre ellas son identificar el contrato con clientes, identificar las obligaciones de desempeño del contrato, determinar el precio de transacción utilizando los métodos que considere dentro del parágrafo 53 del estándar, asignar el precio de transacción a las obligaciones de desempeño, reconocer el ingreso cuando la entidad satisface una obligación de desempeño. De igual forma el experto menciona los principales cambios del estándar internacional respecto al tratamiento bajo decreto 2649 y 2650 los cuales son antes eran muchas reglas y poca aplicación de juicio, ahora más orientación y reglas; escritas y detalladas en cuento al reconocimiento del ingreso en un punto del tiempo o a lo largo del tiempo tal como se evidencia en los parágrafos 22 al 35 del estándar internacional, disgregación de los contratos, asignación de ingreso total o componentes disgregados de acuerdo al parágrafo 31 del estándar internacional y la fecha de aplicación para los periodos que inicien en o después del 1 de enero del 2018; sin embargo, hay una opción retrospectiva (con algunas soluciones prácticas), a todos los periodos presentados, o retrospectiva con el efecto acumulado reconocido al inicio del primer año de aplicación (sin reformulación de periodos anterior) (Comité Tecnico del Sector Real, 2018).

Así mismo el concejero Dr. Luis Henry Moreno Moya y el coordinador del grupo de regulación e investigación contable de la superintendencia de sociedades Mauricio Español León, mencionan algunos impactos que trae este estándar internacional NIIF 15 para su tratamiento contable como la supervisión de los contratos con clientes a nivel de sistemas, controles y procesos, compensaciones forma de hacer negocios y auditorias: 
a) Sistemas: la manera de registrar los ingresos podría cambiar en función del momento en que se satisfagan las obligaciones de desempeño.

b) Controles y procesos: la aprobación, seguimiento y cumplimiento de un contrato tendrá que ser más cuidadosa.

c) Compensaciones: los bonos dependen en ocasiones de los ingresos alcanzados; los cambios en el momento de reconocimiento de ingresos podrían impactar las metas logradas (Comité Tecnico del Sector Real, 2018).

d) Forma de hacer negocios: la celebración de los contratos se podría ver influenciada por ciertos indicadores de la empresa relacionada con el momento que se reconocen sus ingresos; (Comité Tecnico del Sector Real, 2018).

e) Auditorias: las auditorias tendrán que llevarse a cabo mediante una revisión más detallada y un mayor entendimiento del negocio (Comité Tecnico del Sector Real, 2018).

De igual forma la firma de auditoría Deloitte representada por el socio Daniel Bernal menciona los aspectos más relevantes al momento de aplicar una auditoría a este estándar internacional de contabilidad los cuales son para reconocer el ingreso, para la aplicación de la NIIF, consideraciones a tener en cuenta en la auditoría de la NIIF y asuntos relevantes en el proceso de implementación de la NIIF 15 (Comité Tecnico del Sector Real, 2018).

Teniendo en cuenta lo anterior y en concordancia con el aspecto de la aplicación de la NIIF 15 el experto Daniel Bernal menciona que se deben tener en cuenta elementos como identificar el contrato con los clientes, identificar las obligaciones de desempeño en el contrato, determinar el precio de transacción, asignar el precio de transacción a las obligaciones de desempeño y reconocer el ingreso cuando la entidad satisface una obligación de desempeño (Comité Tecnico del Sector Real, 2018).

Por otra parte, la firma de auditoria Deloitte a expedido una guía de implementación del estándar internacional NIIF 15 en la que se mencionan puntos elementales que se considera de suma importancia mencionar algunos de ellos como son:

- Es un estándar más complejo que introduce más requerimientos remplazando a la NIIF 11 contratos de construcción, NIC 18 Ingresos Ordinarios e interpretaciones relacionadas con 
esos estándares, por consiguiente, trajo cambios sustanciales a las políticas de reconocimiento de ingreso de muchas entidades (Deloitte Touche Tohmatsu Limited., 2018).

- Otra de los importantes cambios que trajo este estándar internacional es la cambio de la NIC 18 que proporcionaba criterios sobre el reconocimiento separados de bienes y servicios la cual es eliminada por el estándar internacional NIIF 15 ya que se centra en la identificación de obligaciones de desempeño; de igual forma la NIIF 15 los ingresos ordinarios pueden ser reconocidos con el tiempo para algunos entregables contabilizados (Deloitte Touche Tohmatsu Limited., 2018).

- De igual forma la firma de auditoria Deloitte menciona los principales cambios y consideraciones que las organizaciones debe tener en cuenta en la transición de la implementación del estándar internacional NIIF 15 para los contratos que inicien en o después del 1 de enero del 2018 ya que deberán tener en cuenta todos los requerimientos del estándar y potenciales impactos en la contabilidad como de toda la organización:

a) En cuanto el reconocimiento de ingresos y utilidad: si bien algunos estándares internacionales NIIF permitieron el juicio al idear y aplicar políticas y prácticas para el reconocimiento de los ingresos ordinarios la NIIF 15, es más prescriptiva en muchas áreas y la implementación de estas nuevas reglas dan como resultado importantes cambios en los ingresos ordinarios y al reconocimiento de los costos (Deloitte Touche Tohmatsu Limited., 2018).

b) En cuanto procesos actuales de contabilidad: la implementación de la NIIF 15 en las organizaciones trae con sigo nuevos requerimientos basado en un modelo de 5 pasos, la complejidad de aplicación y producción de este enfoque puede requerir la modificación de los procesos de contabilidad existentes por lo cual es necesario la implementación de estrategias para minimizar el impacto en la fijación de precios y variedad de oferta de productos realizados con los clientes (Deloitte Touche Tohmatsu Limited., 2018).

c) De igual forma es importante mencionar los impactos que se incurrirán en las organizaciones pueden ser afectadas en el proceso de transición del estándar internacional como son: 
- Capacitación de empleados: Las entidades deben proporcionar entrenamiento a los empleados afectados por los cambios como son los contadores, auditores internos, la junta directiva y los responsables por la elaboración de contratos con el cliente.

- Acuerdos de pago con entidades financieras: los cambios en los métodos de contabilidad para el reconocimiento de los ingresos ordinarios pueden cambiar la cantidad, oportunidad y presentación de los ingresos ordinarios, con el consiguiente impacto en utilidades y activos netos. Esto puede afectar los resultados financieros usados en el cálculo de los acuerdos de pago con bancos. Por lo tanto, las entidades afectadas deben buscar discusiones con los prestamistas, para establecer si será necesaria la re-negociación de acuerdos de pago (Deloitte Touche Tohmatsu Limited., 2018).

- Impacto en los indicadores de desempeño: Como se mencionó anteriormente los ingresos ordinarios y las utilidades reportadas pueden verse afectadas por el proceso de implementación del estándar internacional. Por lo tanto, las organizaciones deben evaluar el efecto que este trae en las razones financieras e indicadores de desempeño claves en la organización los cuales pueden ser impactados por los cambios razón por la cual se considera importante realizar un análisis y determinar si es necesario realizar ajustes y como estos se deben revelar ante la junta de socios o accionistas (Deloitte Touche Tohmatsu Limited., 2018).

- Planes de compensación y bonos: Como se mencionó anteriormente los bonos a los empleados se ven afectados ya que estos en algunas organizaciones dependen de la utilidad e ingresos ordinarios reconocidos, debido a esto se considera oportuno reevaluar los términos de los acuerdos de remuneración existentes cuando se considere pertinente (Deloitte Touche Tohmatsu Limited., 2018).

- Capacidad para pagar dividendos: En ciertas jurisdicciones, la capacidad para pagar dividendos a los accionistas es impactada por las utilidades reconocidas, las cuales a su vez son afectadas por la oportunidad del reconocimiento de los ingresos ordinarios. Cuando este sea el caso, las entidades necesitarán determinar si los cambios afectarán de manera importante la oportunidad de los ingresos ordinarios y el reconocimiento de la utilidad y, cuando sea apropiado, comunicar esto a los 
stakeholders y actualizar los planes de negocios (Deloitte Touche Tohmatsu Limited., 2018).

- Impuestos: en cuanto al pago de los impuestos y el reconocimiento dl impuesto diferido puede verse afectado debido a las diferencias en la oportunidad de reconocimiento de los ingresos ordinarios según el estándar internacional NIIF 15 y las diferentes políticas tributarias (Deloitte Touche Tohmatsu Limited., 2018).

- Stakeholders: usuarios de los estados financieros, tales como la junta de directores, comité de auditoría, analistas, inversionistas, acreedores y accionistas requerirán una explicación de los cambios en la NIIF 15 en orden a que entiendan cómo han sido impactados los estados financieros (Deloitte Touche Tohmatsu Limited., 2018).

Ahora bien cabe señalar en el proceso e implementación del estándar NIIF 15 que varios departamentos de las organizaciones se ven involucradas con el objetivo de realizar un buena planificación y seguimiento de este proceso para esto el buen gobierno organizacional deberá estar en armonía con los representantes de los diferentes departamentos como son: (contabilidad, finanzas, operaciones y abastecimiento, tecnología de la información, tesorería e impuestos y junta directiva como accionistas entre otros ); una vez hayan sido identificados los diferentes departamentos y responsables es de suma importancia establecer un cronograma de responsabilidades en donde se identifique las tareas correspondientes a cada departamento en el proceso de implementación de estándares internacionales de contabilidad.

De igual forma la firma Grant Thornton menciona que después de realizar el proceso de adopción del estándar internacional las empresas deberán tomar una serie de decisiones elementales para la transición y buen funcionamiento de la organización como son: actualización de manuales y políticas contables, elección de opción de transición, analizar los impactos contables y administrativos de la norma, analizar si se requieren cambios en los sistemas, procesos y controles (Deloitte touche Tohmatsu Limited, 2014).

Así mismo plantean que con el proceso de implementación del estándar internacional pueden surgir nuevas necesidades como son ¿Cómo incorporar el cálculo del componente financiero en 
contratos con un componente de financiación significativo?, ¿Cómo capturar la información necesaria para los desgloses requeridos en las cuentas anuales? Entre otros interrogantes dependiendo los diferentes contratos que existan (Deloitte touche Tohmatsu Limited, 2014).

De igual forma para el objeto del presente trabajo es necesario indagar las opiniones de los expertos que han estudiado la NIIF 15 en los contratos de construcción civil y arquitectónica y los principales cambios que trae este estándar internacional para el sector.

Como se mencionó anteriormente la firma de auditoria Deloitte realizó un documento en el cual señala las principales perspectivas del sector frente a la norma internacional los cuales se señalarán los más relevantes a continuación:

Entre las perspectivas más importantes para el sector de la construcción consiste en identificar los principales cambios que trae el estándar internacional en una organización. Para iniciar es una norma más prescriptiva la cual abarca varios aspectos relevantes en las organizaciones para el reconocimiento del ingreso y en algunos casos el costo; así mismo entre las implicaciones cabe resaltar: los cambios en los indicadores relevantes, cambios referentes al perfil de pago de impuesto efectivos, disponibilidad de beneficios para la distribución de accionistas, impacto en el tiempo que se genera la obligación de compensaciones basadas en el desempeño, impacto al momento de que se alcanzan los objetivos y la probabilidad en que se cumplan los objetivos e impacto en el cumplimiento (Deloitte touche Tohmatsu Limited, 2017).

De igual forma la firma de auditoria Deloitte soluciona incógnitas del estándar internacional dentro del sector de la construcción como son:

- ¿Debería reconocerse ingreso en el tiempo o en un momento dado?

Ahora bien, entre los grandes cambios que trajo el estándar internacional se considera necesario que el departamento de contabilidad de las organizaciones realice modificaciones al sistema de contabilidad existente o realizar procesos complementarios en los sistemas, para esto es necesario que las organizaciones dispongan del tiempo adecuado para realizar las acciones correspondientes (Deloitte touche Tohmatsu Limited, 2017).

De igual forma para el reconocimiento del ingreso en el tiempo el estándar plasma tres escenarios 
los cuales son: cuando el cliente recibe y consume los beneficios del producto o servicio en la medida que el vendedor se desempeñe, el vendedor está creando un activo de trabajo en curso que es controlado por el cliente, el vendedor está creando un activo de trabajo en curso el que no podría estar dirigido a un cliente distinto y no se dirigirá a clientes diferentes y respecto del cual el cliente tiene la obligación el trabajo hasta la fecha. Si los ingresos deben ser reconocidos en el tiempo el departamento de contabilidad deberá usar un método que refleje de mejor manera los pagos por el bien o el servicio (Deloitte touche Tohmatsu Limited, 2017).

Si la transacción no alcanza con ninguno de los tres escenarios mencionados anteriormente, el ingreso será reconocido en ese punto del tiempo, cuando el control pase al cliente. La norma es diferente y mucho más especifica que el tratamiento incluido anteriormente en la NI IF, y algunas entidades pueden conseguirse que los ingresos pre-reconocidos en un punto del tiempo deben ser reconocidos ahora a en el tiempo, o viceversa. Por ejemplo, los ingresos de una pre-venta de bienes raíces puede verse afectados por el nuevo estándar (Deloitte touche Tohmatsu Limited, 2017).

Si los ingresos debes ser reconocidos en el tiempo o en un punto de tiempo dependerá a menudo de un análisis cuidadoso de los términos específicos del contrato. Diferencias muy pequeñas entre contratos antes consideramos como similares podría tener un impacto fundamental en el momento en el cual se va reconocer los ingresos (Deloitte touche Tohmatsu Limited, 2017).

Para determinar si los ingresos de una venta se reciben en el momento o en el tiempo se deberá presentar especial atención a si una entidad podría tener un uso alternativo para el activo en construcción y el derecho de la entidad a recibir pagos por el trabajo realizado hasta la fecha. a menudo será especialmente importante concentrarse en cualquier termino contractual que permita al cliente cancelar, restringir o modificar significativamente el contrato y si, de producirse tales circunstancias, el vendedor siempre tendría derecho contractualmente a una compensación adecuada por el trabajo realizado hasta la fecha (Deloitte touche Tohmatsu Limited, 2017).

A menudo será especialmente importante centrarse en las condiciones contractuales que permitan al cliente cancelar, restringir o modificar significativamente el contrato y si de producirse tales circunstancias, el vendedor siempre tendría derecho contractual a una compensación adecuada por el trabajo realizado hasta la fecha. La evaluación de estos factores, entre otros, deberá hacerse en 
el contexto tanto de las condiciones contractuales como del entorno legal local (Deloitte touche Tohmatsu Limited, 2017).

Cuando una entidad concluye que los ingresos deben ser reconocidos en el tiempo deberá considerar como medir el progreso hacia la satisfacción total de las obligaciones de desempeño. La NIIF 15 especifica que la medida del progreso excluirá cualquier producto o servicio para el cual la entidad no transfiera el control al cliente. Por lo tanto, la medida del progreso (y por lo tanto los porcentajes de los ingresos deben ser reconocidos) puede verse afectada por el control o no del terreno en el que se está construyendo el bien (y el momento de transferencia) (Deloitte touche Tohmatsu Limited, 2017).

- ¿Cómo se identifican diferentes bienes y servicios dentro de un contrato?

Anteriormente, dada la falta de guía específica en las NIIF, había más espacio para el juicio al identificar los bienes y servicios distintos dentro de un contrato. para el juicio al identificar los bienes y servicios distintos dentro de un contrato ¿Deben capitalizarse el costo del contrato? (Deloitte touche Tohmatsu Limited, 2017).

Las entidades posiblemente tendrán que enmendar sus políticas contables actuales como resultado de la orientación más detallada de la NIIF 15 y, en particular, las nuevas reglas sobre cómo se distribuyen los ingresos entre los diferentes elementos. Las empresas constructoras a menudo tienen contratos con múltiples elementos y la NIIF 15 puede afectar la determinación de si ciertos elementos de un contrato deben ser reconocidos separadamente, lo que puede tener un impacto significativo en el perfil de reconocimiento de ingresos (Deloitte touche Tohmatsu Limited, 2017). Por ejemplo, la nueva Norma puede tener efecto en el caso de la venta de un terreno cuando este se vende como parte de un contrato para la construcción de un edificio, se considera que constituye un bien distinto cuya transacción deba ser contabilizada como obligaciones de desempeño separadas.

- ¿Debería ajustarse los ingresos por efectos del valor temporal del dinero?

Para dar respuesta a esta incógnita es pertinente recordar que los contratos de construcción se desarrollan en más de un periodo contable en muchas ocasiones se modifican, se prorrogan y se 
suspenden por factores macroeconómicos, operativos y climatológicos conllevando que el contrato de construcción se amplié la fecha de terminación afectando el equilibrio financiero y económico del proyecto de construcción.

La NIIF 15 introduce nuevas y más amplias guías sobre los arreglos financieros y el impacto del valor temporal de' dinero. Las ventas por promotores inmobiliarios o empresas de construcción pueden incluir arreglos de financiamiento en el sentido de que el momento de las entradas de efectivo recibido del cliente puede no corresponder con el momento del reconocimiento de ingresos. Conforme a la nueva Norma, el componente de financiamiento, si es significativo, se contabiliza por separado de los ingresos (Deloitte touche Tohmatsu Limited, 2017).

Esto se aplica a los pagos anticipados y atrasados, pero sujetos a una exención cuando el período entre el pago y la transferencia de bienes o servicios sea inferior a un año. Esta nueva guía puede cambiar las prácticas contables actuales en algunos casos (Deloitte touche Tohmatsu Limited, 2017).

Esta norma aplica para los pagos anticipados y atrasados pero sujetos a una exención cuando el periodo entre el pago y la transferencia de bienes o servicios sea inferior a un año (Deloitte touche Tohmatsu Limited, 2017).

- ¿Cuál es el impacto si se modifica un contrato?

Las actuales NIIF incluyen sólo una guía limitada sobre cómo contabilizar las modificaciones a un contrato, deben tenerse en cuenta prospectivamente como un ajuste a los ingresos futuros o retrospectivamente mediante un ajuste cuando ocurre la modificación. Es frecuente que se modifique el alcance o el precio de los acuerdos en la industria, en particular para las empresas de construcción, y por lo tanto estos requisitos pueden dar lugar a un cambio de práctica para algunas entidades (Deloitte touche Tohmatsu Limited, 2017).

Como se mencionó anteriormente en los puntos más importantes que resaltaba la firma de auditoría Detoille para el sector de la construcción trae cambios en los cuales puede generar un gran impacto administrativo como contables en las organizaciones del sector, de ahí el afán de 
que las directrices de las organizaciones hallan considerado todos los cambios y como afectara las empresas creando un plan dentro de las políticas organizacionales y contables que requieran ser modificadas con el fin de disminuir el impacto.

De igual forma en un artículo titulado aplicar e implementar las NIIF publicado por la revista En Obra se señala que al implementar los estándares internacionales presentan oportunidades potenciales que los administradores de las entidades deben examinar con mayor detalle ya que contienen varios asuntos, permitiendo crear oportunidades a los administradores de las empresas del sector; logrando identificar y seleccionar opciones que puedan resultar en representaciones más apropiadas de sus resultados y posición financiera (Revista En Obra, 2016).

Así mismo la revista en obra resalta la importancia de que en las organizaciones del sector de la construcción en Colombia debe implementar las normas internacionales y para que esto sea eficiente es necesario que todas las áreas de la organización se encuentren en sincronía en el proceso de implementación del estándar.

Se deben tomar acertadas decisiones respecto a cualquier consenso global, en relación con las opciones específicas contables para cada industria, no sea que una entidad sea vista como que está en divergencia de la norma. Las juntas directivas, o quien haga sus veces, necesitarán conocer las decisiones tomadas a partir de las opciones existentes y pueden evaluar la lógica utilizada por la administración para establecer por qué son las más apropiadas (Revista En Obra, 2016).

Por otra parte, la revista señala algunos impactos que puede generar el estándar internacional en las empresas del sector de la construcción e ingeniería civil relacionados con la imputación temporal de los ingresos que pueden generar modificaciones relevantes en el reconocimiento de este:

- Los estándares contenidos en los marcos normativos del decreto 2420 de 2015, aplicables al sector de la construcción, dejan más margen al juicio profesional y en cierta medida podría decirse que son más flexibles a la hora de diseñar y aplicar las políticas y procedimientos contables y financieros para el reconocimiento de los ingresos provenientes de contratos de construcción (Revista En Obra, 2016). 
- La NIIF 15 es mucho más restrictiva y contiene más parámetros y reglas que la NIC 18, la NIC 11 y sus interpretaciones, por lo que la aplicación de los nuevos requisitos puede dar lugar a cambios significativos en el perfil de ingresos $\mathrm{y}$, en algunos casos, en el reconocimiento de los costos asociados (Revista En Obra, 2016).

De igual forma también considera que tras la implementación de normas internacionales se generara impactos relacionados con los procedimientos contables de la organización conllevando a cambios significativos como son:

La complejidad de la obligatoria aplicación de la NIIF 15 en entidades del sector de la construcción, y los datos necesarios para componer las notas a los estados financieros correspondientes, que son mucho más detalladas. Puede requerir crear nuevos aplicativos extracontables, sus correspondientes sistemas y procesos, o simplemente modificar los existentes, siempre que se puedan articular (Revista En Obra, 2016).

De igual forma se señala que:

Estas necesidades serán probablemente más significativas en aquellas industrias o empresas que tengan un gran número de contratos diferentes y múltiples ofertas de productos (Revista En Obra, 2016).

Así mismo la revista en obra resalta que con la llegada de estándares internacionales en Colombia ya hace varios años es de suma importancia que las empresas dedicadas al sector de la construcción se encuentren en el proceso de implementación y a actualización ya que no solo afecta al departamento contable sino a todas las áreas de la organización, por lo tanto cualquier entidad que se muestre no estar de acuerdo con los estándares internacionales sale además de vulnerar las leyes contables sale con facilidad del mercado.

De igual forma la firma EY Building a Better Working World en una publicación denominada Tratamiento contable de la NIIF 15 en menciona algunos impactos que puede contraer el estándar internacional como puede afectar a las organizaciones en las diferentes etapas y áreas indica que: 


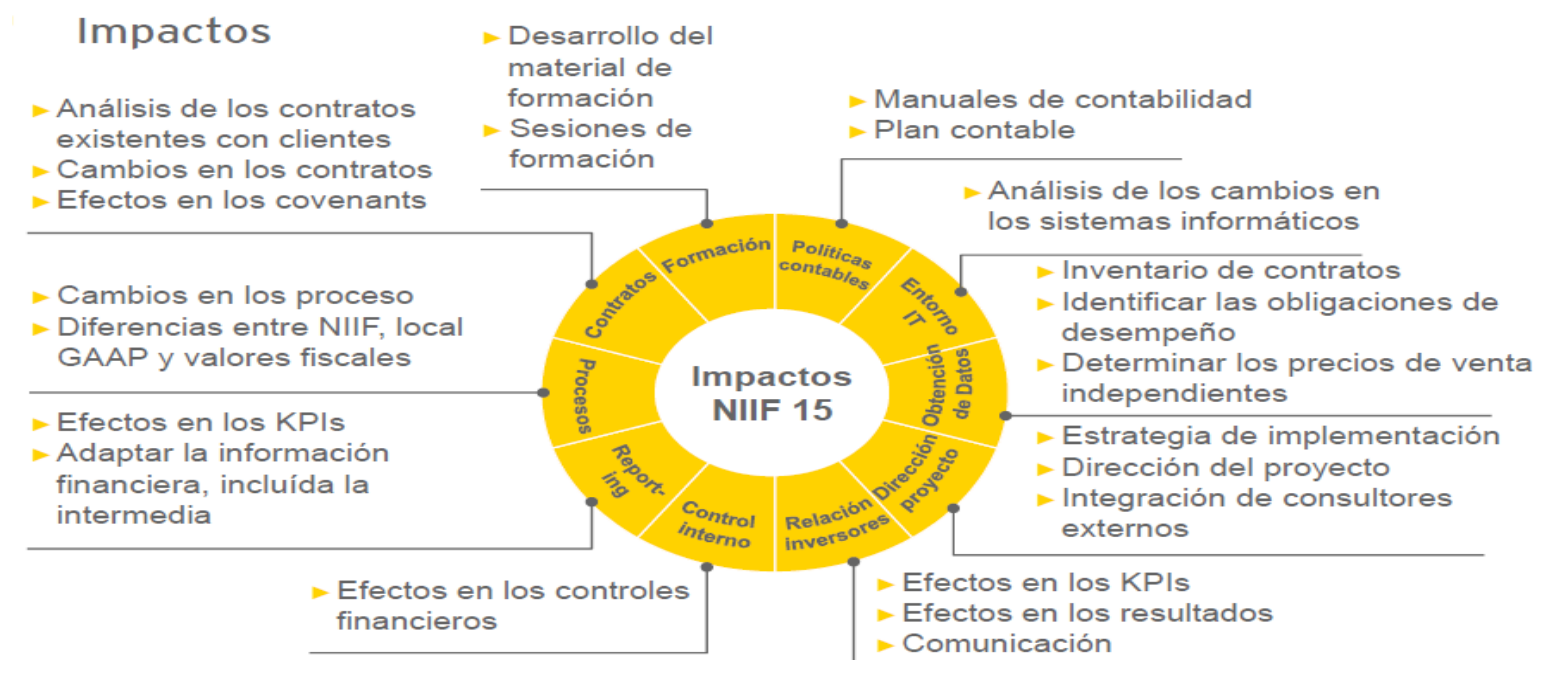

Figura 10. Impacto en el reconocimiento de ingresos NIIF 15. Tomado de Buldding a Better Working World, por Augusto De la Cruz 2017.

Es importante a su vez entender que la gerencia tiene implicaciones al implementar la NIIF 15 tal como lo señala la firma EY Building a Better Working World:

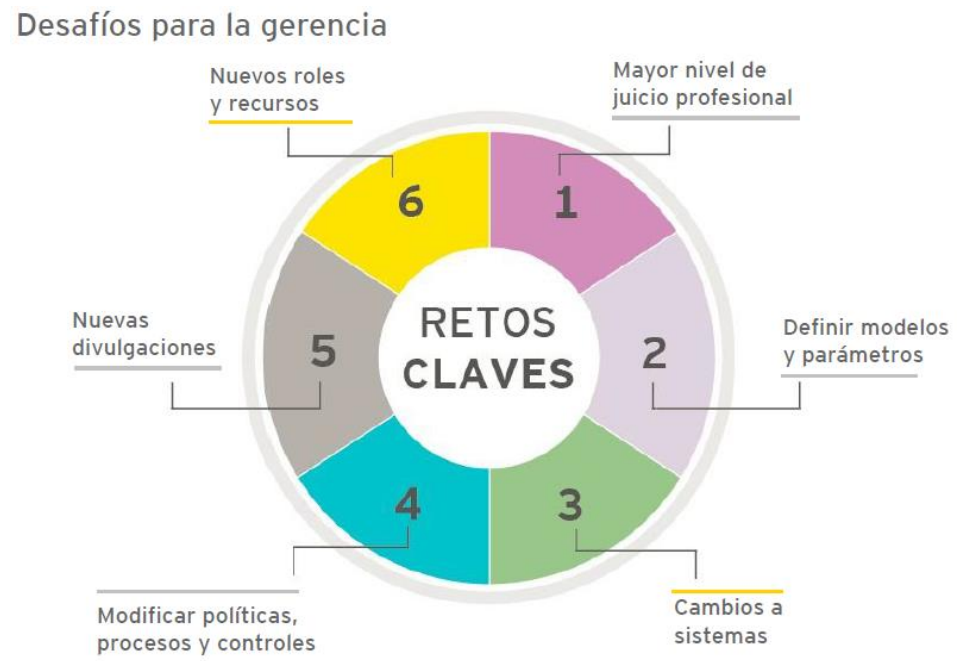

Figura 11. Desafios para la gerencia en el reconocimiento de ingresos NIIF 15. Tomado de Bullding a Better Working World, por Augusto De la Cruz 2017.

De igual forma se plantean los desafíos que las organizaciones deben tener en cuenta en el proceso de implementación del estándar internacional NIIF 15 y su relación con la tributación:

- El impacto fiscal debe estar incorporado como parte del plan de implementación de la NIIF 15 (Bullding a Better Working World, 2017). 
- Medir los efectos fiscales que podrían generarse a partir de la aplicación de NIIF 15 (Bullding a Better Working World, 2017).

- En la medida de lo posible, adecue contratos de modo que reflejen las transacciones que desde IFRS son identificables (Bullding a Better Working World, 2017)

- Documente la posición técnica que adopte finalmente (Bullding a Better Working World, 2017).

- Revise los procedimientos operativos para la liquidación de impuestos, y verificar que se encuentran aptos frente al resto que plantea la NIIF (Bullding a Better Working World, 2017).

Asimismo, cabe mencionar las principales diferencias de las normas locales tanto contables como tributarias con los estándares internacionales como se logra visualizar en la siguiente tabla de acuerdo a los criterios de reconocimiento, medición y revelación:

Tabla 27.Comparación normativa reconocimiento, medición y revelación.

\begin{tabular}{|c|c|c|}
\hline Decreto 2649 de 1993 & $\begin{array}{l}\text { Normas Fiscales } \\
\text { Colombianas }\end{array}$ & $\begin{array}{c}\text { Estándar Internacional } \\
\text { NIIF } 15\end{array}$ \\
\hline \multicolumn{3}{|c|}{ Reconocimiento } \\
\hline $\begin{array}{l}\text { Sección IV normas sobre las } \\
\text { cuentas de resultados Art } 96 \\
\text { "En cumplimiento de las } \\
\text { normas de realización, } \\
\text { asociación y asignación, los } \\
\text { ingresos y los gastos se deben } \\
\text { reconocer de tal manera que se } \\
\text { logre el adecuado registro de } \\
\text { las operaciones en la cuenta } \\
\text { apropiada, por el monto } \\
\text { correcto y en el período } \\
\text { correspondiente, para obtener } \\
\text { el justo cómputo del resultado } \\
\text { neto del período" (Decreto } \\
2649,1993 \text { ). }\end{array}$ & $\begin{array}{l}\text { Parte II Ley } 1819 \text { de } 2016 \\
\text { Art. } 18 \text { "Los contratos de } \\
\text { colaboración empresarial tales } \\
\text { como consorcios, uniones } \\
\text { temporales, joint Ventures y } \\
\text { cuentas en participación, no } \\
\text { son contribuyentes al } \\
\text { impuesto de renta y } \\
\text { complementarios. Las partes } \\
\text { del contrato de colaboración } \\
\text { empresarial, deberán declarar } \\
\text { de manera independiente las } \\
\text { activos, pasivos, ingresos, } \\
\text { costos y deducciones que les } \\
\text { correspondan, de acuerdo con } \\
\text { su participación" (Ley 1819, } \\
\text { 2016). }\end{array}$ & $\begin{array}{l}\text { Etapa 5: Reconocer el } \\
\text { ingreso de actividades } \\
\text { ordinarias cuando (o a } \\
\text { medida que) la entidad } \\
\text { satisface una obligación de } \\
\text { desempeño } \\
\text { "Una entidad reconocerá el } \\
\text { ingreso de actividades } \\
\text { ordinarias cuando (o en la } \\
\text { medida que) satisface una } \\
\text { obligación de desempeño } \\
\text { mediante la transferencia de } \\
\text { un bien o servicio } \\
\text { comprometido con el cliente" } \\
\text { lational Accounting Standards } \\
\text { Boards, 2014). }\end{array}$ \\
\hline
\end{tabular}


Tabla 27. Continuación

\begin{tabular}{|c|c|c|}
\hline $\begin{array}{l}\text { Sección IV normas sobre las } \\
\text { cuentas de resultados Art } 97 \\
\text { "Realización del ingreso. Un } \\
\text { ingreso se entiende realizado } \\
\text { y, por tanto, debe ser } \\
\text { reconocido en las cuentas de } \\
\text { resultados, cuando se ha } \\
\text { devengado y convertido o sea } \\
\text { razonablemente convertible } \\
\text { en efectivo" (Decreto 2649, } \\
\text { 1993). }\end{array}$ & $\begin{array}{l}\text { Parte II Ley } \mathbf{1 8 1 9} \text { de } 2016 \\
\text { Art. } 21 \\
\text { "Para la determinación del } \\
\text { impuesto sobre la renta y } \\
\text { complementarios, en el valor } \\
\text { de } \\
\text { los activos, pasivos, } \\
\text { patrimonio, ingresos, costos y } \\
\text { gastos, los sujetos pasivos de } \\
\text { este impuesto llevar } \\
\text { obligados a los } \\
\text { contabilidad aplicarán } \\
\text { sistemas de reconocimientos y } \\
\text { medición, de conformidad } \\
\text { con los marcos técnicos } \\
\text { normativos contables vigentes } \\
\text { en Colombia, cuando la ley } \\
\text { tributaria remita } \\
\text { expresamente a ellas y en los } \\
\text { casos en que esta no regule la } \\
\text { materia. En todo caso, la ley } \\
\text { tributaria de forma } \\
\text { puede disponer de } \\
\text { expresa un tratamiento } \\
\text { diferente, de conformidad con } \\
\text { el artículo } 4 \text { de la ley } \\
\text { 1314 de 2009" (Ley 1819, } \\
\text { 2016). }\end{array}$ & 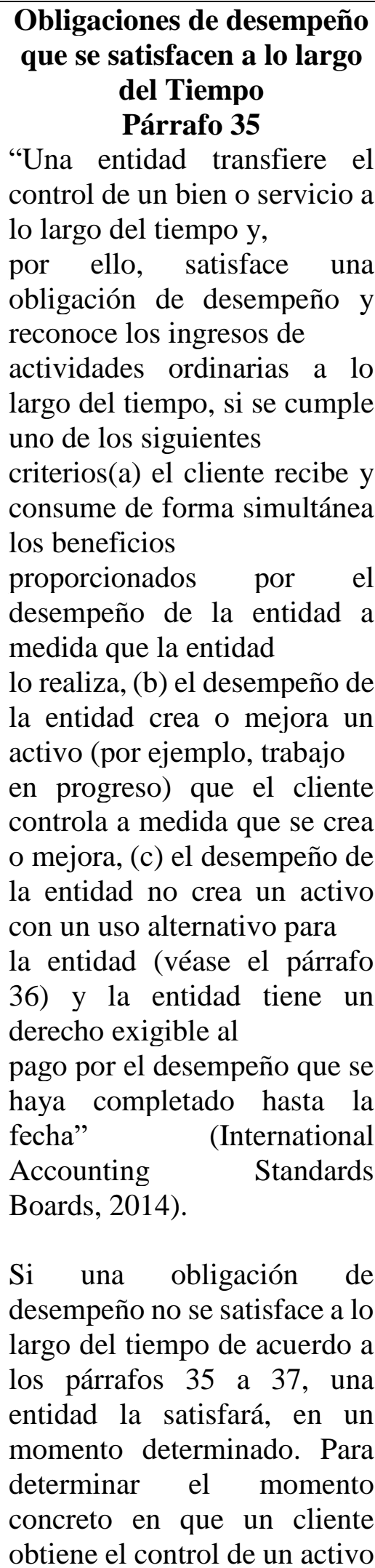 \\
\hline
\end{tabular}




\begin{tabular}{|c|c|c|}
\hline & & 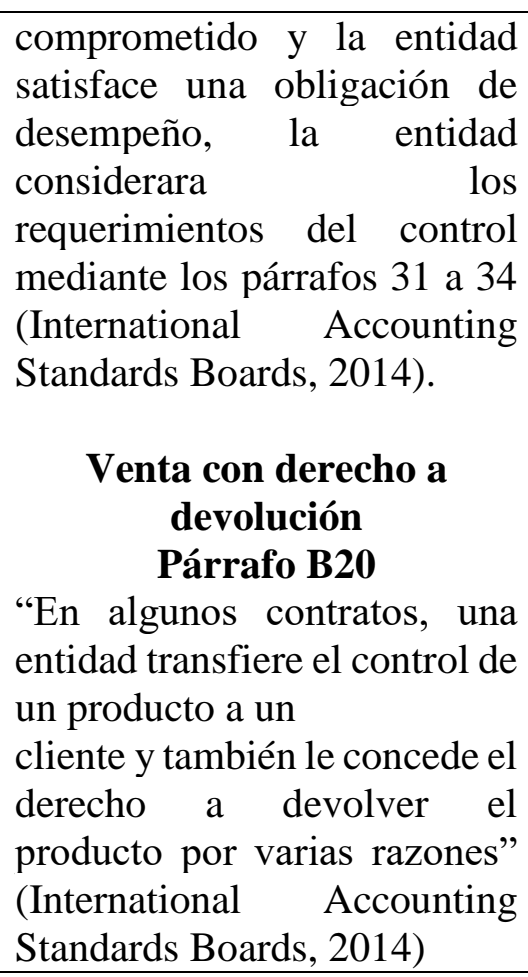 \\
\hline \multicolumn{3}{|c|}{ Medición } \\
\hline $\begin{array}{l}\text { Titulo Segundo de las } \\
\text { técnicas contables } \\
\text { Artículo 49. } \\
\text { "Medición al valor histórico. } \\
\text { Los hechos económicos se } \\
\text { reconocen inicialmente por su } \\
\text { valor histórico, aplicando } \\
\text { cuando fuere necesario la } \\
\text { norma básica de la prudencia" } \\
\text { (Decreto 2649, 1993). }\end{array}$ & $\begin{array}{l}\text { Parte II Ley } \mathbf{1 8 1 9} \text { de } 2016 \\
\text { Artículo 21·1. Para la } \\
\text { determinación del impuesto } \\
\text { sobre la renta y } \\
\text { complementarios, en el valor } \\
\text { de los activos, pasivos, } \\
\text { patrimonio, ingresos, costos y } \\
\text { gastos, los sujetos pasivos de } \\
\text { este impuesto obligados a } \\
\text { llevar contabilidad aplicarán } \\
\text { los sistemas de } \\
\text { reconocimientos y medición, } \\
\text { de conformidad con los } \\
\text { marcos técnicos normativos } \\
\text { contables vigentes en } \\
\text { Colombia, cuando la ley } \\
\text { tributaria remita } \\
\text { expresamente a ellas y en los } \\
\text { casos en que esta no regule la } \\
\text { materia. En todo caso, la ley } \\
\text { tributaria puede disponer de }\end{array}$ & 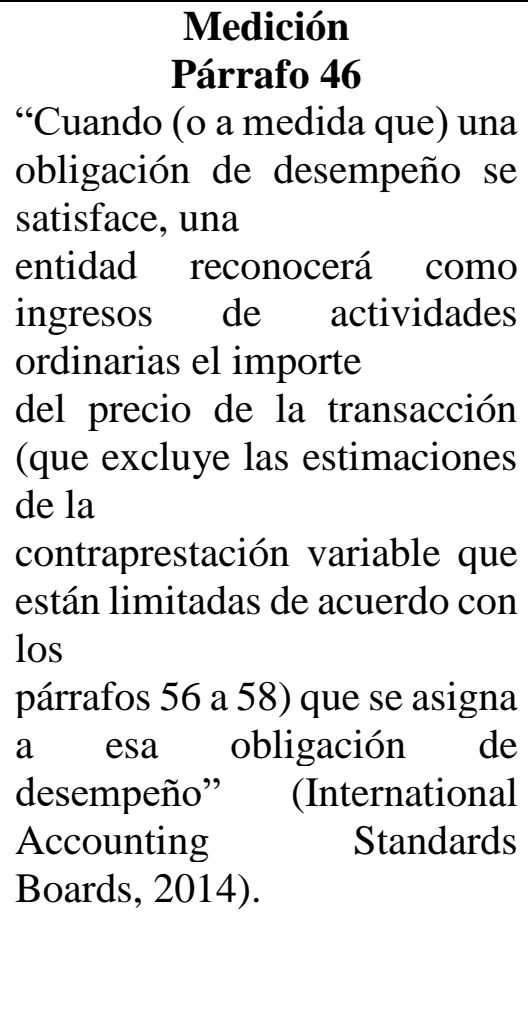 \\
\hline
\end{tabular}




\begin{tabular}{|c|c|c|}
\hline & $\begin{array}{l}\text { forma expresa un tratamiento } \\
\text { diferente, de conformidad con } \\
\text { el artículo } 4 \text { de la ley } 1314 \text { de } \\
2009 \text { (Ley } 1819,2016) \text {. }\end{array}$ & $\begin{array}{l}\text { Medición } \\
\text { Párrafo 47 } \\
\text { "Una entidad considerará los } \\
\text { términos del contrato y sus } \\
\text { prácticas } \\
\text { tradicionales de negocio para } \\
\text { determinar el precio de la } \\
\text { transacción. El precio de la } \\
\text { transacción es el importe de la } \\
\text { contraprestación a la que una } \\
\text { entidad espera tener derecho a } \\
\text { cambio de transferir los bienes } \\
\text { o servicios comprometidos } \\
\text { con cliente, excluyendo los } \\
\text { importes recaudados en } \\
\text { nombre de terceros (por } \\
\text { ejemplo, algunos impuestos } \\
\text { sobre las ventas). La } \\
\text { contraprestación que se } \\
\text { compromete en un contrato } \\
\text { con un cliente puede incluir } \\
\text { importes fijos, importes } \\
\text { variables, o ambos." } \\
\text { (International Accounting } \\
\text { Standards Boards, 2014). }\end{array}$ \\
\hline \multicolumn{3}{|c|}{ Revelación } \\
\hline $\begin{array}{l}\text { Capitulo III } \\
\text { Artículo 113. ámbito de } \\
\text { aplicación. } \\
\text { Las reglas contenidas en este } \\
\text { capítulo son aplicables } \\
\text { respecto de los estados } \\
\text { financieros de propósito } \\
\text { general. Deben observarse } \\
\text { para preparar y presentar otros } \\
\text { estados siempre que fueren } \\
\text { apropiadas. } \\
\text { Los estados financieros y } \\
\text { demás información contable } \\
\text { que deben ser presentados a } \\
\text { las Autoridades o publicados } \\
\text { con su autorización, se rigen } \\
\text { por normas especiales que }\end{array}$ & $\begin{array}{l}\text { La norma fiscal no establece } \\
\text { parámetros a relevar }\end{array}$ & $\begin{array}{l}\text { Información a Revelar } \\
\text { Parrafo110 } \\
\text { El objetivo de los } \\
\text { requerimientos de } \\
\text { información a revelar es que } \\
\text { una } \\
\text { entidad revele información } \\
\text { suficiente que permita a los } \\
\text { usuarios de los } \\
\text { estados financieros } \\
\text { comprender la naturaleza, } \\
\text { importe, calendario e } \\
\text { incertidumbre de los ingresos } \\
\text { de actividades ordinarias y } \\
\text { flujos de } \\
\text { efectivo que surgen de } \\
\text { contratos con clientes. Para } \\
\text { lograr ese objetivo, }\end{array}$ \\
\hline
\end{tabular}


Tabla 27. Continuación

\begin{tabular}{|c|c|}
\hline $\begin{array}{l}\text { estas dicten, las cuales deben } \\
\text { sujetarse al marco conceptual } \\
\text { de la contabilidad y a las } \\
\text { normas técnicas generales. } \\
\text { Las normas contenidas en este } \\
\text { capítulo son aplicables a } \\
\text { elementos o partidas } \\
\text { materiales, es decir, a las que } \\
\text { tienen importancia } \\
\text { significativa para la } \\
\text { evaluación de la situación } \\
\text { financiera de la empresa y sus } \\
\text { resultados (Decreto 2649, } \\
\text { 1993). }\end{array}$ & \begin{tabular}{lr} 
una entidad & \multicolumn{2}{c}{ revelará } \\
información & cualitativa y \\
cuantitativa & (International \\
Accounting & Standards \\
Boards, 2014). &
\end{tabular} \\
\hline
\end{tabular}

Nota: Descripción de la normatividad, por Luis Sebastián Avella, Martínez, 2018

Adaptado de Decreto 2649 de 1990 por el cual se reglamenta la contabilidad en general y se expiden los principios o normas de contabilidad generalmente aceptados en Colombia por el Congreso de la República de Colombia, Ley 1819 por medio de da cual se adopta una reforma tributaria estructural, se fortalecen los mecanismos para la lucha contra la evasión y la elusión fiscal, y se dictan otras disposiciones por el congreso de la república y NIIF 15 ingresos de actividades ordinarias procedentes de contratos con clientes por IASB, 2015.

Ahora bien, para el desarrollo de presente trabajo se considera pertinente poner en contexto los pasos para el reconocimiento de los ingresos ordinarios expuestos por la firma de auditoría Deloitte 1.Identifique el contrato con el cliente, 2.Identifique las obligaciones de desempeño contenidas en el contrato, 3.Determine el precio de transacción, 4. Asigne el precio de transacción a las obligaciones de desempeño separadas y 5.Reconozca los ingresos ordinarios como la entidad satisface la obligación de desempeño (Deloitte Touche Tohmatsu Limited., 2018).

Teniendo en cuenta lo anterior y para el presente trabajo que analiza las implicaciones de la NIIF 15 en las empresas que contratan con entidades públicas, se expondrá un ejercicio práctico sobre los pasos anteriormente mencionados.

Así mismo para el desarrollo del presente trabajo se considera de suma importancia realizar un 
caso práctico en donde se logre identificar los aspectos más importantes del estándar internacional en los contratos de construcción como se logra evidenciar a continuación:

La empresa El Constructor Campesino S.A.S conforma un consorcio denominado la mejor vía de Colombia con el objetivo ejecutar el contrato celebrado con la agencia para la infraestructura del Meta mediante licitación pública cuyo objeto es (mejoramiento de la vía que comunica el municipio de Acacias con el casco urbano del municipio de Guamal- Meta ) por un valor de 10.000.000.000 el cual tiene un plazo para su ejecución de 3 años, la entidad es responsable por de la ejecución completa del contrato de construcción.

Para esto la entidad contratante desembolso el 50\% del valor total del contrato por el concepto de anticipo con el objetivo de que el contratista ejecute el proyecto de construcción de manera eficiente, dentro del contrato celebrado con la entidad contratante y el contratista se estipula las diferentes obligaciones de desempeño, como son limpieza, instalación de redes eléctricas y actividades de embellecimiento como siembra de árboles entre otras actividades estipuladas en el contrato para su correcta ejecución. Así mismo el reconocimiento del ingreso a medida que se satisface la obligación a lo largo del tiempo, cumpliendo los párrafos 27, 29, 35 del estándar internacional.

Ahora bien, al finalizar el primer año se logran identificar los movimientos de ingresos, costos y gastos que tuvo la empresa en la ejecución del proyecto como el porcentaje de ejecución correspondiente a un $35 \%$ entre los cuales se menciona:

- Anticipo pactado en el contrato equivalente al $50 \%$ valor del contrato por valor de 5.000.000.000.

- Compra de insumos para la ejecución del proyecto por valor de 2.700.000.000. como son: (viajes de arena, hierro, concreto, mezcla asfáltica, material pétreo, adoquines, entre otras), del cual para la ejecución de la obra se ha implementado el $85 \%$ del material comprado.

- Costos de mano de obra y seguridad social y parafiscal por valor de 1.300.000.000.

- Costos de desplazamiento de materiales como arena y grava desde la cantera hasta la localización del proyecto por valor de $\$ 520.000 .000$.

- Costos de diseños eléctricos por valor de 180.000.000 y diseños y estudios de paisajismo por valor de $\$ 100.000 .000$. 
- Costos de licitación y estudios previos y adjudicación por valor de \$200.000.000.

- Con base a la información anterior se procede a realizar los correspondientes registros contables

Tabla 28.Registro Anticipo.

\begin{tabular}{|c|c|c|}
\hline \multicolumn{3}{|c|}{ Consorcio la Mejor Vía de Colombia } \\
\hline Concepto & Debito & Crédito \\
\hline Banco El honrado & 5.000 .000 .000 & 5.000 .000 .000 \\
\hline $\begin{array}{c}\text { Ingresos anticipados procedentes de } \\
\text { contratos de construcción }\end{array}$ & & $\mathbf{5 . 0 0 0 . 0 0 0 . 0 0 0}$ \\
\hline Total & $\mathbf{5 . 0 0 0 . 0 0 0 . 0 0 0}$ & \\
\hline
\end{tabular}

NOTA: Concepto y cuantía del consocio la Mejor vía de Colombia, por Luis Sebastián Avella, Martínez, 2018

Ahora bien, se realiza el correspondiente registro de los materiales que se adquirieron con el valor del anticipo.

Tabla 29.Registro de Materiales.

\begin{tabular}{|c|c|c|}
\hline \multicolumn{3}{|c|}{ Consorcio la Mejor Vía de Colombia } \\
\hline Concepto & Debito & Crédito \\
\hline Inventario & 2.700 .000 .000 & 2.700 .000 .000 \\
\hline Bancos & & $\mathbf{2 . 7 0 0 . 0 0 0 . 0 0 0}$ \\
\hline Total & $\mathbf{2 . 7 0 0 . 0 0 0 . 0 0 0}$ & \\
\hline
\end{tabular}

NOTA: Concepto y cuantía del consocio la Mejor vía de Colombia, por Luis Sebastián Avella, Martínez, 2018

Ahora bien, se realiza el correspondiente registro de los materiales que salieron del inventario y fueron utilizados para la ejecución de la obra cuyo valor es el 2.295.000.000 equivalente al 85\% del material comprado por el consorcio.

Tabla 30. Registro de materiales.

\begin{tabular}{|c|c|c|}
\hline \multicolumn{3}{|c|}{ Consorcio la Mejor Vía de Colombia } \\
\hline Concepto & Debito & Crédito \\
\hline Obras de construcción en curso. & 2.295 .000 .000 & \\
\hline Bancos & & 2.295 .000 .000 \\
\hline Total & $\mathbf{2 . 2 9 5 . 0 0 0 . 0 0 0}$ & $\mathbf{2 . 2 9 5 . 0 0 0 . 0 0 0}$ \\
\hline
\end{tabular}

NOTA: Concepto y cuantía del consocio la Mejor vía de Colombia, por Luis Sebastián Avella, Martínez, 2018

De igual forma se procede a registrar los costos equivalentes a nómina cuyo valor será presentado como evidencia ante la entidad contratante con sus respectivos soportes de nómina y pago de parafiscales. Para este caso solo registraremos el valor total que incurrió el consorcio La Mejor vía 
de Colombia correspondiente a nómina del primer año.

Tabla 31.Registro de salarios.

\begin{tabular}{|c|c|c|}
\hline \multicolumn{3}{|c|}{ Consorcio la Mejor Vía de Colombia } \\
\hline Concepto & Debito & Crédito \\
\hline Obras de construcción en curso & 1.300 .000 .000 & \\
\hline Bancos & & 1.300 .000 .000 \\
\hline Total & $\mathbf{1 . 3 0 0 . 0 0 0 . 0 0 0}$ & $\mathbf{1 . 3 0 0 . 0 0 0 . 0 0 0}$ \\
\hline
\end{tabular}

NOTA: Concepto y cuantía del consocio la Mejor vía de Colombia, por Luis Sebastián Avella, Martínez, 2018

Bajo el estándar internacional NIIF 15 reconoce como costos si cumple los requisitos del párrafo 97 del estándar como : (a) mano de obra directa por ejemplo, salarios y sueldos de los empleados que proporcionan los servicios comprometidos directamente con el cliente, (b) materiales directos (por ejemplo, suministros utilizados para prestar los servicios comprometidos con el cliente, (c) distribuciones de costos que se relacionan directamente con el contrato o con actividades del contrato por ejemplo, costos de gestión y supervisión del contrato, seguros y depreciación de herramientas, equipo y activos por derecho de uso utilizados en el cumplimiento del contrato, (d) costos que son imputables de forma explícita al cliente según el contrato y (e) otros costos en los que se incurre solo porque una entidad ha realizado el contrato por ejemplo, pagos a subcontratistas (International Accounting Standards Boards, 2014).

Ahora bien, se hará el registro del transporte de materiales para la ejecución del proyecto.

Tabla 32. Registro Transporte de materiales.

\begin{tabular}{|c|c|c|}
\hline \multicolumn{3}{|c|}{ Consorcio la Mejor Vía de Colombia } \\
\hline Concepto & Debito & Crédito \\
\hline Obras de construcción en curso & 520.000 .000 & \\
\hline Bancos & & 520.000 .000 \\
\hline Total & $\mathbf{5 2 0 . 0 0 0 . 0 0 0}$ & $\mathbf{5 2 0 . 0 0 0 . 0 0 0}$ \\
\hline
\end{tabular}

NOTA: Concepto y cuantía del consocio la Mejor vía de Colombia, por Luis Sebastián Avella, Martínez, 2018

De igual forma se realizará el registro de los diseños técnicos eléctricos y de paisajismo los cuales son elementales para la ejecución del contrato. 
Tabla 33.Registro de diseños técnicos, paisajismo y eléctricos.

\begin{tabular}{|c|c|c|}
\hline \multicolumn{3}{|c|}{ Consorcio la Mejor Vía de Colombia } \\
\hline Concepto & Debito & Crédito \\
\hline Obras de construcción en curso & 280.000 .000 & \\
\hline Bancos & & 280.000 .000 \\
\hline Total & $\mathbf{2 8 0 . 0 0 0 . 0 0 0}$ & $\mathbf{2 8 0 . 0 0 0 . 0 0 0}$ \\
\hline
\end{tabular}

NOTA: Concepto y cuantía del consocio la Mejor vía de Colombia, por Luis Sebastián Avella, Martínez, 2018

Ahora bien, bajo el estándar internacional en el párrafo 127 se señala el tratamiento de los activos reconocidos procedentes de los costos para obtener o cumplir un contrato con un cliente teniendo en cuenta : (a) los juicios realizados para determinar el importe de los costos incurridos para obtener o cumplir un contrato con un cliente de acuerdo con el párrafo 91 o 95 y (b) el método que utiliza para determinar la amortización para cada periodo de presentación (International Accounting Standards Boards, 2014).

Tabla 34. Registro de costos de licitación y estudios previos y adjudicación.

\begin{tabular}{|c|c|c|}
\hline \multicolumn{2}{|c|}{ Consorcio la Mejor Vía de Colombia } \\
\hline Concepto & Debito & Crédito \\
\hline Obras de construcción en curso & 200.000 .000 & \\
\hline Bancos & & 200.000 .000 \\
\hline Total & $\mathbf{2 0 0 . 0 0 0 . 0 0 0}$ & $\mathbf{2 0 0 . 0 0 0 . 0 0 0}$ \\
\hline
\end{tabular}

NOTA: Concepto y cuantía del consocio la Mejor vía de Colombia, por Luis Sebastián Avella, Martínez, 2018

De igual forma se considera de suma importancia realizar el registro del grado de avance del proyecto de construcción que tiene por objeto "Mejoramiento de la vía que comunica el municipio de Acacías con el casco urbano del municipio de Guamal- Meta" el cual para el primer periodo contable evidenció un $35 \%$ para su primer cobro parcial.

Tabla 35. Registro Primer Corte de Avance de Obra.

\begin{tabular}{|c|c|c|}
\hline \multicolumn{3}{|c|}{ Consorcio la Mejor Vía de Colombia } \\
\hline Concepto & Debito & Crédito \\
\hline Ingresos Cobrados por anticipado & 3.500 .00 .000 & 3.500 .000 .000 \\
\hline Ingresos & & $\mathbf{3 . 5 0 0 . 0 0 0 . 0 0 0}$ \\
\hline Total & $\mathbf{3 . 5 0 0 . 0 0 0 . 0 0 0}$ & \\
\hline
\end{tabular}

NOTA: Concepto y cuantía del consocio la Mejor vía de Colombia, por Luis Sebastián Avella, Martínez, 2018

Ahora bien, se considera importante señalar el tratamiento de un contrato con contraprestación variable de contratos de construcción bajo el estándar internacional NIIF 15 con base al párrafo 
84.

Con el fin de abordar otros casos que competen al tratamiento contable de la NIIF 15 se realiza el siguiente caso:

La empresa el constructor el honrado celebró un contrato mediante licitación pública el 12 de enero del 2016 con la gobernación de Boyacá que tiene como objeto "construcción del polideportivo en el municipio de Combita-Boyacá" por valor de 2.085.000.000; cuya duración es de 16 meses y la utilidad estipulada a la hora de liquidar el contrato corresponderá al $15 \%$ del valor del contrato, dentro de las cláusulas de dicho contrato el contratista y el contratante identificaron las diferentes obligaciones de desempeño y el reconocimiento del ingreso será a lo largo del tiempo de igual forma en una de sus cláusulas estipula que si el contratista tarda más del tiempo estipulado en satisfacer las obligaciones de desempeño el valor de la utilidad disminuirá un 2,5\% por cada día de retraso, así mismo si el contratista satisface todas las obligaciones de desempeño estipuladas en el contrato antes de la fecha estipulada de liquidación, el contratante (Gobernación de Boyacá) dará un contraprestación se incrementara en un 0,5\% por día de entrega antes de la fecha de vencimiento del contrato.

El contratista el constructor honrado al finalizar el objeto contractual y satisfacer las obligaciones de desempeño estipuladas en el contrato celebrado el 12 de enero del 2016 con la Gobernación de Boyacá y con fecha de finalización el 12 de abril del 2017.

De acuerdo a lo anterior el contratista finalizó el objeto contractual el día 7 de abril de 2017 por lo cual se acoge a la cláusula estipulada de contraprestación en el contrato.

Para determinar el precio de transacción el supervisor de la entidad contratante verifica que todas las obligaciones de desempeño estipuladas en el contrato se han ejecutado, una vez se haya realizado el respectivo estudio y dictamen la entidad contratante realiza una estimación separada para cada contraprestación que el contratista tiene derecho, implementando los métodos estipulados en el estándar internacional NIIF 15 párrafo 53.

Una entidad estimará un importe de contraprestación variable utilizando alguno de los siguientes 
métodos, dependiendo del método que la entidad espere que prediga mejor el importe de contraprestación al que tendrá derecho: (a) El valor esperado - el valor esperado es la suma de los importes ponderados según su probabilidad en un rango de importes de contraprestación posibles. Un valor esperado puede ser una estimación apropiada del importe de la contraprestación variable si una entidad tiene un gran número de contratos con características similares y (b) El importe más probable - el importe más probable es el importe individual más probable en un rango de importes de contraprestaciones posibles (es decir, el desenlace individual más probable del contrato). El importe más probable puede ser una estimación apropiada del importe de la contraprestación variable si el contrato tiene solo dos desenlaces posibles (por ejemplo, una entidad logra una prima de desempeño o no la logra) (International Accounting Standards Boards, 2014).

Con base a lo anterior la gobernación de Boyacá decide utilizar el método de valor esperado para estimar la contraprestación asociada al incentivo en este caso (es decir \$1'563.750 por día de haber entregado el objeto contractual con todas las obligaciones de desempeño antes de la fecha de vencimiento del contrato); fue de 7 días antes del vencimiento del contrato por lo cual tendrá derecho a 10’946.250.

De igual forma la entidad contratante tiene en cuenta las limitaciones de las contraprestaciones estipuladas en los párrafos 56 y 57 del estándar internacional NIIF 15 como son:

Párrafo 56: Un entidad incluirá en el precio de la transacción todo o parte del importe de la contraprestación variable estimada de acuerdo con el párrafo 53 solo en la medida en que sea altamente probable que no ocurra una reversión significativa del importe del ingreso de actividades ordinarias acumulado reconocido cuando posteriormente se resuelva la incertidumbre sobre la contraprestación variable (International Accounting Standards Boards, 2014).

Párrafo 57: Al evaluar si es altamente probable que no ocurra una reversión significativa en el importe de los ingresos de actividades ordinarias acumulados reconocidos, una vez que se resuelva posteriormente la incertidumbre sobre la contraprestación variable, una entidad considerará la probabilidad y la magnitud de la reversión de los ingresos de actividades ordinarias. Los factores que podrían incrementar la probabilidad o la magnitud de una reversión de los ingresos de actividades ordinarias incluyen, pero no se limitan a, cualquiera de los siguientes aspectos: (a) El 
importe de la contraprestación es altamente sensible a factores que están fuera de la influencia de la entidad. Dichos factores pueden incluir la volatilidad en un mercado, el juicio o las acciones de terceros, las condiciones climatológicas y un alto riesgo de obsolescencia del bien o servicio comprometido, (b) La incertidumbre sobre el importe de la contraprestación no se espera que se resuelva durante un largo periodo de tiempo, (c) La experiencia de la entidad (u otra evidencia) con tipos similares de contratos es limitada, o esa experiencia (u otra evidencia) tiene un valor predictivo limitado, (d) La entidad tiene por práctica ofrecer un amplio rango de reducciones de precios o cambiar los términos y condiciones de pago de contratos similares en circunstancias parecidas y (e) El contrato tiene un gran número y amplio rango de importes de contraprestación posibles (International Accounting Standards Boards, 2014).

Ahora bien, para el presente trabajo se considera de suma importancia tratar determinar el grado de terminación de un contrato de construcción bajo el estándar internacional NIIF 15.

La empresa constructora el obrero honesto S.A.S celebró un contrato mediante licitación pública con la gobernación de Santander el 30 de julio del 2017 cuyo objeto es "construcción de un Centro de Desarrollo en la ciudad de Bucaramanga- Santander" que tiene plazo para ejecución de 16 meses, dentro del contrato se estipulan las obligaciones de desempeño, el valor del contrato por \$ 1'500.000.000 y las satisfacciones de las obligaciones de desempeño se reconocerán a lo largo del tiempo.

La empresa determina sus costos totales del contrato los cuales son equivalentes a 1'500.000.000. durante su periodo de ejecución.

Al 31 de diciembre de 2017 el contratista el obrero honesto S.A.S incurrió en los siguientes costos por valor de 1'275.000.000:

- 300 bultos de cemento por valor de $\$ 250^{\prime} 000.000$.

- 400 metros de acero por valor de $\$ 400 ` 000.0000$.

- Estudios técnicos y de diseño por valor de \$180’000.000.

- Mano de obra, seguridad social y parafiscales por valor de $125^{\prime} 000.000$.

- Costos de adjudicación del contrato por valor de 20’000.000.

- Otros costos de materiales y maquinaria por valor de 195'000.000. 
- Gastos de transporte de empleados 5’000.000.000.

Ahora bien, el supervisor por parte de la gobernación de Santander determino que al finalizar el año 2017 la constructora el obrero honesto S.A.S a ejecutado un 68\% del objeto contractual.

El contratista el obrero honesto determina el grado de terminación del contrato de construcción tomando como referencia la proporción de los costos incurridos a la fecha por el trabajo realizado mediante la siguiente ecuación.

$$
\text { Grado determinacion de Obra }=\frac{\text { Costos Ejecutados }- \text { Costos por Ejecutar }}{\text { Total de los costos }}
$$

Figura 12. Formula determinación grado de terminación Contrato de Construcción, por Luis Sebastián Avella, Martínez, 2018

Tabla 36.Resultado Grado de Terminación Contrato de Obra.

\begin{tabular}{|l|r|}
\hline \multicolumn{1}{|c|}{ Concepto } & \multicolumn{1}{c|}{ Valor } \\
\hline Costos Ejecutados & 1.275 .000 .000 \\
\hline Costos por Ejecutar & 225.000 .000 \\
\hline Costos Totales & 1.500 .000 .000 \\
\hline Grado de Terminación & $70 \%$ \\
\hline
\end{tabular}

NOTA: Costos del contrato, por Luis Sebastián Avella, Martínez, 2018

Como se logra visualizar el grado de terminación del objeto contractual es del $70 \%$ de la empresa constructora el obrero honesto S.A.S a 31 de diciembre del 2017. 


\section{Conclusiones}

De acuerdo al análisis realizado, el sector de la construcción juega un papel fundamental dentro de la economía colombiana; el tratamiento contable y la generación de reportes financieros de alta calidad bajo la adopción de estándares internacionales de contabilidad permite a los empresarios tomar mejores decisiones económicas.

Es pertinente que las compañías en pleno siglo XXI estén a la vanguardia, no obstante; en Colombia muchas organizaciones se han mostrado reacias a la implementación de los estándares internacionales de contabilidad, sin embargo; esta trae importantes cambios en materia contable, operativa como organizacional; de igual forma el sector de la construcción ha evidenciado resistencia al momento de implementar los estándares internacionales NIC 11 y posteriormente NIIF15.

Como el análisis realizado en el presente trabajo en todas sus fases de puede concluir que las empresas las construcción además de jugar un papel fundamental en el PIB del país, la implementación de estándares internacionales de contabilidad a los contractos de construcción NIIF 15 trae nuevas implicaciones para las empresas del sector como son la actualización y cambios en las políticas organizacionales ya sea para un contrato celebrado con una empresa privada como para una entidad pública; teniendo en cuenta las etapas que estipula el estándar internacional para el debido reconocimiento del contrato, las características a la hora de identificar las obligaciones de desempeño, así como la debida asignación del precio y posteriormente el reconocimiento del ingreso entre otras consideraciones que pueda tener los contratos con clientes en su reconocimiento, medición y revelación

Este estándar es mucho más exigente y detalla todas las consideraciones que puede tener un contrato, dando libertad a la junta directiva como al departamento contable de las organizaciones para tomar criterios de medición, reconocimiento, presentación y revelación.

Es de suma importancia que las empresas del sector de la construcción diseñen políticas que se ajusten a disminuir el impacto a la hora de implementar estándares internacionales de contabilidad, como en los contratos en los contratos celebrados con entidades públicas. 
Con base a lo anterior por medio del presente trabajo se pudo visualizar que las empresas que celebran contratos con entidades públicas el contratista y a el contratante le es más tedioso aplicar e influir en las 5 etapas que estipula el estándar internacional de contabilidad ya que dichos contratos están estipulados bajo el presupuesto bajo el plan de desarrollo departamental con base al presupuesto que el departamento o municipio tenga asignado; con forme se adjudique y ejecute el contrato de construcción el contratista y el contratante puede modificar, adicionar, obligaciones de desempeño al contrato inicial y estas revelarlas bajo el estándar internacional. Otro de los aspectos a considerar es el tratamiento que trae el estándar internacional para los costos que se incurren para la adjudicación u obtención de un contrato. Para las empresas que contratan con entidades públicas estos costos se evidencian en la etapa precontractual del contrato como gastos y costos de estudios previos, costos y gastos de legalización ante cámara de comercio, póliza precontractual entre otros que bajo el decreto 2649 eran clasificados como gastos no deducibles ya que existe el grado de incertidumbre de la efectiva adquisición del contrato; mientras que bajo el estándar internacional estos son reconocidos como costos incrementales para la obtención del contrato tal como se estipula el párrafo 91 del estándar.

De igual forma para el reconocimiento del ingreso bajo las normativas colombianas, aunque poseen varias similitudes el estándar internacional es mucho más restrictivo detallando de forma simple la hora de reconocer los ingresos como lo estipula el párrafo 31, a satisfacción de las obligaciones de desempeño, detallado la información y las actividades que son elementales para el reconocimiento del contrato con clientes, facilitado el tratamiento contable y financiero a las organizaciones logrando una mayor competitividad ante el mercado.

Con base a lo anterior es pertinente resaltar que las empresas que contratan con entidades públicas en Colombia bajo el estándar internacional NIIF 15 reconocerán las actividades de desempeño a lo largo del tiempo como lo estipula el párrafo 35, ya que por procedimientos administrativos estos contratos en la gran mayoría finalizan en una fecha posterior de la acordada en el contrato inicial por lo cual se considera pertinente implementar este método que estipula el estándar ya que se reconoce el ingreso durante la ejecución de dicho contrato.

Ahora bien uno de los impactos que trajo para las empresas de construcción que ya han implementado estándares internacionales como la NIC 11 Contratos de Construcción, actualmente los departamentos de contabilidad y finanzas como las juntas directivas se han visto obligadas 
al ponerse a la vanguardia implementado la Norma internacional de Información Financiera NIIF 15 la cual entro para aplicación el 1 de enero de 2018, derogando la NIC 11, representando un importante cambio financiero, contable y administrativo, en donde todas las áreas de las organizaciones debe trabajar de manera sincronizada con el objetivo de perder participar en un mercado más competitivo implementado estándares internacionales de contabilidad.

De igual forma las organizaciones dedicadas a este rubro además de afrontar las diferentes implicaciones que trae consigo la implementación del estándar internacional para los contratos de construcción deben armonizar la información bajo normas fiscales y locales para la presentación de informes y obligaciones tributarias antes la Dirección de impuestos y Aduanas Nacionales, como municipales además obligaciones ante las entidades de control generando un gran impacto tributario, requiriendo mayor estructuración y planeación organizacional para poder satisfacer de manera eficiente las necesidades y obligaciones de la empresa ante la sociedad.

Así mismo cabe señalar que uno de los principales objetivos de los estándares internacionales creados por el IASB de hablar un idioma contable de manera homogénea, ofreciendo exactitud en la presentación de los estados financieros ante mercados internacionales, disminuyendo el grado de discrepancia e incomprensibilidad de los mismos.

Para finalizar es imperativo resaltar que la adopción de los estándares internacionales de información financiera NIIF 15 en las organizaciones dedicadas al sector de la construcción que licitan con entidades públicas además de reestructurar la información financiera y administrativa de los contratos de construcción, sirve como una excelente herramienta de control ya permite visualizar el estado actual de los contratos en ejecución hasta su liquidación, permitiendo al contratista realizar un exhaustivo seguimiento de todas las etapas esenciales del contrato, y determinar su respetivo grado de eficiencia ante la sociedad. 


\section{Impacto esperado}

\section{En la sociedad}

Por medio de esta investigación se espera sea un punto de referencia, para las organizaciones, academia, profesionales de la contaduría pública y áreas afines para conocer el tratamiento contable de la información financiera bajo el estándar internacional NIIF 15 en las empresas colombianas que contratan con entidades públicas en el sector de la construcción. 


\section{Resultados esperados}

Realizar un análisis del estándar internacional de contabilidad NIIF 15 para las empresas Colombianas de Construcción que contratan con entidades públicas en Colombia. 


\section{Cronograma de actividades}

Tabla 37.Cronograma del proyecto.

\begin{tabular}{|l|l|l|l|}
\hline Fase 1: Revisión teórica sobre el estado & Mes 1,2,3,4 & Mes 5,6,7,8 & Mes 9, 10,11, 12 \\
actual de las empresas de la & & & \\
construcción. & & \\
\hline $\begin{array}{l}\text { Fase 2: Análisis Actual de la } \\
\text { Administración Contable del Sector de la }\end{array}$ & & & \\
Construcción que Contrata con & & & \\
Entidades Públicas. & & & \\
\hline $\begin{array}{l}\text { Fase 3: Analizar las implicaciones de la } \\
\text { NIIF 15 para las empresas de la }\end{array}$ & & & \\
construcción. & & & \\
\hline
\end{tabular}

NOTA: Cronograma de actividades para llevar a cabo el análisis de la NIIF 15, en las empresas colombianas de construcción que contratan con entidades públicas., por Luis Sebastián Avella Martínez, 2018 


\section{Presupuesto del proyecto}

Tabla 38. Presupuesto del proyecto.

\begin{tabular}{|l|l|l|}
\hline$\#$ & Rubros & Capital \\
\hline 1 & $\begin{array}{l}\text { Materiales de } \\
\text { papelería }\end{array}$ & $\$ 50.000$ \\
\hline 2 & $\begin{array}{l}\text { Capacitaciones } \\
\text { especializadas }\end{array}$ & $\$ 120.000$ \\
\hline 3 & $\begin{array}{l}\text { Pasajes y medios de } \\
\text { transporte }\end{array}$ & 50.000 \\
\hline Total & $\mathbf{\$ 2 2 0 . 0 0 0}$ \\
\hline
\end{tabular}

NOTA: Descripción y cuantía para el desarrollo del proyecto, por Luis Sebastián Avella Martínez, 2018 


\section{Referencias bibliográficas}

Agencia Nacional de Infraestructura (ANI). (29 de 12 de 2015). Abierta licitación para modernización de aeropuertos de Armenia y Neiva. La República. Obtenido de https://www.ani.gov.co/abierta-licitacion-para-modernizacion-de-aeropuertos-dearmenia-y-neiva

Agencia Nacional de Infraestructura (ANI). (22 de Diciembre de 2016). Por Fin, Despues de 14 años, Sera Inagurada laDoble Calzada Bogotá - Tunja. Obtenido de ani.gov.co: https://www.ani.gov.co/por-fin-despues-de-14-anos-sera-inaugurada-la-doble-calzadabogota-tunja

Bullding a Better Working World. (5 de Julio de 2017). Desayuno Ejecutivo NIIF 15. Perú. Obtenido de https://www.ey.com/Publication/vwLUAssets/EY-presentacion-desayunoejecutivo-niif-15/\$FILE/EY-presentacion-desayuno-ejecutivo-niif-15.pdf

Cámara Colombiana de la Construcción (CAMACOL). (28 de Agosto de 2008). Hechos estilizados y principales determinantes del nivel de actividad. 40. Bogotá, Colombia: CAMACOL.

Caracol Radio. (28 de Octubre de 2017). En diciembre entregan ampliación del aeropuerto José María Córdovar Obtenido de caracol.com.co/: http://caracol.com.co/emisora/2017/10/27/medellin/1509112418_233780.html

Catelli, F. (23 de Enero de 2017). Construccion en Colombia: reforma tributaria y expectativas para el 2017. Bogota, Colombia .

Comité Tecnico del Sector Real. (24 de Mayo de 2018). Memorias Panel NIIF 15. Bogota, Colombia: CTSR. Obtenido de https://incp.org.co/Site/publicaciones/info/archivos/Memorias-panel-NIIF-1506072018.pdf

Consecionaria Covipacifico S.A.S. (2015). Frequently Asked Questions - Generales. Obtenido de covipacifico.co: http://www.covipacifico.co/preguntas-frecuentes

Decreto 019. (10 de Enero de 2012). Por el cual se dictan normas para suprimir o reformar regulaciones, procedimientos y trámites innecesarios existentes en la Administración Pública. Bogotá, Colombia: Diario Oficial No. 48.308 . Obtenido de 
http://www.secretariasenado.gov.co/senado/basedoc/decreto_0019_2012.html

Decreto 1510. (17 de Julio de 2013). Por el cual se reglamenta el sistema de compras y contratación pública. Bogota, Colombia: Diario Oficial 48854. Obtenido de https://www.alcaldiabogota.gov.co/sisjur/normas/Norma1.jsp?i=53776

Decreto 2649. (29 de Diciembre de 1993). Por el cual se reglamenta la Contabilidad en General y se expiden los principios o normas de contabilidad generalmente aceptados en Colombia. Bogota, Colombia: Diario Oficial 41156 . Obtenido de https://www.alcaldiabogota.gov.co/sisjur/normas/Norma1.jsp?i=9863

Deloitte touche Tohmatsu Limited. (Junio de 2014). NIIF 15 Ingresos Procedentes de Contratos con Clientes. Deloitte. Obtenido de https://www2.deloitte.com/content/dam/Deloitte/es/Documents/auditoria/Deloitte_ES_A uditoria_NIIF-15-ingresos-procedentes-de-contratos-con-clientes.pdf

Deloitte touche Tohmatsu Limited. (2017). NIIF 15 Perspectivas para la Construcción y Sector Inmobiliario.

Deloitte Touche Tohmatsu Limited. (2018). Ingresos Ordinarios Provinientes de Contratos con Clientes, Una guia para la NIIF 15. Deloitte. Obtenido de https://www2.deloitte.com/content/dam/Deloitte/pe/Documents/audit/Gu\%C3\%ADa\%20 Implementaci\%C3\%B3n\%20IFRS\%2015\%20(2018).pdf

Departamento Administrativo Nacional de Estadística (DANE). (05 de Junio de 2015). Censo de edificaciones I trimestre de 2015. Bogotá, Colombia: DANE.

Departamento Administrativo Nacional de Estadística (DANE). (3 de Septiembre de 2015). Censo de Edificaciones II trimestre de 2015. Bogotá, Colombia: DANE. Obtenido de https://www.dane.gov.co/index.php/268-noticias/noticias/3549-censo-de-edificaciones-iitrimestre-2015

Departamento Administrativo Nacional de Estadística (DANE). (3 de Diciembre de 2015). Censo de Edificaciones trimestre III de 2015. Bogotá, Colombia: DANE. Obtenido de https://www.dane.gov.co/index.php/268-noticias/noticias/3604-censo-de-edificacionesiii-trimestre-2015

Departamento Administrativo Nacional de Estadística (DANE). (11 de Junio de 2015). Indicador de invercion en obras civiles primer trimentre del 2015. Bogota, Colomvia: DANE. Obtenido de https://www.dane.gov.co/index.php/52-espanol/noticias/noticias/3266- 
indicador-de-inversion-en-obras-civiles-i-trimestre-de-2015

Departamento Administrativo Nacional de Estadística (DANE). (2016). Boletin tecnico, Cuentas Trimetrales Colombia, producto interno bruto PIB cuarto trimestre del 2016. Bogota: DANE.

Obtenido de https://www.dane.gov.co/files/investigaciones/boletines/pib/bol_PIB_IVtrim16_oferta_d emanda.pdf

Departamento Administrativo Nacional de Estadística (DANE). (2016). Boletin Tecnico: Cuentas trimestrales Colombia producto interno bruto PIB primer trimestre de 2016. Bogota: DANE.

Departamento Administrativo Nacional de Estadística (DANE). (24 de Noviembre de 2016). Censo de Edificaciones trimestre III de 2016. Bogotá, Colombia: DANE.

Departamento Administrativo Nacional de Estadística (DANE). (31 de Mayo de 2016). Censo de edificaciones I trimestre de 2016. Bogotá, Colomnia: DANE.

Departamento Administrativo Nacional de Estadística (DANE). (26 de Agosto de 2016). Censo de edificaciones II trimestre de 2016. Bogotá, Colombia: DANE.

Departamento Administrativo Nacional de Estadística (DANE). (3 de Marzo de 2016). Censo de edificaciones IV trimestre de 2015. Bogotá, Colombia: DANE.

Departamento Administrativo Nacional de Estadística (DANE). (9 de Marzo de 2016). Indicador de nvercion en obras civiles IV trimestre 2015. Bogota, Colombia: DANE. Obtenido de https://www.dane.gov.co/files/investigaciones/boletines/obras/bol_obr_civi_IVtrim15.pdf

Departamento Administrativo Nacional de Estadística (DANE). (9 de Noviembre de 2017). Censo de Edificaciones CEED III trimestre de 2017. Bogotá, Colombia: DANE. Obtenido de https://www.dane.gov.co/index.php/52-espanol/noticias/noticias/4375-censo-deedificaciones-ceed-iii-trimestre-2017

Departamento Administrativo Nacional de Estadística (DANE). (14 de Agosto de 2017). Censo de edificaciones CEED II trimestre de 2017. Bogotá, Colombia: DANE. Obtenido de https://www.dane.gov.co/index.php/52-espanol/noticias/noticias/4278-censo-deedificaciones-ceed-ii-trimestre-2017

Departamento Administrativo Nacional de Estadística (DANE). (18 de Mayo de 2017). Censo edificaciones - CCEED I trimestre de 2017. Bogotá, Colombia: DANE. Obtenido de https://www.dane.gov.co/index.php/52-espanol/noticias/noticias/4172-censo-de- 
edificaciones-ceed-i-trimestre-2017

Departamento Administrativo Nacional de Estadística (DANE). (21 de Febrero de 2017). Censo edificaciones IV Trimestre 2016. Bogotá, Colombia: DANE. Obtenido de https://www.dane.gov.co/index.php/52-espanol/noticias/noticias/4077-censo-deedificaciones-ceed-iv-trimestre-2016

Departamento Administrativo Nacional de Estadística (DANE). (18 de Mayo de 2017). Indicador de invercion en obras civiles IIOC primer trimestre 2017. Bogota, Colombia: DANE. Obtenido de https://www.dane.gov.co/index.php/52-espanol/noticias/noticias/4173indicador-de-inversion-en-obras-civiles-iioc-i-trimestre-de-2017

Departamento Administrativo Nacional de Estadística (DANE). (16 de Febrero de 2017). Licencias de construccion ELIC diciembre 2016. Bogotá, Colombia: DANE. Obtenido de https://www.dane.gov.co/index.php/52-espanol/noticias/noticias/4069-estadisticas-delicencias-de-construccion-elic-diciembre-2016

Departamento Administrativo Nacional de Estadística (DANE). (17 de Enero de 2018). Licencias de constuccion ELIC noviembre 2017. Bogotá, Colombia: DANE. Obtenido de https://www.dane.gov.co/index.php/52-espanol/noticias/noticias/4454-estadisticas-delicencias-de-construccion-elic-noviembre-2017

Diario El País. (21 de Agosto de 2017). Sector de la construcción creceria en 2,4\% en este segundo semestre del 2017. Diario El País. Obtenido de https://www.elpais.com.co/economia/sector-de-la-construccion-creceria-2-4-en-estesegundo-semestre-del-2017-camacol.html

Diario El Portafolio. (27 de Octubre de 2016). Proyecto de ley crearía 'antídoto' contra la corrupción en la contratación pública. Diario El Portafolio. Bogota, Colombia: Casa $\begin{array}{lllll}\text { Editorial } & \text { El } & \text { Tiempo. } & \text { Obtenido }\end{array}$ https://www.portafolio.co/economia/infraestructura/proyecto-para-limpiar-lacontratacion-publica-501282

Diario El Tiempo. (05 de Agosto de 2002). Crisis Financiera y Fin de UPAC. Diario El Tiempo, pág. 2. Obtenido de EL TIEMPO: http://www.eltiempo.com/archivo/documento/MAM1347546

Diario El Tiempo. (19 de Enero de 2017). Las preguntas claves sobre el escándalo de corrupción de Odebrecht. Diario El Tiempo. Obtenido de 
https://www.eltiempo.com/archivo/documento/CMS-16795929

Direccion de Impuestos y Aduanas Nacionales (DIAN). (27 de Abril de 2017). Oficio 009810. Impuesto sobre la Renta y Complementarios. Impuesto a las ventas. Bogota, Colombia: DIAN. Obtenido de https://www2.deloitte.com/content/dam/Deloitte/co/Documents/tax/DocumentosBoletinA sesor/impuestoscorporativos/junio2017/segundasemana/DIANConceptoNo9810del27de marzode2017.pdf

El Pais. (02 de Agosto de 2016). Conozca las nuevas alternativas en el sector de la construcción. Diario El país. Obtenido de https://www.elpais.com.co/economia/conozca-las-nuevasalternativas-en-el-sector-de-la-construccion.html

Flórez, G. E. (16 de Octubre de 2016). El sector constructor está pasando el año en Colombia. Diario El Portafolio. Bogota: www.portafolio.co. Obtenido de http://camacolbolivar.com/el-sector-constructor-esta-pasando-el-anio-en-colombia/

Huertas, \& Alberto, M. (21 de Julio de 2016). Total de conexiones 2. Obtenido de La silla vacia: http://lasillavacia.com/quienesquien/perfilquien/mario-alberto-huertas-cotes

International Accounting Standards Boards (IASB). (Diciembre de 1993). NIC 11 Contratos de $\begin{array}{llll}\text { Construcción. } & \text { IASB. } & \text { Obtenido de }\end{array}$ http://www.normasinternacionalesdecontabilidad.es/nic/pdf/nic11.pdf

International Accounting Standards Boards. (Mayo de 2014). Norma NIIF 15. Ingresos de Actividades Ordinarias Procedentes de Contratos con Clientes. Obtenido de https://www.mef.gob.pe/contenidos/conta_publ/con_nor_co/vigentes/niif/NIIF15_2014_ v12112014.pdf

International Accounting Standards Boards. (Mayo de 2014). NORMA NIIF 15 Ingresos de Actividades Ordinarias Procedentes de Contratos con Clientes .

Janks, C. (6 de Julio de 2015). Las 4G impulsaran la infraestructura. Diario La Republica. Obtenido de https://www.larepublica.co/analisis/carlos-jacks-505997/las-4g-impulsaranla-infraestructura-2273401

Ley 1150. (16 de Julio de 2007). Por medio de la cual se introducen medidas para la eficiencia y la transparencia en la Ley 80 de 1993 y se dictan otras disposiciones generales sobre la contratación con Recursos Públicos. Bogotá, Colombia: Diario Oficial No. 46.691. Obtenido de http://www.secretariasenado.gov.co/senado/basedoc/ley_1150_2007.html 
Ley 1314. (13 de Julio de 2009). Por la cual se regulan los principios y normas de contabilidade información financiera y de aseguramiento de información aceptados en Colombia, se señalan las autoridades competentes, el procedimiento para su expedición y se determinan l. Bogotá, Colombia: Diario Oficial No. 47.409. Obtenido de http://www.secretariasenado.gov.co/senado/basedoc/ley_1314_2009.html

Ley 1474. (12 de julio de 2011). Estatuto Anticorrupción. Colombia: Diario Oficial No. 48.128. Obtenido de http://www.secretariasenado.gov.co/senado/basedoc/ley_1474_2011.html

Ley 1819. (29 de Diciembre de 2016). "Por Medio de la cual se Adopta un Reforma Estructural, se Fortalecen los Mecanismo, para la Lucha Contra la Evación y Elución Fiscal y se Dictan otras Disposiciones". Bogota, Colombia: Diario Oficial No. 50.101. Obtenido de http://www.secretariasenado.gov.co/senado/basedoc/ley_1819_2016.html

Ley 80. (28 de Octubre de 1993). Por la cual se expide el Estatuto General de Contratación de la Administración Pública. Bogotá, Colombia: Diario Oficial No. 41.094. Obtenido de http://www.secretariasenado.gov.co/senado/basedoc/ley_0080_1993.html

Ley de Vivienda . (23 de Diciembre de 1999). Ley 546. Colombia: Diario Oficial No. 43.827. Obtenido de http://www.secretariasenado.gov.co/senado/basedoc/ley_0546_1999.html

Melendez, M. (2017 de Febrero de 2017). Razón Publica. Obtenido de https://razonpublica.com/index.php/economia-y-sociedad/10045-corrupci\%C3\%B3n-ycontrataci\%C3\%B3n-p\%C3\%BAblica-problemas-y-soluciones.html

Ortiz, D. (5 de Febrero de 2017). En 2017 sector edificador repuntará en su crecimiento. Diario El Colombiano. Obtenido de http://www.elcolombiano.com/negocios/economia/camacolpreve-mejor-desempeno-en-2017-EG5877042

Paladino, N. (s.f.). Tipos de obras civiles. Obtenido de academia.edu: https://www.academia.edu/11858507/TIPOS_DE_OBRAS_CIVILES

Revista Dinero. (2013). Las 15 confesiones del Carrusel de la Contratación. Revista Dinero. Obtenido de https://www.dinero.com/pais/articulo/las-confesiones-del-carruselcontratacion/188288

Revista Dinero. (2 de Febrero de 2017). El futuro de las 4G tras el escándalo de Odebrecht. Obtenido de https://www.dinero.com/edicion-impresa/caratula/articulo/que-pasara-conlas-4g-tras-escandalo-de-odebrecht-en-colombia/241530

Revista Dinero. (14 de Noviembre de 2017). Sector de edificaciones cerraría el 2017 con una caída 
de 5,7\%. Revista Dinero. Obtenido de https://www.dinero.com/economia/articulo/sectorde-edificaciones-cierre-de-2017-camacol/252338

Revista En Obra. (14 de Octubre de 2016). Aplicar e Implementar las NIIF.

Ruiz, L. F. (4 de Noviembre de 2017). Sector Constructor debe mantener confianza; el 2018 será mejor. Obtenido de vanguardia.com: http://www.vanguardia.com/economia/local/414783sector-constructor-debe-mantener-confianza-el-2018-sera-mejor

Superintendencia de Industria y Comercio. (30 de Octubre de 2002). Concepto No.1 . Concepto 02097465. Bogota D.C, Colombia. Obtenido de https://www.alcaldiabogota.gov.co/sisjur/normas/Norma1.jsp?i=13447

Superintendencia de sociedades. (2013). Desempeño del Sector De Infraestructura 2008-2012. 4. Bogotá, Colombia: SuperSociedades. Obtenido de https://www.supersociedades.gov.co/Noticias/Documents/2013/Informe-Estudio-SectorConstruccion-Infraestructura.pdf

Umaña, Y. (2003). El sector de la construcción: un sector líder. Superintendencia Bancaria De Colombia, $4 . \quad$ Obtenido de https://www.superfinanciera.gov.co/descargas/institucional/pubFile1031827/yolimauman a.pdf

Uribe, L. R. (2011). Enfoque a las Normas Internacionales de Contabilidad en Colombia. Bogotá: Nueva legislación ltda. 